\title{
Propiciando cambio personal y social alrededor del género, sexualidad y VIH: Evaluación de impacto de la estrategia de comunicación de Puntos de Encuentro en Nicaragua
}

Irela Solorzano

Amy Bank

Rodolfo Pena

Henry Espinoza

Mary Ellsberg

See next page for additional authors

Follow this and additional works at: https://knowledgecommons.popcouncil.org/departments_sbsr-hiv

Part of the Demography, Population, and Ecology Commons, Health Communication Commons, Health Policy Commons, Immune System Diseases Commons, International Public Health Commons, Medicine and Health Commons, Public Health Education and Promotion Commons, and the Virus Diseases Commons How does access to this work benefit you? Let us know!

\section{Recommended Citation}

Solorzano, Irela, Amy Bank, Rodolfo Pena, Henry Espinoza, Mary Ellsberg, and Julie Pulerwitz. 2008. "Propiciando cambio personal y social alrededor del género, sexualidad y VIH: Evaluación de impacto de la estrategia de comunicación de Puntos de Encuentro en Nicaragua," Horizons Final Report. Washington, DC: Population Council. 


\section{Authors}

Irela Solorzano, Amy Bank, Rodolfo Pena, Henry Espinoza, Mary Ellsberg, and Julie Pulerwitz 
Propiciando cambio personal y social alrededor del género, sexualidad y VIH:

Evaluación de impacto de la estrategia de comunicación de Puntos de Encuentro en Nicaragua
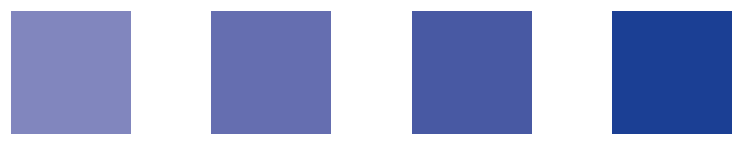

Puntos de Encuentro

CIDS/UNAN León

PATH

Horizons Program 
Propiciando cambio personal y social alrededor del género, sexualidad y VIH:

Evaluación de impacto de la estrategia de comunicación de Puntos de Encuentro en Nicaragua

\author{
Puntos de Encuentro \\ CIDS/UNAN León \\ PATH \\ Horizons Program
}

2008 


\section{Créditos}

\section{Coordinación de investigación}

Julie Pulerwitz, Horizons/PATH; Mary Ellsberg, PATH; Rodolfo Peña, Universidad Nacional Autónoma de Nicaragua (CIDS, UNAN-León); Henry Espinoza, independiente; Irela Solórzano, Amy Bank, Humberto Abaunza (2002-3) y Jeaneth Corrales (2002-4),

Puntos de Encuentro

\section{Estudio de panel y análisis cuantitativo}

Estudio de panel: Rodolfo Peña, investigador principal Análisis estadístico: Rodolfo Peña, Bismark Rodríguez (CIDS), Teresa Somarriba García, Consuelo Flores Montalbán y Rafael Espinoza Montenegro (UNANLeón)

Modelo stepwise: Rodolfo Peña y Bismark Rodríguez Análisis RAP: Mary Ellsberg

Análisis adicional: Sarah Bradshaw y Brian Linneker (Progressio/Middlesex University)

\section{Estudios cualitativos}

Cualitativo 1: Oswaldo Montoya

Cualitativo 2: Camilo Antillón y Henry Espinoza

Cualitativo 3: Almachiara D'Angelo y Patrick Welsh

\section{Monitoreo}

Irela Solórzano, Jeaneth Corrales, Karime Ulloa, Olga Rocha y Maria Belén Díaz

\section{Asistente de investigación \\ Olga Rocha}

\section{Traducción:}

Claudia Ferreira

(Esta publicación como un homenaje a Claudia, que nos dejo físicamente en junio de 2008)

Edición técnica: Henry Espinoza

Edición de estilo: Inés Izquierdo

Revisiones: Tania Montenegro, Juritzia Cruz, Kristen Shelby

Diagramación: Horizons

\section{Donantes al proyecto (2002-2005)}

Las siguientes agencias donantes apoyaron, en maneras grandes y pequeñas, la implementación y evaluación de SDSI 2002-2005: Real Embajada de Noruega, Embajada de Austria, DFID (Gran Bretaña), Real Embajada de Dinamarca, Oxfam Novib (Holanda), Fundación Ford (México/NY), UNICEF (Nicaragua), Forum Syd (Suecia), Terre des Hommes (Alemania), Progressio (Gran Bretaña), The Summit Foundation (EEUU), The Moriah Fund (EEUU), Oxfam (Canadá), Broederlijk Delen (Bélgica), Banco Interamericano de Desarrollo, UNFPA (Nicaragua), Save the Children (Noruega), Embajada de Gran Bretaña, Christian Aid (Gran Bretaña), CCFD (Francia), PATH (EEUU) y Horizons Program/ Population Council (EEUU).

Créditos adicionales aparecen en los Apéndices 1 y 2.

El estudio fue ejecutado por:
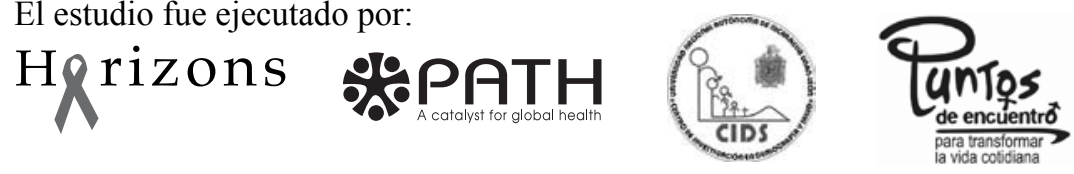

Apoyo adicional para el informe final de:

\section{(1) Population Council OSAID}

El informe final fue financiado, en parte, por el Plan de Emergencia del Presidente para Aliviar el SIDA y el apoyo generoso del pueblo estadounidense a través la Agencia Estadounidense para el Desarrollo Internacional (USAID), bajo los términos del Acuerdo de Cooperación No. HRN-A-00-97-00012-00. El contenido es responsibilidad de Horizons Program y no necesariamente refleja las opiniones de USAID o el gobierno de los Estados Unidos.

Publicado en junio de 2008. Copyright (C) 2008. The Population Council Inc.

Referencia recomendada: Solórzano, Irela, Amy Bank, Rodolfo Peña, Henry Espinoza, Mary Ellsberg y Julie Pulerwitz. 2008. "Propiciando cambio personal y social alrededor del género, sexualidad y VIH: Evaluación de impacto de la estrategia de comunicación de Puntos de Encuentro en Nicaragua," Informe Final Horizons. Washington, DC: Population Council. 


\section{Indice}

$\begin{array}{ll}\text { Resumen } & 1\end{array}$

Introducción $\quad 3$

Contexto 3

La intervención y la evaluación $\quad 3$

Los sitios de estudio $\quad 4$

La intervención: Somos Diferentes, Somos Iguales 5

$\begin{array}{ll}\text { Modelo conceptual } & 7\end{array}$

Metodología de la evaluación del impacto 12

$\begin{array}{ll}\text { Componente cuantitativo } & 12\end{array}$

$\begin{array}{ll}\text { Componente cualitativo } & 18\end{array}$

La triangulación de resultados: integración de datos cuantitativos y cualitativos 20

$\begin{array}{ll}\text { Resultados } & \mathbf{2 1}\end{array}$

$\begin{array}{ll}\text { Características de la muestra } & 21\end{array}$

Percepción del contexto social $\quad 23$

$\begin{array}{ll}\text { Alcance y características de la exposición a SDSI } & 24\end{array}$

Impacto de SDSI

$\begin{array}{ll}\text { Normas de género } & 38\end{array}$

$\begin{array}{ll}\text { Estigma } & 39\end{array}$

Conocimiento y uso de los servicios $\quad 42$

Conocimiento del VIH y percepción del riesgo $\quad 44$

$\begin{array}{ll}\text { Comunicación } & 46\end{array}$

$\begin{array}{ll}\text { Eficacia individual } & 50\end{array}$

Uso del condón y otros comportamientos de prevención $\quad 52$

Capital social y eficacia colectiva $\quad 54$

Más sobre impacto: dos métodos de análisis revelan el 62 impacto de SDSI

La relación indirecta de SDSI con el uso del condón: una validación $\quad 62$ del marco conceptual de SDSI

Entre Amigas: un ejemplo de análisis del impacto sinérgico y neto 66 de Sexto Sentido en niñas de 10 a 14 años 
Debate y reflexiones en torno a los resultados y sus implicaciones

Impacto a gran escala

$\begin{array}{ll}\text { Impacto sobre procesos complejos } & 68\end{array}$

$\begin{array}{ll}\text { Género, edad y el paso del tiempo } & 68\end{array}$

$\begin{array}{ll}\text { La relativa falta de uso de los servicios sociales y de salud } & 69\end{array}$

$\begin{array}{ll}\text { Preservando niveles de prevención a lo largo del tiempo } & 69\end{array}$

$\begin{array}{ll}\text { La importancia de la comunicación interpersonal } & 70\end{array}$

El asunto de la "predisposición” o la "autoselección” 70

Acercarse e impactar a diferentes grupos dentro de la población juvenil y adolescente $\quad 71$

Eficacia con relación al costo de SDSI $\quad 71$

Reflexiones sobre la metodología del estudio $\quad 73$

$\begin{array}{ll}\text { Rigor y confiabilidad } & 73\end{array}$

$\begin{array}{ll}\text { El efecto Hawthorne } & 73\end{array}$

Desafíos metodológicos y la necesidad de varios enfoques distintos $\quad 74$

$\begin{array}{ll}\text { Bibliografía } & 76\end{array}$

$\begin{array}{ll}\text { Apéndice } & 78\end{array}$ 


\section{Resumen}

Somos Diferentes, Somos Iguales ${ }^{1}$ (SDSI) es una estrategia de comunicación para el cambio social, cuyo objetivo es prevenir futuras infecciones por VIH en Nicaragua mediante acciones con medios de comunicación masiva que incluyen programas de entretenimiento educativo, fortalecimiento de la capacidad local y el desarrollo de vínculos, coordinación y alianzas dentro de las comunidades.

Este informe presenta los resultados del estudio de impacto de SDSI, una evaluación interinstitucional que incluyó la colaboración de PATH, el Programa Horizons/Population Council, del Centro de Investigación Demográfica y de Salud (CIDS) de la Universidad Nacional Autónoma de Nicaragua (UNAN-León), de consultores independientes y de Puntos de Encuentro, un ONG nicaragüense.

El propósito de la evaluación era explorar el impacto que la intervención tuvo, tanto en un grupo representativo de jóvenes, como en procesos colectivos y en el entorno local. En particular, la evaluación midió el impacto de la estrategia SDSI en las siguientes áreas: equidad de género, reducción del estigma, personalización de la percepción de riesgo, conocimientos y uso de los servicios, comunicación interpersonal, prácticas de prevención del VIH y eficacia individual y colectiva para su prevención.

En el contexto nacional de Nicaragua donde hay una baja prevalencia del VIH, el reto actual del país es la prevención de futuras infecciones. La estrategia SDSI se ejecutó entre 2002 y 2005, y se centró en el abordaje de los temas sociales y culturales que crean barreras para la prevención del VIH. Las actividades de intervención del proyecto se diseñaron para que se reforzaran entre sí e incluyeron: una telenovela social a nivel nacional, un programa radial nocturno de llamadas para jóvenes, la elaboración y distribución de materiales metodológicos para su uso por parte de grupos locales y varias actividades basadas en la comunidad, como talleres de capacitación para jóvenes involucrados en trabajo de comunicación, campamentos de liderazgo juvenil y coordinación con organizaciones locales sin fines de lucro y con proveedores de servicios sociales y de salud. La serie televisiva semanal Sexto Sentido fue el componente mayor de la estrategia y se transmitió no sólo en Nicaragua, sino también en Costa Rica, Guatemala, Honduras, México, y Estados Unidos. ${ }^{2}$

En la evaluación de la estrategia SDSI se utilizaron instrumentos de sondeo cuantitativos y cualitativos, además de encuestas a hogares, entrevistas y grupos focales con jóvenes participantes de las actividades, no participantes y actores clave. Se realizó un estudio de panel longitudinal para evaluar cuantitativamente el impacto de la estrategia SDSI que consistió en tres encuestas, realizadas en octubre de 2003, 2004 y 2005 al mismo grupo de jóvenes, cuyas edades en el 2003 oscilaban entre los 13 y los 24 años. Las encuestas se hicieron en tres ciudades nicaragüenses: Estelí, Juigalpa y León. $^{3}$

\footnotetext{
${ }^{1}$ Documentos sobre Somos Diferentes, Somos Iguales y esta evaluación están disponibles en la página Web de Puntos de Encuentros en inglés y en español.

${ }^{2}$ Esta evaluación sólo estudió el impacto en Nicaragua.

${ }^{3}$ Un informe descriptivo titulado Expectativas y Realidades: Jóvenes nicaragüenses navegando entre las olas del genero, sexualidad, VIH y más, resume algunos de los patrones más contundentes que emergen de los datos recopilados entre 2003 y 2005. Desagregados por género, edad y ubicación, los datos brindan una compleja imagen de las realidades sexuales y reproductivas entre las y los jóvenes nicaragüenses. Disponible en inglés y español en www.puntos.org.ni.
} 
Los resultados de la evaluación revelan que hubo un amplio contacto con el proyecto SDSI. Al final de la intervención, nueve de cada diez personas entrevistadas estaban familiarizadas con al menos uno de los componentes de comunicación masiva. Sexto Sentido TV fue sintonizado de manera amplia y periódica por una gran parte de la población adolescente y joven, con un 59 por ciento de la muestra correspondiente a la categoría "de mayor exposición" (personas que miraron al menos dos de las tres temporadas previas de Sexto Sentido TV "casi siempre" o "de vez en cuando"). Asimismo, la proporción de personas que había escuchado el programa radial Sexto Sentido aumentó considerablemente con el tiempo, pasando de un 9\% en 2003 a 29\% en 2005.

Los resultados de la encuesta indican que una mayor exposición a la estrategia SDSI condujo a cambios positivos en la población. La intervención resultó en una reducción significativa de actitudes estigmatizadoras y con inequidad de género, un incremento en el conocimiento y uso de los servicios relacionados con el VIH, así como un incremento significativo en la comunicación interpersonal sobre la prevención del VIH y el comportamiento sexual. Los resultados cualitativos indican que SDSI desempeñó un importante papel en la promoción del diálogo basado en la comunidad en torno a temas importantes, fortaleció el liderazgo de las y los jóvenes y promovió alianzas entre organizaciones.

Los datos sugieren que una mayor exposición a SDSI tiene efectos positivos en la comunicación interpersonal, lo que a su vez ayuda a las personas a percibir su propio riesgo personal de contraer el VIH y propicia mayor capacidad a los individuos para que aborden el tema de la prevención con sus parejas. La comunicación entre parejas sobre la prevención del VIH está directa y positivamente correlacionada con el uso regular del condón. La evaluación sugiere que los efectos indirectos de SDSI en el uso del condón son fuertes y positivos, y al mismo tiempo hubo también una asociación directa entre SDSI y uso del condón con las parejas casuales.

La evaluación del impacto demostró que la estrategia SDSI ha hecho una gran contribución en aspectos clave de la prevención del VIH. Además de los cambios individuales en el comportamiento directamente asociados con una mayor exposición a SDSI y los cambios a nivel social identificados en los estudios cualitativos, los resultados validan el marco conceptual, tanto de la intervención como de la evaluación. Los resultados sugieren que los comportamientos individuales (p. ej., el uso regular del condón en las relaciones sexuales) no están aislados del entorno donde viven las personas, más bien están relacionados con los contextos y procesos sociales.

Son pocos los estudios en el campo de la comunicación social que han sido tan rigurosamente realizados como esta evaluación de impacto. En ese sentido, los resultados representan una importante contribución a la literatura internacional sobre la eficacia de este tipo de programa y brindan una oportunidad para explorar, reflexionar sobre las metodologías utilizadas para evaluar la comunicación para el cambio social, mejorar el diseño y la ejecución de los programas de prevención, analizar temas e inquietudes relacionados con el cambio en el comportamiento colectivo e individual y analizar el potencial para integrar la educación-entretenimiento y la movilización social con la prevención del VIH. 


\section{Introducción}

\section{Contexto}

En Nicaragua las tasas de infección por VIH son bajas, pero en las dos últimas décadas han mostrado una tendencia hacia el aumento. Entre 1987 y 2002, el Ministerio de Salud de Nicaragua reportó 1,081 casos positivos de VIH (Programa Nacional de Sida 2003). Para finales del 2006, se habían reportado 2,433 casos, el 94 por ciento de los cuales ocurrieron como resultado del contacto sexual (Programa Nacional de ITS/VIH). Entre 1998 y 2003, se triplicó la incidencia del VIH en Nicaragua se pasa de 1.3 a 3.9 personas infectadas por cada 100,000 habitantes. Para 2006, esta tasa se había más que duplicado, con 7.1 por cada 100,000 habitantes. La actual prevalencia de la infección entre personas de 15 a 49 años se estima en un 0.2 por ciento, y el virus se propaga principalmente por contacto sexual.

El mayor reto en este contexto de baja prevalencia del VIH es la prevención de futuros caso porque si bien las bajas tasas de VIH en Nicaragua son alentadoras, las actuales condiciones económicas y socioculturales del país lo hacen muy vulnerable a una futura diseminación rápida de la enfermedad. Estas condiciones incluyen crecientes niveles de pobreza y migración, y el hecho que la epidemia se ha vuelto generalizada en los países vecinos de Honduras y Guatemala. Como comentara en 2006 Peter Piot, quien encabeza el programa conjunto de Naciones Unidas sobre el VIH (ONUSIDA), "cuando miro a América Latina, pienso que América Central es la más vulnerable ante la diseminación del VIH" (Cohen, 2006).

Son muchos los factores que contribuyen a la vulnerabilidad de Nicaragua ante la futura diseminación del VIH. Durante la década de 1980 y parte de 1990, la guerra y los conflictos políticos mantuvieron a Nicaragua casi aislada política y económicamente. Asimismo, las normas culturales y sociales basadas en el machismo y las construcciones de género y sexualidad, históricamente han promovido prácticas sexuales inseguras, como múltiples parejas sexuales entre los hombres y una falta de capacidad de negociación entre las mujeres. Otros problemas incluyen la limitada disponibilidad de información y la falta de una educación real en torno a la sexualidad, junto a normas que impiden que esa educación se brinde a la juventud. Nicaragua también tiene una limitada disponibilidad de servicios para realizar pruebas y brindar tratamiento, lo que reduce la probabilidad de una detección y atención tempranas.

La prevención del VIH requiere que se eduque a los individuos sobre comportamiento riesgoso, se luche contra el estigma y la discriminación que rodea al VIH, y se promueva un entorno sociocultural que conduzca a prácticas sexuales más seguras. Esto a su vez requiere el abordaje y el análisis crítico de las normas sociales que regulan la sexualidad, en especial las normas basadas en el género.

\section{La intervención y la evaluación}

El proyecto SDSI se ejecutó entre 2002 y 2005 como parte de una estrategia de comunicación para el cambio social dirigida a prevenir la expansión de la epidemia en Nicaragua mediante acciones de comunicación masiva, procesos interpersonales para fortalecer las capacidades locales y el desarrollo de vínculos, coordinación y alianzas entre grupos locales y nacionales que trabajan con jóvenes o con salud y derechos sexuales y reproductivos. 


\section{Los sitios de estudio}

Los sitios de investigación para el estudio se seleccionaron incluyendo áreas con diferentes cualidades sociales, como por ejemplo, tener diferentes niveles de actividades comunitarias en torno al VIH, así como diversidad en la capacidad institucional de las organizaciones locales. Asimismo, se procuró que los sitios representaran diferentes niveles de colaboración organizativa local con Puntos de Encuentro y diferente intensidad de ejecución de SDSI de las actividades no relacionadas con los medios masivos de comunicación (tales como talleres).

Basados en los criterios anteriores, el estudio cuantitativo se ejecutó en las áreas urbanas de tres cabeceras municipales: Juigalpa (capital del departamento de Chontales), Estelí y León, ubicadas en los departamentos con esos mismos nombres.

Estelí pertenece a la Región Norte del país, León a la Región del Pacífico y Juigalpa a la Región Central. (León tiene la mayor población de las tres y es la segunda ciudad más grande del país en términos poblacionales).

Los estudios cualitativos incluyeron estas mismas tres ciudades, además de Bilwi (también conocida como Puerto Cabezas) en la Región Autónoma del Atlántico Norte. La población de Bilwi es multiétnica, multicultural y multilingüe, y la ciudad es mucho más pequeña y pobre que las otras tres.

Al inicio del estudio cuantitativo, se identificó a Estelí y a León como ciudades con altos niveles de actividad comunitaria, un fuerte tejido social compuesto por numerosas organizaciones de vieja data, un intenso trabajo con SDSI, y un alto nivel de alianzas. Juigalpa, por su parte, se identificó como una ciudad con niveles más bajos de esas características. Estelí posee más organizaciones y centros que brindan servicios a adolescentes y a los jóvenes, mientras que Juigalpa es la que menos tiene y además es también la más conservadora en lo social y político de las tres ciudades.

En términos generales, los sitios seleccionados son municipios con una población fundamentalmente urbana. A nivel nacional, la población de Nicaragua es 56 por ciento urbana y un tercio la conforman jóvenes entre 10 y 24 años (Instituto Nicaragüense de Estadísticas y Censos, INEC, 2006). Si bien Chontales tiene la tasa más alta de analfabetismo (28 por ciento) de estos tres departamentos, las tasas de analfabetismo en Estelí y León son también significativas (19 por ciento y 16 por ciento cada una). Las tres ciudades tienen tasas relativamente similares de embarazo en adolescentes y de ITS, y a nivel departamental entre una quinta y una cuarta parte de las mujeres entre los 15 y los 19 años han estado embarazadas por lo menos una vez, la prevalencia de ITS entre las mujeres de 15 a 49 años oscila entre el 10 y el 17 por ciento (INEC, 2002). 


\section{La intervención: Somos Diferentes, Somos Iguales}

Puntos de Encuentro, una ONG nicaragüense, feminista, que trabaja con grupos de mujeres y jóvenes para promover los derechos humanos, inició en el 2000 la estrategia SDSI. Puntos buscaba coordinar sus propias actividades mediáticas complementarias, de fortalecimiento de capacidades y de trabajo en red. El proyecto realizado entre 2002-2005 que se evalúa en este informe, constituye la segunda fase de toda la estrategia SDSI. El objetivo general era promover los derechos de las y los jóvenes, el empoderamiento individual y colectivo, en especial lo referido a los temas de salud y derechos sexuales y reproductivos, que incluyen el VIH, la violencia basada en el género, la anticoncepción de emergencia y el abuso/adicción a drogas.

Puntos de Encuentro, una organización que se define a sí misma como de "cambio social progresivo" diseñó el proyecto con el fin de combinar los catalizadores del cambio individual y social que operan de manera simultánea y a lo largo del tiempo. El diseño del proyecto utiliza el alcance y la legitimidad de los programas mediáticos de educación y entretenimiento, reforzado mediante el fortalecimiento de las capacidades con jóvenes líderes y comunicadores a nivel de base, la construcción de redes y la movilización a nivel local.

Los principales componentes del proyecto son:

- Sexto Sentido, una telenovela semanal transmitida en las estaciones nacionales comerciales y en las estaciones de cable locales. La serie integra varias historias basadas en temas y logró, con éxito, introducir en los hogares temas delicados y complejos como la sexualidad.

- Sexto Sentido Radio, un programa radial nocturno de llamadas que se transmite de forma simultánea en una estación de radio FM nacional y en nueve estaciones de radio locales. En este programa se discuten y debaten temas planteados en la serie televisiva.

- Capacitación en liderazgo juvenil y fortalecimiento de capacidades con líderes y comunicadores de base, dirigido a fortalecer las habilidades analíticas y de liderazgo relacionadas con temas de salud y derechos sexuales y reproductivos. Estas habilidades se centran en especial en género, estigma, discriminación y violencia basada en el género. Un componente importante del trabajo es la promoción de alianzas entre diferentes grupos, como jóvenes y líderes adultos/as de sus organizaciones, con el fin de promover una participación más efectiva de los jóvenes. (En varias de las actividades de fortalecimiento de capacidades participan adultos).

- Participación y coordinación con jóvenes a nivel local y nacional, y también con coaliciones que trabajan en pro de los derechos sexuales y reproductivos, los derechos humanos, los temas de la mujer y contra la violencia.

- Coordinación con periodistas locales y nacionales, con medios de comunicación, y en particular, con jóvenes comunicadores.

- Elaboración y distribución de materiales de apoyo, paquetes de recursos metodológicos y campañas temáticas.

- Coordinación con organizaciones juveniles y con líderes en otros países centroamericanos, como una manera de ampliar el proyecto a nivel regional.

- Actividades de monitoreo y evaluación continuas. En el caso de este proyecto, la evaluación se realizó en conjunto con el Programa Horizons, PATH, el Centro de Investigación en Demografía y Salud de la Universidad de León e investigadores independientes. 
La segunda fase del proyecto (ejecutada en 2002-2005) incluyó un enfoque especial en la prevención del VIH dentro del contexto de la sexualidad de las y los jóvenes, las normas de género, la percepción de riesgo y la toma de decisiones. El enfoque del "machismo como un factor de riesgo" estuvo en el centro del trabajo del proyecto con adolescentes y jóvenes (mujeres hombres).

Este trabajo incluyó una campaña multimedia y una serie de talleres regionales desarrollados bajo el lema Necesitamos Poder Hablar. La idea era mostrar el poder de hablar sobre temas tabú y la importancia del apoyo social en el proceso de crear cambio. La campaña incluyó la producción y distribución de ediciones especiales de la serie de televisión Sexto Sentido, centradas en el VIH y el abuso sexual. También comprendió guías metodológicas para los talleres y cursos de capacitación para los activistas locales, además de convenios con proveedores locales de servicios sociales y de salud. En 17 ciudades se colocaron vallas que publicitaban el lema Sexto Sentido TV y Radio, e identificaban a los proveedores de servicios de salud en cada lugar. Las organizaciones locales distribuyeron folletos y volantes educativos. Estos materiales también se distribuyeron durante las giras del elenco a las escuelas y centros comunitarios, donde los miembros del elenco de Sexto Sentido condujeron debates sobre el VIH y el abuso sexual.

Esta fase también incluyó un esfuerzo conjunto con el proyecto PATH/Entre Amigas, un programa innovador de múltiples niveles que aborda temas de salud sexual y reproductiva de relevancia para niñas entre los 10 y los 14 años, una población que está particularmente subatendida. 


\section{Modelo conceptual}

El estigma, la discriminación y la negación (EDN) en relación con el VIH siguen siendo los aspectos menos comprendidos de la epidemia del VIH y están entre los más grandes obstáculos para el éxito de los programas en torno al VIH. La declaración de compromiso de Naciones Unidas sobre el Sida identifica el estigma, la discriminación y la negación como elementos esenciales a los que debe apuntarse en la respuesta global ante el desafío de la pandemia del VIH/Sida (Declaración de Compromiso 2001). A menudo el EDN está orientado a las personas que viven con el VIH así como a individuos y grupos asociados de alguna forma con la enfermedad, como las y los trabajadores del sexo y hombres homosexuales. El EDN inhibe tanto la prevención del VIH como los esfuerzos dirigidos a brindar tratamiento, atención y apoyo.

Desde la perspectiva de la prevención, negarse a utilizar condones es una actitud que puede surgir de la falta de una percepción del riesgo del VIH o de la preocupación de plantear el tema del riesgo de enfermedad al solicitar el uso del condón. El temor al estigma o a la discriminación, al igual que la negación del riesgo, pueden conducir a una renuencia a buscar asesoría, pruebas e incluso al tratamiento y apoyo disponibles para el VIH (Malcolm et al. 1998). Si bien desde que inició la pandemia ha habido sensibilización sobre la importancia del tema, hasta la fecha se cuenta con limitada evidencia sobre intervenciones exitosas.

En un estudio de la literatura sobre las intervenciones que abordan el estigma relacionado con el VIH se encontraron 21 evaluaciones publicadas en todo el mundo y apenas una campaña nacional multimedia (Brown et al. 2001). La relativa escasez de estrategias exitosas para la reducción del estima destaca la necesidad de mejorar la comprensión sobre cómo funciona el EDN, y sugiere que se deben desarrollar y evaluar nuevos esfuerzos por entender el uso potencial de la reducción del EDN, como una estrategia para reducir el riesgo del VIH.

El estigma relacionado con el VIH tiene que ver con creencias y actitudes negativas hacia las personas que son portadoras del VIH o que están asociadas con el virus (p. ej., la creencia de que se debe evitar el contacto con las personas con VIH o que éstas tienen la culpa de su enfermedad). La discriminación relacionada con el VIH se refiere a los comportamientos que resultan de visiones estigmatizadas ( $\mathrm{p}$. ej., que a alguien lo despidan de su empleo a causa de su situación en torno al VIH). Al respecto, a la discriminación también se le conoce como "la representación del estigma" o "la manifestación del estigma."

La negación relacionada con el VIH se refiere a la renuencia de un individuo o de la sociedad a percibir el riesgo del VIH. ${ }^{4}$ El EDN relacionado con el VIH proviene del temor al contagio y a la enfermedad, y a la culpa asociada con tener comportamientos que en muchas culturas se consideran "inmorales" o "malos", tales como la actividad sexual antes del matrimonio para las mujeres.

Estos comportamientos no normativos, también están típicamente asociados con ciertos grupos que ya están marginados, tales como las y los trabajadores del sexo y los homosexuales. Por consiguiente, el EDN relacionado con el VIH está inextricablemente vinculado a los estigmas asociados con la

\footnotetext{
${ }^{4}$ La negación está íntimamente vinculada al estigma y a la discriminación, pero en este documento la diferencia radica en que tiene un enfoque más sicológico, mientras que el estigma y la discriminación tienen un enfoque más social.
} 
sexualidad y el género, y a menudo viene combinado con estigmas asociados con raza y pobreza. El estigma hacia lo que algunas personas llaman "grupos de alto riesgo"-en particular hombres que tienen sexo con hombres y con trabajadores del sexo - crea un entorno donde las personas que tienen un comportamiento de alto riesgo pero que no se identifican con estos grupos, no se dan cuenta que están en riesgo de infección y, por consiguiente, no tienen prácticas sexuales seguras.

El abordaje exitoso del EDN relacionado con el VIH requiere lidiar con las múltiples fuentes del estigma vinculado al VIH, incluidas las asociaciones con sexualidad y género. Por ejemplo, si las mujeres que tienen actividad sexual antes de casarse o múltiples parejas sexuales experimentan estigma debido a normas de género inequitativas, las mujeres evitarán buscar información sobre salud sexual y prevención de enfermedades, para no sugerir que tienen una vida sexual activa o varias parejas. Mientras que la homofobia siga siendo generalizada, los hombres que tienen sexo con hombres seguirán siendo clandestinos al respecto y pueden tener prácticas sexuales inseguras con hombres o mujeres con quienes estén involucrados. Los hombres casados que tienen sexo fuera del matrimonio pueden no utilizar condones con sus esposas puesto que saben que eso sugeriría que están teniendo sexo extramarital.

Los análisis de los estudios sobre salud sexual y reproductiva, incluida la prevención del VIH, indican la eficacia de estrategias que utilizan "entretenimiento-educación [o entretenimiento-educativo]" - especialmente novelas radiales y televisivas - en combinación con la movilización de la comunidad y la promoción de redes de apoyo social (Singhal and Rogers 1999). Al juntar varias historias y temas, las telenovelas radiales y televisivas de educación y entretenimiento pueden abordar una variedad de temas de forma compleja e integral.

El formato permite que temas íntimos, tales como la sexualidad, se introduzcan en el hogar de una manera eficiente y con sensibilidad cultural. También promueve la identificación con personajes e historias, lo cual puede crear una impresión en los espectadores en cuanto a las consecuencias de diferentes actitudes y acciones. Estas relaciones "parasociales" entre espectadores y actores promueven la eficacia individual y pueden inspirar en los espectadores confianza en su habilidad de tener comportamientos que han visto modelados por personajes ficticios. Esto se puede aplicar tanto a los comportamientos para la prevención del VIH como en la reducción del estigma.

Los estudios han concluido que conocer a una persona que sea portadora del VIH o que tenga sida y hable abiertamente del tema está asociado con un estigma reducido hacia el VIH (Green et al., 2006). Incluir en una telenovela a un personaje que es VIH positivo o tener a una persona que es VIH positivo y que comparte sus experiencias en un programa radial, puede crear una relación parasocial que actúa como substituto de conocer a una persona así. Estos formatos también permiten un contacto repetido con diferentes aspectos del mismo tema, durante un periodo de tiempo prolongado.

Asimismo, los formatos de telenovela y de programa radial promueven el debate sobre los temas de los programas entre televidentes/radioescuchas y sus redes sociales, incluida la familia, las amistades y las parejas sexuales. Esto es particularmente importante dada la evidencia existente de que la cohesión social y la difusión de información sobre el VIH es un factor importante en la reducción substancial de la prevalencia del VIH. Evidencia de Uganda, por ejemplo, sugiere que las redes personales son más eficaces que los "expertos" de la salud en la reducción de la prevalencia del VIH (Stoneburner et al. 2000). 
La estrategia SDSI retoma la Teoría Cognitiva Social (TCS) de Bandura (Bandura 1977) y las opiniones teóricas de la comunicación para el cambio social como un proceso de diálogo mediante el cual las personas definen quiénes son, qué desean y cómo pueden alcanzar sus metas (Gray-Felder y Dean 1999). En la TCS, el comportamiento humano resulta de la interacción de comportamientos, de factores personales (incluidos los pensamientos y las percepciones) y de influencias ambientales. La TCS asume que existe una interacción dinámica y recíproca entre un individuo, su comportamiento y el entorno donde tiene lugar el comportamiento.

La TCS es la perspectiva teórica más común donde subyacen el drama o las intervenciones basadas en entretenimiento-educativo, debido a su enfoque en la modelación social. La estrategia promueve cambios de comportamiento al tener personajes con los cuales los televidentes pueden identificarse y quienes practican los tipos de actitudes y comportamientos que promueve la intervención. Un metaanálisis de doce intervenciones para la reducción del riesgo del VIH en el que se utilizó la TCS en pruebas experimentales controladas, encontró que todas lograron cambios positivos en la reducción del comportamiento riesgoso, con un tamaño de efecto moderado que cumple o bien excede los efectos de otras intervenciones para el cambio de comportamiento basadas en dicha teoría (Greenberg 1996).

Uno de los principales postulados de la TCS es la eficacia individual o la confianza en la habilidad personal de manifestar o poner en práctica un cierto comportamiento (Bandura 1986). Más reciente, el concepto de la eficacia colectiva ha recibido considerable atención. La eficacia colectiva se puede definir como el grado que los individuos en un sistema creen poder organizar y ejecutar los cursos de acción requeridos para alcanzar las metas colectivas. La investigación en torno a las intervenciones de entretenimiento-educativo sugiere que si bien el cambio estimulado por los medios contiene paradojas y contradicciones, los elementos clave de ese proceso incluyen interacción parasocial, comunicación entre pares y eficacia colectiva (Papa et al. 2000).

Estudios previos sobre salud reproductiva han concluido que reforzar el modelo de entretenimientoeducativo con la movilización de la comunidad y la promoción de redes de apoyo social es algo particularmente prometedor. Estas estrategias pueden influir en los procesos colectivos que conducen a la inequidad - y la preservan - en las relaciones sociales cotidianas. Al respecto, los programas de comunicación estratégica necesitan diseñarse dentro de un marco más amplio de procesos sociales, políticos y culturales.

El cambio social está relacionado con varios procesos: la participación y el compromiso que asumen los actores sociales, el fortalecimiento de las redes de apoyo interpersonales e institucionales, la creación o el fortalecimiento de las capacidades individuales y colectivas y el aseguramiento de condiciones favorables para un diálogo y un debate abiertos en torno a temas relacionados con la sexualidad y las relaciones de género. El diálogo y la acción colectiva pueden a su vez trascender el nivel individual y contribuir al cambio social de varias maneras: al mejorar las habilidades necesarias para lograr nuevos comportamientos; cambios de conocimiento, valores, riesgos percibidos, normas subjetivas e imagen personal, respuestas basadas en la solidaridad, la empatía y la confianza y creciente confianza y apoyo dentro de las comunidades. Además, el diálogo y la acción colectiva influyen en las intenciones de los individuos de asumir comportamientos nuevos y específicos en el futuro (Figueroa et al. 2002).

La eficacia colectiva se puede evaluar sobre la base de la confianza que tiene el grupo en la toma de decisiones y acciones colectivas, en la percepción de los talentos y las capacidades de otros miembros 
del grupo para tal fin y en la confianza percibida de que los miembros del grupo son capaces de cumplir con sus responsabilidades individuales. Además del liderazgo, otros indicadores de cambio que se proponen para evaluar los resultados de la comunicación para el cambio social incluyen el grado y la equidad de la participación, la equidad en la información, el sentido de propiedad (apropiación), la cohesión social y las normas sociales.

El modelo conceptual SDSI incorpora tanto la importancia de influir en el conocimiento, las actitudes y las normas individuales, como en el contexto social más amplio, a fin de influir en el cambio social a gran escala, que contribuye al cambio en el comportamiento individual entre las y los jóvenes en Nicaragua y en la región centroamericana (Véase figura 1).

\section{Figura 1 Modelo conceptual SDSI 2002-2005: Promoción de un entorno más facilitador para la prevención del VIH}

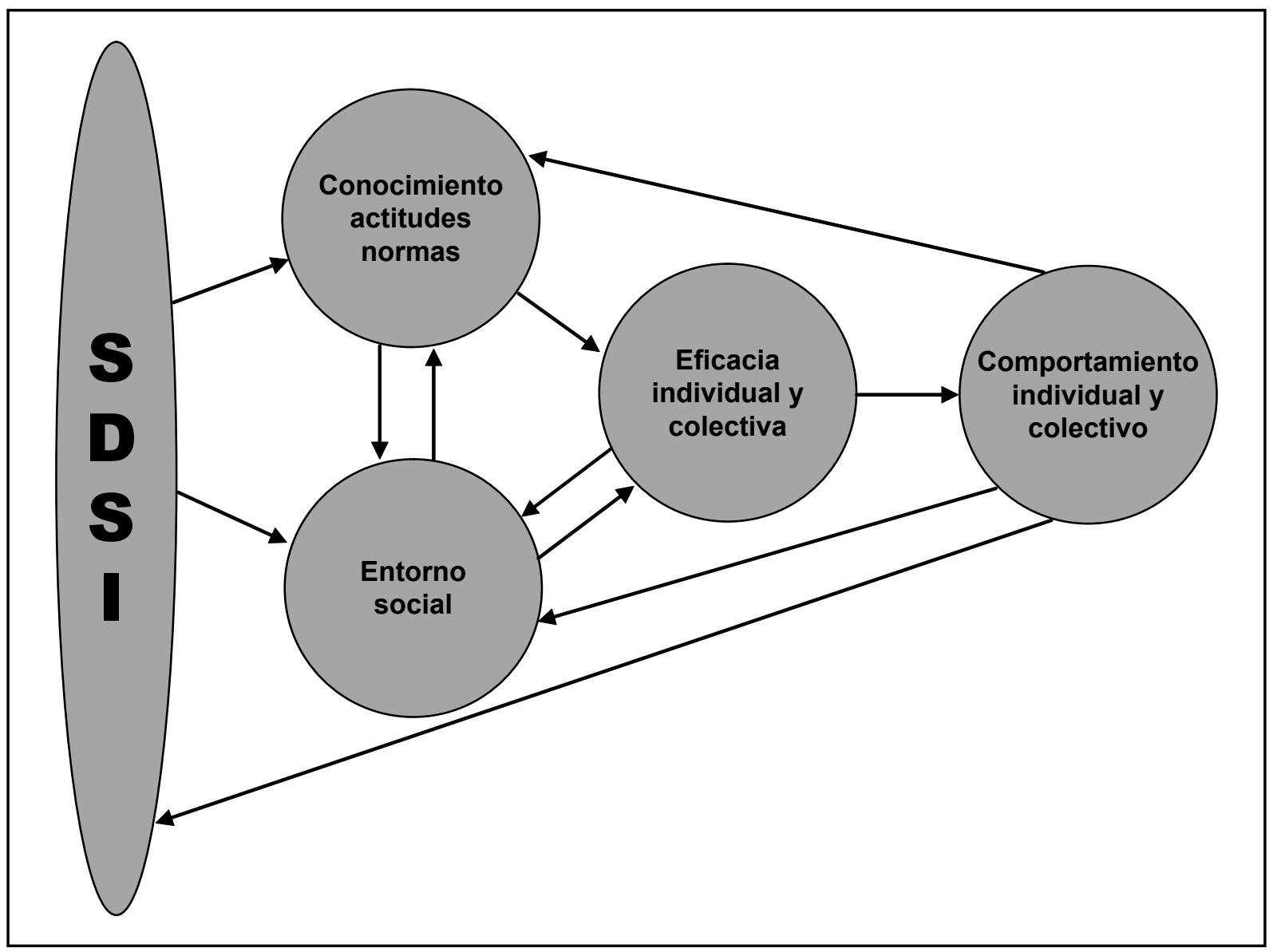

El modelo propone relaciones dinámicas entre cuatro grandes esferas: 1) el conocimiento, las actitudes y normas de género del individuo, 2) el contexto social, 3) la eficacia individual y colectiva y 4) los comportamientos individuales y colectivos. El estudio de impacto de SDSI se centró en el análisis 
de esas esferas en relación a la prevención del VIH, el ejercicio de una sexualidad responsable y la prevención de la violencia basada en el género.

Para fines del estudio, la esfera del conocimiento, actitudes y normas, comprendió conocimientos, actitudes y comportamientos individuales relacionados con la vida sexual, la negociación con la pareja y el riesgo y la prevención del VIH; las actitudes y prácticas relacionadas con la violencia, incluido el abuso sexual, las actitudes y normas sociales relacionadas con los roles y las relaciones de género, la sexualidad, y la discriminación y el estigma relacionados con el VIH.

Se estudió la percepción del entorno social, así como de los vínculos con redes o estructuras de apoyo identificadas a nivel comunitario. La eficacia individual se analizó con respecto a la comunicación interpersonal, en particular en lo que se refiere a la comunicación y a la negociación con las parejas sexuales en torno a la prevención del VIH. La eficacia colectiva se analizó a nivel local y dentro del grupo generacional de los participantes. 


\section{Metodología de la evaluación del impacto}

La evaluación del impacto de SDSI incluyó varios estudios en el marco de un enfoque cuantitativocualitativo. Se comparó la información generada por los estudios y el monitoreo con una metodología integral basada en los objetivos del proyecto SDSI. Un equipo interinstitucional e interdisciplinario procedió entonces a analizar y a interpretar los datos.

\section{Componente cuantitativo}

Se realizó un estudio de panel o longitudinal para evaluar de manera cuantitativa el impacto de SDSI en los individuos, consistió en tres encuestas, realizadas en octubre 2003, 2004 y 2005 al mismo grupo de jóvenes, cuyas edades oscilaban entre los 13 y los 24 años en el 2003 y vivían en Estelí, Juigalpa y León, tres ciudades nicaragüenses seleccionadas según criterios que pretendían incorporar diferentes cualidades del tejido social, acciones comunitarias contra el Sida y trabajo previo con SDSI. Comparado con Estelí y León, en Juigalpa había menos trabajo basado en alianzas y menos presencia de SDSI.

\section{Muestra}

La muestra es representativa de los grupos de población estudiados en las tres ciudades, se hizo por conglomerados y en varias etapas. Los conglomerados se seleccionaron por bloques en cada ciudad y luego se seleccionaron los participantes dentro de cada bloque.

La muestra es urbana, se estimó en 4,800 participantes, con 1,600 individuos ( 800 hombres y 800 mujeres) de cada uno de los tres sitios de investigación. Los insumos para los cálculos incluyeron una probabilidad máxima del 50 por ciento $(0.50)$ para cambios y no cambios en comportamientos y actitudes, con un poder del 80 por ciento para detectar ese cambio. El cálculo de la muestra también tiene un nivel de confiabilidad del 95 por ciento. En otras palabras, cada vez que se observaba un resultado, éste estaría correcto para 95 de cada 100 observaciones. Como la selección de la muestra se basó en la definición del conglomerado y en la técnica de selección, la muestra se multiplicó por 1.5 para el tamaño necesario a fin de corregir cualquier error por el uso del muestreo por conglomerado. Se agregó un 32 por ciento adicional para cubrir a los individuos que no pudieron localizarse entre una encuesta y otra, es decir las "pérdidas de seguimiento".

\section{Identificación y seguimiento}

Para la identificación y seguimiento de los participantes, se construyeron mapas georeferenciados para cada una de las tres ciudades del estudio. Primero se ubicaron mapas digitales o no digitales para cada ciudad o cabecera departamental (áreas urbanas) los cuales alimentaron al programa computarizado Arc View. Este programa permitió georeferenciar los mapas y los datos del cálculo de la muestra y de la encuesta de línea de base. 
Una vez que se georeferenciaron los mapas en el programa Arc View, se delimitaron y se contaron los barrios, manzanas y casas. Luego se procedió a calcular el número de individuos entre los 13 y los 24 años por cada hogar y se seleccionaron y codificaron los barrios, las manzanas y casas. Este fue un paso fundamental para dar seguimiento en el tiempo a las/los participantes seleccionados y para controlar la calidad de la información obtenida.

\section{Tasa de respuesta, pérdidas de seguimiento y "sobrevivientes"}

Una muy alta proporción de personas aceptaron participar en el estudio y hubo un nivel aceptable de pérdida para el seguimiento en el transcurso de la evaluación. Un total de 4,567 personas estuvieron de acuerdo con que se les incluyera en la primera encuesta (línea de base) en 2003, lo que representó una respuesta positiva del 95 por ciento.

Las pérdidas de seguimiento totales al final del estudio con relación a la muestra inicial fueron del 35 por ciento, dato que se aproxima bastante a la pérdida anticipada cuando se calculó la muestra (32 por ciento). El análisis final para medir el impacto de SDSI se basa en la muestra de "sobrevivientes," un término que se utiliza para describir a las 3,099 personas que participaron en las tres encuestas y cuyas respuestas se utilizaron para analizar el impacto. ${ }^{5}$

Se hicieron comparaciones entre las muestras totales y la muestra de "sobrevivientes" para determinar si había diferentes tendencias o características entre las dos muestras, pero las tendencias y características eran las mismas. Por ejemplo, no había diferencias en el porcentaje de entrevistados que escuchaban los programas de radio de SDSI cuando se compararon las muestras totales de cada ronda (9 por ciento, 19 por ciento y 29 por ciento) con los datos reportados por los sobrevivientes (9 por ciento, 18 por ciento y 29 por ciento). La tabla 1 muestra otras variables que se observaron.

\footnotetext{
${ }^{5}$ De hecho, la muestra total de "sobrevivientes" fue de 3,137 personas, pero por razones técnicas sólo se pudieron utilizar 3,099 respuestas en el análisis.
} 
Tabla 1 Tabla comparativa de muestras totales y de "sobrevivientes"

\begin{tabular}{|c|c|c|c|}
\hline & $\begin{array}{c}2003 \\
\%\end{array}$ & $\begin{array}{c}2004 \\
\%\end{array}$ & $\begin{array}{c}2005 \\
\%\end{array}$ \\
\hline \multicolumn{4}{|l|}{ Tiene hijos } \\
\hline Sobrevivientes* & 15 & 21 & 24 \\
\hline Total $^{* *}$ & 17 & 22 & 25 \\
\hline \multicolumn{4}{|l|}{ Estudios } \\
\hline Sobrevivientes* & 70 & 63 & 58 \\
\hline Total $^{\star *}$ & 66 & 60 & 57 \\
\hline \multicolumn{4}{|c|}{ Pertenece a algún grupo u organización } \\
\hline Sobrevivientes* & 19 & 22 & 17 \\
\hline Total $^{* *}$ & 19 & 21 & 17 \\
\hline \multicolumn{4}{|c|}{$\begin{array}{l}\text { Las mujeres con condones en sus billeteras son mujeres fáciles } \\
\text { (respondido correctamente "no") }\end{array}$} \\
\hline Sobrevivientes* & 48 & 53 & 64 \\
\hline Total $^{* *}$ & 47 & 54 & 64 \\
\hline \multicolumn{4}{|c|}{ Escucha SDSI en la radio } \\
\hline Sobrevivientes* & 9 & 18 & 29 \\
\hline Total $^{* *}$ & 9 & 19 & 29 \\
\hline
\end{tabular}

*Sobrevivientes $=3,099$ participantes en las tres encuestas cuyas respuestas se utilizaron para analizar el impacto a lo largo del tiempo.

${ }^{* *}$ Total por ronda de encuesta $=4,567$ en la primera; 3,682 en la segunda; y 3,366 en la tercera.

Se utilizaron dos cuestionarios diferentes para recopilar información durante cada ronda:

- El primero lo aplicó el personal encuestador y contenía las siguientes secciones: aspectos sociodemográficos, percepción del entorno, actitudes sobre normas de género y violencia basadas en el género, salud sexual y reproductiva, incluido el VIH; actitudes hacia la prevención del VIH, y eficacia individual y colectiva para tal fin, discriminación y racismo en Nicaragua y exposición general a los medios de comunicación y a SDSI.

- El segundo era un cuestionario escrito, fácil de leer, que cada participante llenaba por su cuenta (autollenado) y luego lo colocaba en un sobre (si lo necesitaban, podían solicitar ayuda para completar el formulario). Este cuestionario exploraba los aspectos más sensibles sobre sexualidad y prevención del VIH, como haberse hecho la prueba del VIH o estar interesado en hacerlo, prácticas sexuales, uso del condón e historia de abuso sexual.

Los instrumentos se pilotaron y validaron, cada encuesta se supervisó en las tres ciudades. Las entrevistas fueron dividas por sexo: mujeres entrevistaban a mujeres y, hombres a otros hombres. En términos generales, las entrevistas tuvieron lugar en el hogar del participante y duraron aproximadamente una hora. 


\section{Aspectos éticos}

Se obtuvo consentimiento informado de cada persona previo a la realización de la encuesta. El equipo de investigación se aseguró que al inicio del estudio, y durante cada encuesta, todos los participantes entendían: a) la importancia y la naturaleza de su participación, b) a quién contactar para aclarar cualquier duda sobre el estudio, c) la necesidad de que se les visitara de nuevo, d) que daban su consentimiento para participar en el estudio, e) que tenían la opción de retirarse en cualquier momento. Al finalizar la entrevista se entregó a los participantes material informativo sobre los diferentes temas. Durante la tercera encuesta, también se brindó información sobre los centros locales donde podían recibir servicios relacionados con salud y violencia.

\section{Análisis de los datos}

El estudio de panel lo ejecutó el Centro de Investigaciones en Demografía y Salud (CIDS) de la Universidad Nacional Autónoma de Nicaragua, UNAN-León con el apoyo de PATH, del Programa Horizons del Population Council y de consultores independientes. Se organizaron dos equipos complementarios de análisis estadísticos. Uno de ellos evaluó los efectos de la exposición a SDSI tomando en cuenta factores sociodemográficos. El otro, exploró los efectos de la exposición y su relación con actitudes previas identificadas en la línea de base, a fin de determinar cómo esas actitudes pudieron haber predispuesto a las personas a la exposición a SDSI o al cambio de comportamiento. En ambos casos se construyó una variable para la aproximación a la exposición a SDSI, basada en la exposición al programa de televisión, y en un conjunto de índices relacionados con los principales temas. A continuación se describen los diferentes pasos para el análisis.

\section{Los análisis de tipo univariado, bivariado y modelos longitudinales con múltiples variables}

El análisis general comprendió una serie de diferentes etapas. El primer análisis se realizó de inmediato después de la primera encuesta (línea de base), lo cual proporcionó un perfil de la situación inicial de los participantes

La segunda etapa del análisis se realizó después de la segunda encuesta y los resultados se compararon con la línea de base. Los resultados relevantes se volvieron a explorar en el segundo estudio cualitativo. Los aspectos que se examinaron estaban relacionados con el contexto social, las normas de género, el estigma relacionado con el VIH, el conocimiento sobre el VIH y la percepción del riesgo de infección, el conocimiento sobre los servicios disponibles y el uso de los mismos, exposición a los medios de comunicación y a SDSI.

Tras los resultados de la tercera encuesta se empezaron a observar tendencias entre los datos de los tres grupos de medición y se construyeron variables longitudinales para permitir la evaluación individual de los cambios. El seguimiento de la cohorte de adolescentes y jóvenes generó datos para variables biológicas que no cambiaron con el tiempo (p. ej., sexo); para variables que sí cambiaron con el tiempo en una sola dirección (p. ej., aumento en la edad); y para variables sociodemográficas y respuestas de opinión que cambiaron en múltiples direcciones (p. ej., percepción del riesgo, actitudes, situación de la pareja íntima, nivel educativo, interés en hacerse la prueba del VIH). Hubo dos tipos 
principales de variables de resultado: variables categóricas dicotómicas (dos respuestas: si o no; acuerdo o desacuerdo) y variables numéricas continuas (p. ej., edad, índices con varios rangos de valores).

Para evaluar la validez interna de los datos, se aplicaron una serie de pruebas a variables clave. Por ejemplo, para la confiabilidad y la consistencia interna de los índices creados se utilizó la prueba Alpha de Cronbach y el análisis factorial. En el caso de las respuestas relacionadas con la sexualidad y el VIH, se evaluó la reproducibilidad de las respuestas en el tiempo y en ambos tipos de cuestionarios, calculando el valor estadístico Kappa y el factor de correlación Pearson.

La evaluación de la asociación entre los cambios observados y la exposición a SDSI implicó la construcción de modelos longitudinales multivariados y la exploración de la interacción entre variables. Dichos modelos se ajustaron para controlar el efecto de las variables sociodemográficas, que se ven particularmente afectadas por cambios que dependen del tiempo (p. ej., edad, educación, estado civil), y también el de las variables como el sexo y la localidad. Las pruebas estadísticas empleadas dependían de si la variable que se estaba evaluando era continua o categórica.

En el caso de los índices se aplicaron modelos lineales (modelo lineal general) para mediciones repetidas con pruebas de medias marginales estimadas, mientras que los modelos de regresión logística, tales como las ecuaciones para estimaciones generalizadas (EEG, o GEE en inglés), se utilizaron para las variables categóricas dicotómicas (p. ej., el uso del condón). El nivel de significación considerado en el estudio es $\mathrm{p}=0.05$, lo que significa que cualquier asociación con una probabilidad de más de 0.05 (p. ej., 0.15) no se considera estadísticamente significativa. Mientras tanto, se utilizó un intervalo de confianza del 95 por ciento, lo cual significa que el resultado estaría dentro de un rango definido de 95 de cada 100 veces. En la sección de los resultados, estas cifras se presentan junto con detalles sobre el resultado si es estadísticamente importante.

Cada prueba trató de descartar la posibilidad de que las diferencias detectadas se debieran a relaciones causales entre las variables. Los métodos identificaron y controlaron los efectos de confusión de otras variables sociodemográficas que pudieran haberse asociado con una prolongada exposición a SDSI (p. ej., edad, educación). De esta manera, fue posible determinar si realmente había una relación causal entre SDSI y las variables de impacto (p. ej., índices). Pero el análisis también permitió identificar y ver a nivel individual el efecto de otras variables, como edad y sexo, y si éstas contribuyeron al resultado. El diseño del estudio también controló otros posibles efectos de la interacción de variables independientes (exposición, edad, sexo) en variables de impacto.

\section{Mediciones con indices}

El impacto de la intervención se midió parcialmente creando índices. Se agruparon varias preguntas alrededor de un concepto o indicador de impacto para formar un solo índice. Esto permitió un entendimiento más global de un concepto dado y captado en el índice y complementó los resultados obtenidos de las mediciones individuales.

Cada pregunta entre los diferentes rubros de los índices requería que el participante expresara una posición de acuerdo, desacuerdo o ninguna. Se sumaron las respuestas para cada uno de los rubros a fin de dar un valor al índice que luego podía procesarse como una sola variable. La consistencia 
interna de cada índice se evaluó de forma estadística mediante el uso de la prueba Alpha de Cronbach. Las respuestas neutrales se volvieron a codificar y se trataron como respuestas no deseadas. El valor promedio de las respuestas se asignó a cualquier rubro que no tuviera respuesta.

Durante los análisis, se construyeron índices para normas de género, de estigma relacionado con el VIH, de capital social, de eficacia individual, de eficacia colectiva y de poder dentro de la relación. Para medir las actitudes hacia las normas de género relacionadas con la prevención del VIH, la violencia sexual y las relaciones de pareja, se seleccionaron ítems de la escala de hombres con equidad de género (HEG), la cual se elaboró y se validó en Brasil (Pulerwitz y barrer, 2007).

Mientras tanto, para medir el estigma relacionado, se utilizaron las preguntas derivadas de las recomendaciones formuladas por el grupo de trabajo interagencial de los indicadores del estigma (Nyblade y MacQuarrie, 2006). En el caso de los índices para medir el capital social y la eficacia, el equipo de la evaluación formuló ítems siguiendo procedimientos comunes para la formulación de este tipo de pregunta. Por último, para medir el poder dentro de la relación se utilizó una serie de rubros de la subescala de control de la escala de poder en la relación sexual. (Pulerwitz, Gortmaker, y DeJong, 2000).

\section{Otros análisis}

La influencia preventiva de SDSI que se puede atribuir a la población se calculó para un subconjunto de variables de resultado usando la formula siguiente:

$R A P=[($ porcentaje de personas expuestas a SDSI entre los casos positivos) $x$ (relación de probabilidad -1)]/relación de probabilidad.

Este análisis permite calcular el número de personas con una cierta respuesta que se podrían atribuir directamente al impacto de la intervención; en otras palabras, calcula el número de personas que habrían dado diferentes respuestas si no se hubiera implementado SDSI. Sobre este cálculo, los números absolutos se proyectan con respecto a la población juvenil en los sitios del estudio y luego se proyectan de manera más amplia basados en la población nacional de jóvenes urbanos.

Los modelos conceptuales se construyeron de forma colectiva tomando en cuenta la variable de exposición, las variables del participante (utilizadas para ajustar el modelo) y las variables en la respuesta. El enfoque estadístico se basó en regresión logística stepwise para las variables de respuesta dicotómica (p. ej., el uso del condón durante la última relación sexual con una pareja estable). Los resultados se presentaron en relaciones de probabilidad crudas y ajustadas, y se utilizó un intervalo de confianza (IC) del 95 por ciento, para evaluar el nivel de importancia estadística.

\section{Exposición a SDSI}

La intensidad de la exposición a Sexto Sentido TV se tomó como la medida de aproximación a la exposición a SDSI. Este diseño se basó en la solidez numérica y el detalle de la información en televisión, lo que permitió la definición de los grupos con diferentes grados de exposición. También 
se evaluaron los grupos expuestos a otros componentes de SDSI, pero los resultados correspondientes a las características de esos grupos eran similares a los relacionados con la televisión, de manera que se consideró apropiado utilizar la exposición a Sexto Sentido TV como la variable para la exposición a SDSI. Asimismo, el alcance masivo de la intervención imposibilitó la identificación de un grupo sólido de personas "no expuestas" a SDSI o a Sexto Sentido TV, de manera que la comparación se basó en "más" o "menos" exposición. Esa definición se describe a continuación.

\section{Confiabilidad de las respuestas a temas delicados}

La validez de las respuestas a temas delicados se evaluó midiendo la confiabilidad con la cual la misma respuesta podría obtenerse a la misma pregunta formulada en diferentes instrumentos o en diferentes momentos. Se utilizó la prueba del índice de Kappa, o el Kappa estadístico para evaluar la reproducción de respuestas a preguntas delicadas incluidas, tanto en el cuestionario aplicado por el/la entrevistador/a, como en el autollenado. Por ejemplo, la pregunta, ¿Has tenido relaciones sexuales?" se hizo en la entrevista cara a cara y también apareció en el cuestionario autollenado.

Los resultados mostraron un 93 por ciento de concordancia en las respuestas, dando un valor Kappa de exactamente 0.93 , el cual está por encima de $0.80 \mathrm{y}$, por consiguiente, tiene importancia estadística $(\mathrm{p}<.001)$. La replicabilidad de las respuestas obtenidas en diferentes momentos también se evaluó con la pregunta "¿Qué edad tenías vos cuando tuviste tu primera relación sexual?" Lo que se hizo fue establecer la correlación (medir la coincidencia) entre las respuestas brindadas en la segunda y la tercera encuesta. Estadísticamente, esto se evaluó utilizando la correlación de Pearson de chi cuadrado porque la edad es una variable continua (p. ej., 13, 14, 15). La correlación resultante fue de 0.918 , que es muy cercana a una correlación perfecta de 1.000. Esto significa, por ejemplo, que de 100 personas que en la segunda encuesta dijeron haber tenido su primera relación sexual a la edad de 13 años, 91 personas dieron la misma respuesta (13 años) cuado se les preguntó nuevamente en la tercera encuesta.

Sin embargo, la concordancia no fue tan alta para otras preguntas, como las respuestas dadas a la pregunta sobre el uso del condón. A los/las participantes se les pidió que compararan su nivel de honestidad al responder las preguntas formuladas verbalmente por la persona encuestadora versus las respuestas dadas en el cuestionario autollenado. Ocho de cada diez participantes dijeron que habían sido igualmente honestos/as en ambas partes, mientras que el resto (dos), dijeron que lo habían sido en el cuestionario autollenado, que en la entrevista cara a cara. Por esta razón, el análisis de las preguntas delicadas (sobre prácticas sexuales, incluyendo el uso del condón) se basó en los datos de los cuestionarios respondidos por los propios participantes, bajo el supuesto de que éste tenía respuestas más confiables.

\section{Componente cualitativo}

La información de los estudios cualitativos complementó aquella aportada por los resultados cuantitativos del estudio de panel. Se realizaron tres estudios cualitativos durante tres años consecutivos (2004, 2005 y 2006) en los mismos sitios donde se realizaron las encuestas. En dos estudios se incluyó a la ciudad de Bilwi (Puerto Cabezas) en la región de la costa Caribe de Nicaragua. Se examinaron hasta tres grupos distintos de jóvenes que tenían algún vínculo con organizaciones, los/ 
as participantes en el estudio de panel y jóvenes que no tenían ningún vínculo con organizaciones, con SDSI o con el estudio. También se incluyeron adultos vinculados a organizaciones locales.

\section{Primer estudio cualitativo (cualitativo 1 o estudio cualitativo de línea de base)}

El estudio cualitativo de línea de base se implementó en el 2004, en las mismas ciudades donde se realizó el estudio de panel, y también en la ciudad de Bilwi, se enfatizó la percepción del entorno local. Dado que el estudio se hizo después de empezado el proyecto y una vez que había concluido el primer periodo de la serie televisiva, también se evaluaron la aceptación y los efectos inmediatos de SDSI.

En total se formaron 16 grupos focales con jóvenes: ocho grupos con jóvenes que estaban vinculados a organizaciones afines a SDSI y ocho jóvenes que no estaban; se realizaron diez entrevistas de grupo con representantes de organizaciones locales. Participaron cien jóvenes y 45 líderes de organizaciones. Los temas principales que se exploraron incluyeron los principales problemas relacionados con el contexto social local, los medios de comunicación, la comunicación (interpersonal) sobre los temas de interés, las alianzas entre organizaciones, el apoyo social y personal, las actitudes y las normas sociales en torno al VIH, las normas relacionadas con género (machismo), la violencia doméstica y el abuso sexual, la homosexualidad/el lesbianismo, el estigma y la aceptación de Sexto Sentido TV y Radio.

\section{Segundo estudio cualitativo (estudio de medio término o exploración de estudio de panel)}

El segundo estudio cualitativo se realizó a finales de 2005 con jóvenes de las tres ciudades que se incluyeron en el estudio de panel. El objetivo era explorar en detalle los resultados comparativos entre la primera y la segunda encuesta. Estuvo dirigido a entender mejor algunos de los elementos que pudieron haber contribuido a los cambios en la población y la interacción entre esos cambios y los componentes de SDSI. También pretendía entender e interpretar mejor aquellos resultados inesperados o intrigantes. Se hicieron 45 entrevistas detalladas, dos tercios de ellas con jóvenes tomados del estudio de panel y el resto con jóvenes provenientes de la población general (el grupo de control).

El estudio trató de identificar las fuentes de información y de influencia que podrían contribuir a los cambios revelados en la comparación de las dos primeras encuestas. Se exploró lo siguiente: percepción de cambios en el contexto social local, normas de género y opiniones sobre equidad de género, la percepción del riesgo, la eficacia individual y colectiva, comunicación entre parejas en torno al VIH, el uso de los proveedores de servicios de salud sexual y reproductiva, la motivación para hacerse la prueba del VIH y las consecuencias del estudio de panel.

\section{Tercer estudio cualitativo (o estudio del contexto social local y de las alianzas)}

El tercer estudio cualitativo examinó los posibles vínculos entre la implementación de SDSI y los cambios en el entorno local y en los procesos colectivos. Se trató de determinar, tanto con jóvenes como con adultos/as en organizaciones aliadas, el contexto social local y los posibles vínculos entre 
SDSI y los cambios percibidos en el contexto social local. La intención era utilizar este enfoque para recopilar información sobre los efectos de SDSI y la relación dinámica entre los diferentes componentes de proyecto, tanto a nivel individual como organizacional. Por razones de tiempo y presupuesto, este estudio sólo se realizó en dos de las tres ciudades seleccionadas (Estelí y Juigalpa) y en Bilwi. Se hicieron 39 entrevistas individuales con representantes de 21 organizaciones de la sociedad civil, cinco entidades estatales, tres organismos de coordinación y nueve medios de comunicación locales. También se condujeron cuatro grupos focales (uno en Estelí, uno en Juigalpa, y dos en Bilwi), con la participación de 39 jóvenes (24 mujeres y 15 varones).

Una parte central de este tercer estudio cualitativo consistía en explorar los procesos de comunicación masiva y los vínculos de los diferentes componentes de comunicación masiva de SDSI con los cambios en el contexto social local. El estudio también evaluó el impacto de los procesos de fortalecimiento de la capacidad, trabajo en redes y participación en coaliciones, así como el vínculo de los diferentes componentes con respecto a los grupos meta. Igualmente evaluó el grado al cual las organizaciones e instituciones aliadas incorporaron los temas y enfoques a su propio trabajo.

Las acciones de monitoreo brindaron retroalimentación al equipo coordinador de SDSI antes, durante y después de la implementación de los diferentes componentes del proyecto. Por ejemplo, el abordaje del tema del VIH en Sexto Sentido estuvo acorde con las demandas expresadas por las y los jóvenes durante la serie anterior y en las giras del elenco. Los procesos de monitoreo brindaron información de seguimiento y analizaron, entre otras fuentes, las llamadas telefónicas al programa radial, la compilación de sugerencias hechas por la audiencia y los participantes durante las giras del elenco, los grupos focales con los televidentes, las entrevistas con las organizaciones aliadas y las actividades de monitoreo en coordinación con proveedores de servicios sociales y de salud.

\section{La triangulación de resultados: integración de datos cuantitativos y cualitativos}

Los diferentes resultados se integraron mediante un proceso de "triangulación", lo cual significa comparar los datos derivados de múltiples fuentes utilizando múltiples métodos. Se crearon matrices para cada objetivo de SDSI a fin de comparar los diversos resultados. Se utilizaron múltiples fuentes de datos cualitativos para explorar más o explicar ciertas conclusiones del estudio de panel. Los estudios cualitativos también han generado información específica para ciertos componentes de SDSI, como el contexto local y movilización social. Por último, investigadores/as de CIDS, PATH, Horizons e investigadores/as independientes también integraron y revisaron los datos. 


\section{Resultados}

Esta sección contiene las principales características sociodemográficas, tanto de la muestra del estudio, como del grupo más expuesto a Somos Diferentes, Somos Iguales, así como las principales conclusiones del análisis longitudinal y de los estudios cualitativos.

\section{Características de la muestra}

El análisis longitudinal cuantitativo incorpora información correspondiente a los "sobrevivientes" de la encuesta (personas que participaron en las tres encuestas). Las principales características sociodemográficas de la muestra se presentan más abajo. Por ser un estudio longitudinal, las características de ésta varían a lo largo del tiempo, a excepción de las variables de sexo y localidad que son independientes del tiempo.

Basado en las edades de los encuestados al momento de la última encuesta, se formaron dos grupos etarios para el análisis: (18 y menos) y (19 y más). Esta agrupación corresponde al rango etario para los jóvenes propuesto por Naciones Unidas. (Al inicio del estudio, los participantes tenían entre 13 y 25 años). La tabla 2 muestra la distribución de la muestra por edad y otros factores en el transcurso de las tres encuestas cuantitativas.

En los diferentes años, las encuestas se centraron en recopilar diversos datos sobre los antecedentes de los/as participantes. En la primera encuesta se exploró el nivel de pobreza; preguntas relacionadas con la religión se incluyeron en la última encuesta. Se valoró la afiliación o la práctica religiosa para determinar si la exposición u otras variables estaban condicionadas por un perfil religioso. El índice de la pobreza para determinar el nivel socioeconómico fue el método de las necesidades básicas insatisfechas (NBI), que clasifica a sujetos u hogares como "pobres" o "no pobres" según una serie de variables que incluyen tener servicios de energía eléctrica y agua potable, de saneamiento; evalúa el tipo de piso y paredes, poseer un aparato de radio o de televisor y la actividad económica de las y los miembros del hogar.

La población en el estudio SDSI tenía un porcentaje mayor clasificado como "pobres" que la tasa nacional para los hogares urbanos reportada por el Instituto Nacional de Información para el Desarrollo (INIDE), en su encuesta nacional a hogares para medir las condiciones de vida (MECOVI). Esto podría ser el resultado de las diferencias metodológicas. MECOVI midió la incidencia de la pobreza en un consumo mínimo para satisfacer las necesidades básicas y reveló una tasa nacional de pobreza del 50 por ciento ( 20 por ciento en pobreza extrema), mientras que para la población urbana, el porcentaje que vive por debajo de la línea de la pobreza era de 31 por ciento (comparado con 45 por ciento de la muestra de este estudio). Los resultados relacionados con la presencia de un televisor en la casa fueron similares a las cifras registradas en la encuesta de Demografía y Salud del 2002 realizada por el Instituto Nacional de Estadísticas y Censos (INEC), que reportaron televisores en 85 por ciento de los hogares urbanos en estos tres municipios. 
Tabla 2 Características demográficas y socioculturales relevantes de la muestra

\begin{tabular}{|c|c|c|c|}
\hline Variables & $\begin{array}{c}\mathrm{I}-2003 \\
\%\end{array}$ & $\begin{array}{c}\mathrm{II}-2004 \\
\%\end{array}$ & $\begin{array}{c}\mathrm{III-2005} \\
\%\end{array}$ \\
\hline \multicolumn{4}{|l|}{ Sexo } \\
\hline Femenino & 54 & 54 & 54 \\
\hline Masculino & 46 & 46 & 46 \\
\hline \multicolumn{4}{|l|}{ Edad } \\
\hline 18 años o menos & 62 & 53 & 44 \\
\hline 19 años o más & 38 & 47 & 56 \\
\hline \multicolumn{4}{|l|}{ Municipio (ciudad) } \\
\hline Estelí & 28 & 28 & 28 \\
\hline León & 35 & 35 & 35 \\
\hline Juigalpa & 38 & 38 & 38 \\
\hline Tiene pareja ${ }^{* *}$ & 39 & 45 & 60 \\
\hline Tiene uno o más hijos & 15 & 21 & 24 \\
\hline Pobre* & 45 & $\mathrm{n} / \mathrm{a}$ & $\mathrm{n} / \mathrm{a}$ \\
\hline Está actualmente en la escuela & 70 & 63 & 58 \\
\hline \multicolumn{4}{|l|}{ Último nivel de escolaridad } \\
\hline Primaria & 19 & 16 & 12 \\
\hline Secundaria & 64 & 63 & 61 \\
\hline Superior/universidad & 15 & 19 & 22 \\
\hline Actualmente trabaja & 19 & 32 & 43 \\
\hline \multicolumn{4}{|c|}{ Importancia de la religión en su vida* } \\
\hline Poca o ninguna & $\mathrm{n} / \mathrm{a}$ & $\mathrm{n} / \mathrm{a}$ & 19 \\
\hline Importante o muy importante & $\mathrm{n} / \mathrm{a}$ & $\mathrm{n} / \mathrm{a}$ & 81 \\
\hline \multicolumn{4}{|l|}{ Afiliación religiosa* } \\
\hline Católica & $\mathrm{n} / \mathrm{a}$ & $\mathrm{n} / \mathrm{a}$ & 57 \\
\hline Evangélica/otra protestante & $\mathrm{n} / \mathrm{a}$ & $\mathrm{n} / \mathrm{a}$ & 28 \\
\hline Ninguna & $\mathrm{n} / \mathrm{a}$ & $\mathrm{n} / \mathrm{a}$ & 15 \\
\hline \multicolumn{4}{|c|}{ Frecuencia con la que va a la iglesia* } \\
\hline Una o dos veces a la semana & $\mathrm{n} / \mathrm{a}$ & $\mathrm{n} / \mathrm{a}$ & 39 \\
\hline Ocasionalmente & $\mathrm{n} / \mathrm{a}$ & $\mathrm{n} / \mathrm{a}$ & 35 \\
\hline No va & $\mathrm{n} / \mathrm{a}$ & $\mathrm{n} / \mathrm{a}$ & 27 \\
\hline Afiliación a una organización & 19 & 22 & 17 \\
\hline Tiene un grupo de amigos & 79 & 81 & 73 \\
\hline Tiene un televisor en la casa* & 93 & $\mathrm{n} / \mathrm{a}$ & $\mathrm{n} / \mathrm{a}$ \\
\hline
\end{tabular}

*Basado en preguntas hechas en sólo una encuesta.

**La palabra "pareja" se refería a varios tipos de relaciones (novio/novia, parejas que viven juntas, marido/mujer). 


\section{Percepción del contexto social}

Se creó un índice para evaluar los aspectos de la percepción del contexto social, es decir del entorno en el que viven y operan. Esta variable no se consideró una variable de los resultados sino que más bien se creó para entender mejor la relación, si la hubiese, entre percepciones del contexto local y respuestas individuales sobre otros temas.

Los resultados de las tres encuestas muestran una tendencia hacia una reducción gradual en el índice. Esto se puede interpretar como una percepción de deterioro del entorno social, o en el contexto social local. Hubo una mayor percepción de deterioro en el entorno social entre las mujeres que entre los hombres $(\mathrm{p}<.001)$; $\mathrm{y}$ en Juigalpa en relación con Estelí y León $(\mathrm{p}<.001)$.

Cabe señalar que el modelo lineal general reveló que este deterioro no estaba asociado de ninguna manera con la exposición a SDSI. Por el contrario, SDSI sí estuvo positivamente asociado con mayor eficacia colectiva, es decir, la percepción de que los/as jóvenes y las personas a su alrededor (familiares, vecinos) podían hacer algo juntos.

Los estudios cualitativos ayudan a explicar la percepción sobre el deterioro en el contexto social local. Los problemas en el entorno local comúnmente identificados en los tres últimos años incluyeron drogas, alcoholismo, pandillas, desempleo, pobreza, violencia y embarazo en adolescentes.

Los estudios revelaron que, en gran medida, la percepción del contexto local o del entorno social estaba vinculada tanto a las experiencias personales como a los eventos externos. Nuevas responsabilidades y experiencias de vida como resultado de la edad y la madurez, así como el género, son todos elementos que parecen afectar esta percepción del deterioro social. El tipo de experiencias negativas que podrían acompañar la experiencia de ser parte de una pareja, por ejemplo, puede variar considerablemente en hombres y mujeres.

En el primer estudio cualitativo, las y los participantes reflexionaron sobre los "cambios" negativos percibidos en su contexto social local, tales como la presencia y el incremento en el consumo y abuso de las drogas, que según comentó un participante en la encuesta "ahora se venden como caramelos" (estudio cualitativo 1; varón no organizado; Juigalpa).

El segundo estudio cualitativo también encontró que en Juigalpa se percibieron menos cambios positivos, especialmente con respecto a la administración de las autoridades locales. En Estelí y León, por otra parte, mucho más adolescentes y jóvenes hablaron sobre los logros y sobre el buen trabajo de ciertas organizaciones y de las instituciones de gobierno locales. En el caso de Estelí, también mencionaron la creciente actividad comercial.

La administración del Alcalde pasado fue bastante buena. Se miraron bastantes proyectos, digamos, nuevas calles adoquinadas, puentes.

Estudio cualitativo 2; varón adolescente del estudio de panel en Estelí

Las cosas importantes que han pasado aqui en Esteli, digamos, es el crecimiento en el comercio. Esto genera más empleo aqui en la ciudad.

Estudio cualitativo 2; hombre adolescente del estudio de panel en Estelí 


\section{Alcance y características de la exposición a SDSI}

Esta sección contiene datos relacionados con la exposición a diferentes componentes del proyecto SDSI y con la aceptación de los mismos, como: Sexto Sentido TV y Sexto Sentido Radio, las vallas publicitarias y el folleto Necesitamos Poder Hablar. Los componentes relacionados con capacitación y coordinación con otras organizaciones se estudiaron cualitativamente.

\section{Definición de "exposición” para fines del análisis del impacto}

Como la exposición al proyecto SDSI fue tan amplia — al final de la intervención, nueve de cada diez personas entrevistadas conocían por lo menos la serie Sexto Sentido TV-fue imposible identificar un grupo considerable de "no expuestos/as" para fines de comparación (Véase el diagrama 2).

\section{Diagrama 2 Exposición a los componentes de comunicación masiva de SDSI}

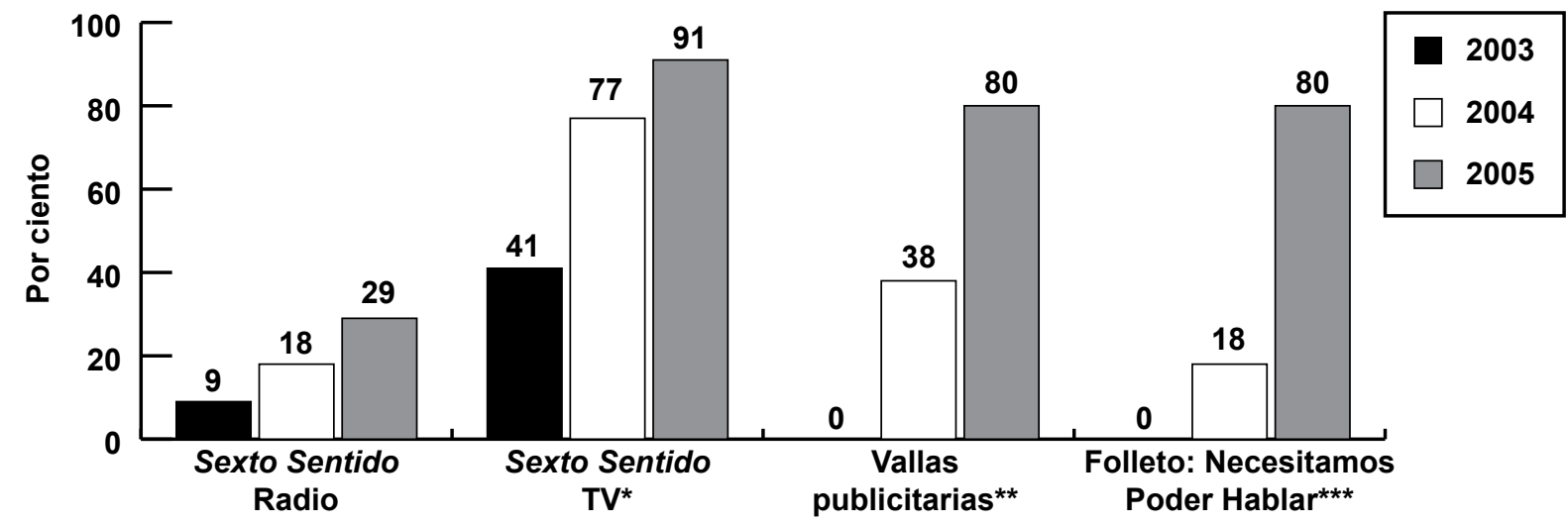

*La encuesta del 2003 se hizo antes que la primera de las tres temporadas del proyecto saliera al aire. Dos años después de la transmisión de la primera temporada, se preguntó qué tanto recordaban de la serie.

**En el momento de la encuesta de 2004 , no hacía mucho que se habían colocado las vallas publicitarias.

***En el momento de la encuesta de 2002 aún no había una distribución masiva de los folletos.

El análisis reveló que las personas que habían escuchado Sexto Sentido Radio o que habían visto el folleto o la valla publicitaria en las calles, también habían mirado Sexto Sentido TV. Por consiguiente, se decidió utilizar la exposición a Sexto Sentido TV como la medida de aproximación para analizar el impacto de la exposición a SDSI.

Para fines de comparación, la muestra se dividió en dos grupos, uno con "más exposición" y otro con "menos exposición" (Véase el cuadro 1).
Cuadro 1 Definiciones de "más" y "menos" exposición

Menos exposición = Las personas que nunca miraron Sexto Sentido, que "casi nunca" la miraron, o que sólo miraron una de las tres temporadas del proyecto (independientemente de la frecuencia con la que miraron esa temporada).

Más exposición = Las personas que la miraron "casi siempre" u "ocasionalmente" durante por lo menos dos de las tres temporadas del proyecto transmitidas entre 2003 y 2005. 


\section{Exposición a Sexto Sentido TV}

Sexto Sentido TV fue ampliamente vista de manera regular por una gran parte de la población adolescente y joven (Véase el diagrama 3 ).

\section{Diagrama 3 Exposición a Sexto Sentido TV}

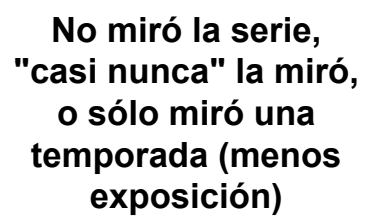

No miró la serie, "casi nunca" la miró, o sólo miró una temporada (menos exposición)

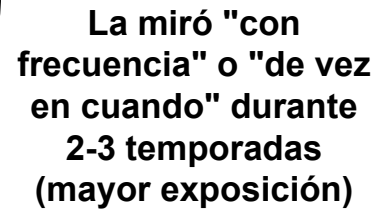

\section{Diferencias por municipio}

La ubicación geográfica de la audiencia (el municipio donde vive) fue un factor relevante en términos de la exposición a los diferentes componentes de SDSI (véase el diagrama 4). En el caso de Sexto Sentido Radio y Sexto Sentido TV, Juigalpa fue el de mayor audiencia "leal" (el municipio mas conservador desde el punto de vista social y con el menor numero de organizaciones trabajando en torno a los temas abordados por SDSI).

\section{Diagrama 4 Exposición por municipio (2005)}

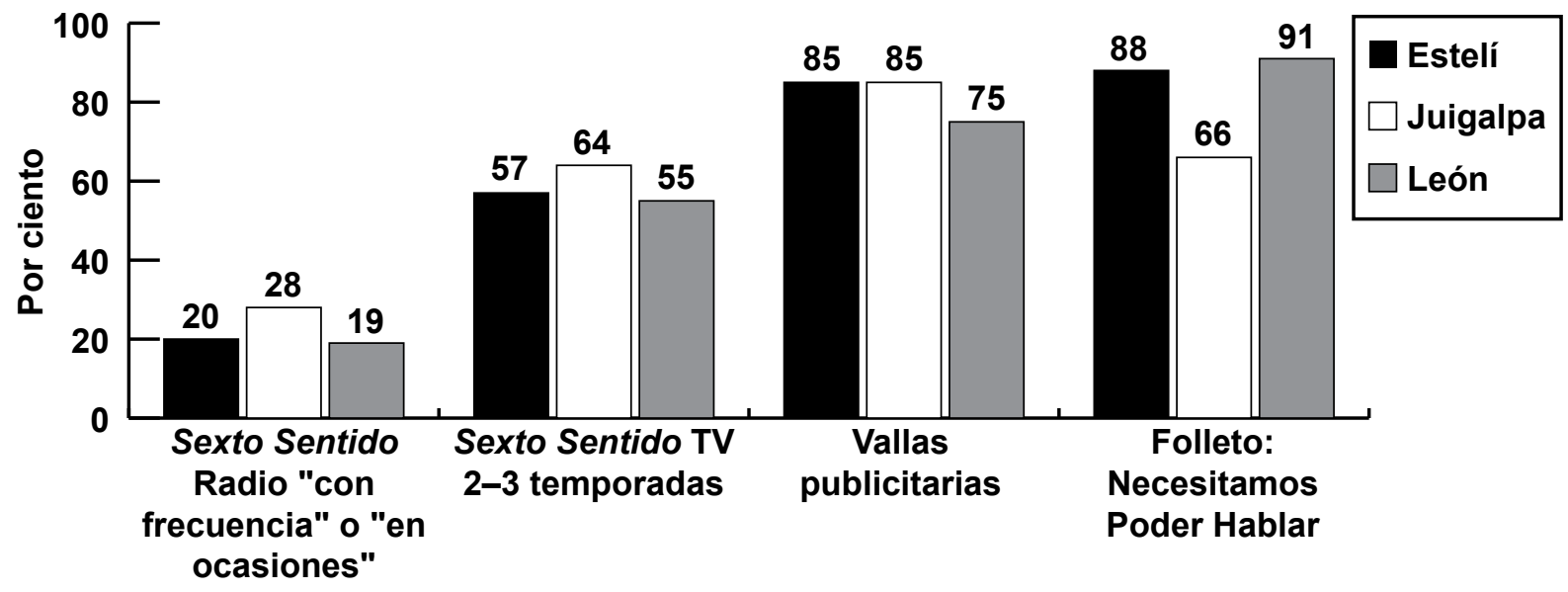


Número proyectado de jóvenes "más expuestos”

Dado que las muestras son representativas de los lugares donde se realizó la encuesta, es posible proyectar las poblaciones jóvenes "más expuestas" en estas tres localidades (véase la tabla 3). Esto se hizo aplicando el porcentaje de jóvenes con "más exposición" en cada municipio, a la población urbana general de cada departamento, entre las edades de 15 y 24 años (INIDE, 2005).

Tabla 3 Juventud proyectada con más exposición por municipio

\begin{tabular}{lccc}
\hline Departamento & $\begin{array}{c}\text { Población urbana } \\
\text { adolescente y juvenil } \\
\text { (15-24 años) }\end{array}$ & $\begin{array}{c}\text { \% de más } \\
\text { exposición por } \\
\text { municipio }\end{array}$ & $\begin{array}{c}\text { \# de adolescentes y } \\
\text { jóvenes (15-24 años) } \\
\text { con más exposición }\end{array}$ \\
\hline Estelí & 27,249 & 55 & 14,905 \\
Chontales (Juigalpa) & 19,935 & 64 & 12,738 \\
León & 47,448 & 57 & 27,188 \\
Subtotal para las tres & 94,632 & & 54,831 \\
áreas & & & \\
\hline
\end{tabular}

La audiencia real en estos departamentos puede ser considerablemente mayor que la cifra combinada de 54,831 calculada en la muestra, ya que ésta sólo incluía a jóvenes de más de 13 años. El mismo cálculo basado en la población entre 10 y 29 años da una proyección de 105,346 personas con "más exposición" que residen en los tres departamentos. La mitad de quienes miraron Sexto Sentido TV dijeron que lo hicieron con otras personas y una gran proporción lo vieron con "toda la familia".

\section{Proyección nacional ${ }^{6}$}

Si bien la muestra del estudio no tiene representatividad nacional, es posible hacer una proyección nacional conservadora aplicando el porcentaje para los tres municipios (59 por ciento) a la población urbana nacional de 15 a 24 años y de 10 a 29 años. (Véase la tabla 4).

Tabla 4 Exposición nacional proyectada en los jóvenes

\begin{tabular}{lccc}
\hline Todo el país & $\begin{array}{c}\text { Población } \\
\text { adolescente/juvenil } \\
\text { urbana }\end{array}$ & $\begin{array}{c}\text { \% más exposición } \\
\text { (promedio) }\end{array}$ & $\begin{array}{c}\text { \# adolescentes/ } \\
\text { jóvenes con mayor } \\
\text { exposición }\end{array}$ \\
\hline 15 a 24 años & 644,711 & 59 & 380,379 \\
10 a 29 años & $1,236,922$ & 59 & 729,784 \\
\hline
\end{tabular}

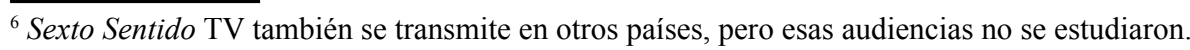


Características de las personas con "más exposición” a Sexto Sentido TV

Además del municipio, los otros factores relevantes fueron:

- Sexo: Proporcionalmente más mujeres que hombres miraron Sexto Sentido TV, con el 64 por ciento de las mujeres entrevistadas en el grupo de "más exposición”, comparado con el 53 por ciento de los hombres.

- Educación: Una mayor proporción de personas que habían culminado sus estudios secundarios o habían ingresado a la universidad miraron el programa, que personas que sólo tenían educación primaria.

- Trabajo: Una mayor proporción de personas sin empleo remunerado miraron el programa que de personas con empleo remunerado.

El análisis mostró que otros factores sociodemográficos importantes no están correlacionados con el nivel de exposición a Sexto Sentido. Los factores analizados incluyen:

- Edad: Una misma proporción de adolescentes (13-17 años) y de jóvenes (18-24 años) miraron la serie.

- Nivel económico: Una misma proporción de personas "pobres" y "no pobres" miraron la serie.

- Religión: No hubo correlación entre religión y tasas de exposición. No se descubrieron diferencias entre los varios niveles de exposición a Sexto Sentido y características religiosas, entre ellas, la importancia de la religión en sus vidas, profesar una religión particular, o la frecuencia con la que asisten a

Cuadro 2 La audiencia de Sexto Sentido y la religión

La importancia de la religión en las vidas de las personas que miraron Sexto Sentido con mayor frecuencia fue igual que para aquéllas que no miraron la serie con la misma frecuencia

- El 82 por ciento consideró que la religión es "importante" o "muy importante" en sus vidas, mientras que el 18 por ciento consideró que tenía "poca" o "ninguna" importancia.

- El 40 por ciento dijo que iba a misa una o más de una vez cada semana, el 36 por ciento va "en ocasiones" y el 24 por ciento no va del todo. la iglesia (Véase el cuadro 2).

- Afiliación a una organización: Una misma proporción de personas afiliadas y no afiliadas a una organización miraron la serie.

- Con o sin hijos/as: Una misma proporción de personas con y sin hijos/as miraron la serie.

\section{Exposición a otros componentes}

\section{Sexto Sentido Radio}

La proporción de personas que habían escuchado el programa Sexto Sentido Radio aumentó considerablemente a lo largo del tiempo, desde 9 por ciento en 2003 a 29 por ciento en 2005 . En 2005 se encontró que la mitad de las personas que habían escuchado el programa de radio, en algún momento dijeron que lo habían hecho dentro de los seis meses anteriores.

La inmensa mayoría de quienes escucharon este programa, reportaron haberlo hecho "en ocasiones" o “con frecuencia”. Entre 2003 y 2005, esta proporción aumentó de 74 por ciento a 82 por ciento, con un 
mayor incremento entre las mujeres, nivelando así la proporción de mujeres y hombres en la audiencia regular del programa. En 2005, el 23 por ciento del total de la muestra dijo haber escuchado Sexto Sentido Radio más o menos con regularidad. Desde la óptica de la competencia por las audiencias radiales debido a la enorme cantidad de estaciones, la audiencia cautiva de Sexto Sentido Radio es relativamente alta. Los cálculos de audiencia se limitaron a las poblaciones en estos tres municipios (INIDE, 2005) debido a que las frecuencias de las estaciones de radio no llegaban más allá del municipio.

Tabla 5 Exposición a Sexto Sentido Radio por municipio (2005)

\begin{tabular}{lccc}
\hline Ciudad & $\begin{array}{c}\text { Población urbana } \\
\text { adolescente/juvenil } \\
\text { (15-24 años) }\end{array}$ & $\begin{array}{c}\text { \% que escucha “en } \\
\text { ocasiones" o “con } \\
\text { frecuencia" }\end{array}$ & $\begin{array}{c}\text { \# de adolescentes/ } \\
\text { jóvenes (15-24 años) } \\
\text { con más exposición }\end{array}$ \\
\hline Estelí & 20,985 & 24 & 4,973 \\
Juigalpa & 9,825 & 28 & 2,790 \\
León & 31,638 & 19 & 6,043 \\
$\begin{array}{l}\text { Subtotal para las tres } \\
\text { ciudades }\end{array}$ & 62,448 & & 13,806 \\
\hline
\end{tabular}

Utilizando el mismo método de cálculo, la audiencia calculada para el 2005 se duplica a 27,352 cuando se toman en cuenta las otras cinco ciudades pequeñas donde se transmitía Sexto Sentido Radio. ${ }^{7}$ Esta estimación excluye a la audiencia de Managua, que es muy difícil de calcular dada la competencia entre estaciones de radio y la falta de estudios confiables de medición de audiencias.

\section{Los folletos Necesitamos Poder Hablar}

Los folletos Necesitamos Poder Hablar se distribuyeron hacia finales de 2004 por medio de las organizaciones vinculadas a Puntos de Encuentro. También se distribuyeron durante las giras del elenco de Sexto Sentido a varias ciudades nicaragüenses.

Cuando se hizo la última encuesta, ocho de cada diez personas entrevistadas dijeron que habían visto el folleto. Más mujeres que hombres lo habían visto ( 86 por ciento comparado con 75 por ciento), y también hubo importantes diferencias según el municipio (Estelí: 88 por ciento; Juigalpa: 66 por ciento; León: 91 por ciento). Esto es posible debido a que en Juigalpa, comparado con los otros municipios, había relativamente menos organizaciones para distribuir los folletos.

\section{Vallas publicitarias}

En las quince cabeceras departamentales y en las capitales de las dos Regiones Autónomas de la Costa Caribe se colocaron vallas publicitarias que contenían información sobre los servicios sociales y de

\footnotetext{
${ }^{7} \mathrm{Al}$ multiplicar la población de las ciudades por 23 por ciento, que es la proporción promedio que escucha el programa "con frecuencia” o "en ocasiones" Las otras ciudades son: Boaco, Chinandega, Masaya, Jinotega y Somoto.
} 
salud locales adonde las personas podían acudir. Al inicio se colocaron durante la segunda mitad de 2004 en preparación para la segunda temporada de Sexto Sentido TV. Posteriormente su contenido se cambió a inicios de 2005, previo a la temporada final.

Durante la última encuesta, ocho de cada diez personas entrevistadas dijeron que habían visto la valla publicitaria en su ciudad. A diferencia de los folletos, los municipios donde mejor se conocían las vallas eran Estelí y Juigalpa, ambos con 85 por ciento, mientras que en León, sólo un 71 por ciento sabía sobre las vallas. Esto podría deberse al hecho de que en León las vallas se ubicaron en la periferia de la ciudad, mientras que en Estelí y Juigalpa estaban en lugares más céntricos.

\section{Otras actividades}

Como habría de esperarse, las actividades del proyecto no relacionadas con la comunicación masiva se dieron a una escala menor que las de comunicación masiva. Por ejemplo, sólo el 6 por ciento de los/ as participantes en la encuesta dijo que había estado en una actividad celebrada por el elenco de Sexto Sentido TV en su área.

\section{Dinámica de las audiencias de Sexto Sentido TV y radio (nacional comparada con local)}

\section{Sexto Sentido TV}

Nueve de cada diez personas mencionaron el canal 2, —el de mayor audiencia en el país, con cobertura casi nacional — como el canal donde vieron Sexto Sentido. ${ }^{8}$ Algunas personas en cada localidad mencionaron que habían visto la serie en su servicio de cable local: el 14 por ciento de las personas entrevistadas en Juigalpa mencionó el canal 14; el 8 por ciento de las personas en Estelí mencionaron Telenorte de Estelí y el 5 por ciento en León mencionó el canal 55.

\section{Sexto Sentido Radio}

A diferencia de Sexto Sentido TV - y contrario a años anteriores cuando Sexto Sentido Radio sólo lo transmitía una estación de radio ubicada en Managua - las encuestas para este estudio demostraron la importancia de las estaciones locales en la red radial que transmitía simultáneamente Sexto Sentido Radio. En cada una de las tres ciudades incluidas en el estudio de panel, los/as participantes mencionaron su radio local como la principal estación donde escuchaban el programa. ${ }^{9}$ El estudio también reveló un aumento en la audiencia del programa en cada una de las ciudades, con notables incrementos a lo largo del tiempo en Estelí y León, aunque el programa siguió siendo más escuchado en Juigalpa.

\footnotetext{
${ }^{8}$ Este estudio se hizo antes de que la serie fuera retransmitida por el canal nacional de cable, el canal 11.

${ }^{9}$ Estas estaciones de radio son: Stereo Mundo en Estelí, Radio Centro en Juigalpa y La Amistad en León.
} 
En términos generales, las personas que miraban Sexto Sentido TV lo hacían con cierta regularidad. En 2004, el 72 por ciento de todas las personas encuestadas veía Sexto Sentido TV "con frecuencia” o "de vez en cuando". En 2005, sin embargo, ese porcentaje cayó a 54 por ciento.

Las razones de este descenso parecen estar fuertemente vinculadas al cambio en el horario del programa. Para la última temporada de la serie en 2005, el canal 2 cambió el horario pasándolo de temprano en la tarde del domingo a las doce meridiano del mismo día. Más del 80 por ciento de las personas que en 2005 dijo que no miraban el programa indicaron que era "debido al horario" o "porque no tenían tiempo" (Véase el diagrama 5).

\section{El horario es importante}

Después que cambió el horario del programa en 2005 , el 80 por ciento de quienes no miraban Sexto Sentido dijeron que era "debido al horario" o "debido a la falta de tiempo".

El estudio cualitativo identificó que el nuevo horario entraba en conflicto con actividades tales como ir a la iglesia, las labores domésticas o la preparación del almuerzo. Sólo el 7 por ciento de quienes no miraban el programa dijo que no les interesaba o no les gustaba, mientras que el 4 por ciento dijo no tener televisor.

\section{Diagrama 5 Razones para no mirar Sexto Sentido TV (2005)}

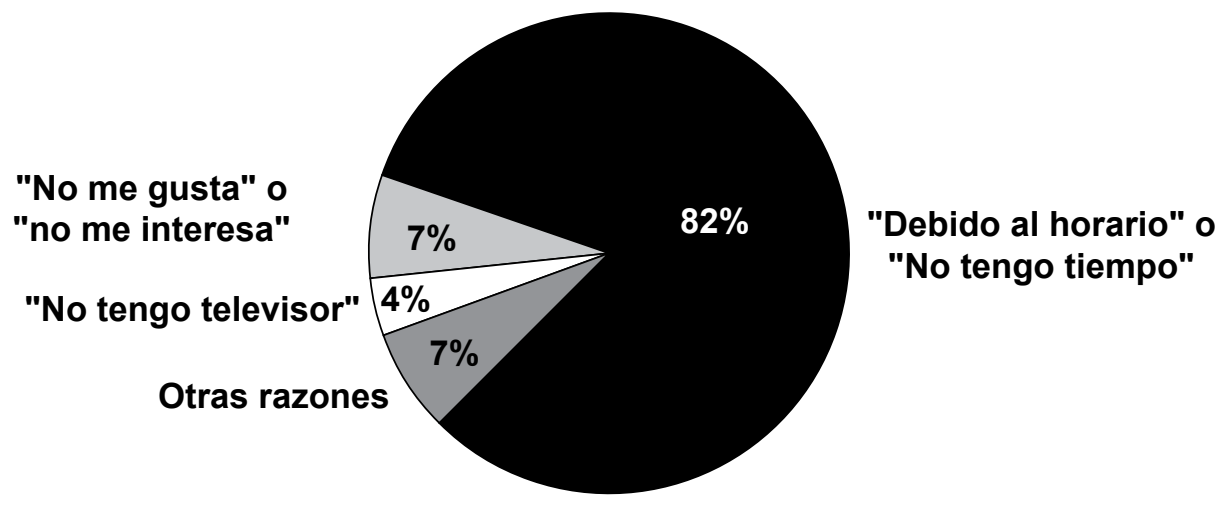

\section{Aceptación}

\section{Sexto Sentido TV}

Si bien en 2005 bajó el total de la audiencia de televidentes “frecuentes", la aceptación de la serie aumentó entre quienes la miraron. En 2004, la mitad de quienes vieron el programa dijo que les gustaba "bastante"; esta cifra aumentó a dos tercios de los entrevistados en 2005 (Véase el diagrama $6)$. 


\section{Diagrama 6 Sexto Sentido TV les gusta "bastante"}

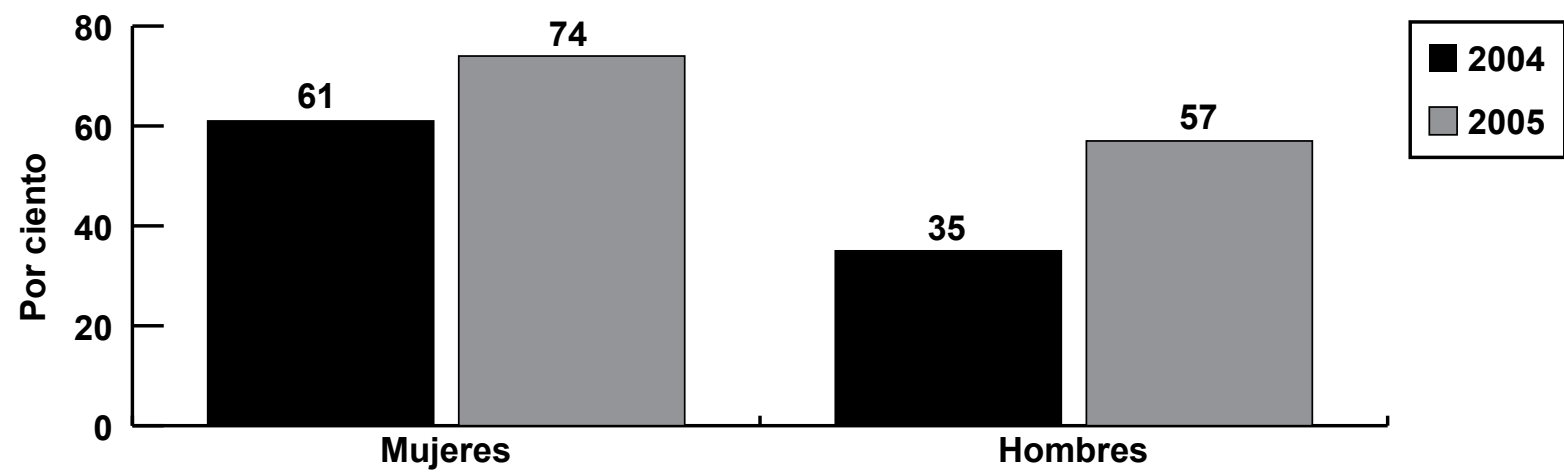

Entre 2004 y 2005, hubo un incremento en la proporción de personas que mencionaron Sexto Sentido TV de forma espontánea en respuesta a una pregunta abierta sobre sus programas de TV dominicales de producción nacional favoritos. En 2004, cuatro de cada diez personas mencionaron Sexto Sentido de forma espontánea. En 2005, esta cifra se elevó a seis de cada diez entrevistados/as, y más mujeres que hombres mencionaron el programa. Al mismo tiempo, la popularidad del programa aumentó entre los hombres a lo largo del tiempo, pasa de 29 por ciento que lo citó en 2004 como su programa de producción nacional favorito a 57 por ciento en 2005 (Véase el diagrama 7). De hecho, por la primera vez en la historia de Sexto Sentido, en 2005 una misma proporción de hombres y mujeres miraron la serie.

\section{Diagrama 7 Entrevistados que mencionaron Sexto Sentido de forma espontánea}



El incremento en la aceptación del programa sugiere que si en 2005 no se hubiera cambiado el horario, la audiencia para la última temporada hubiera crecido y habría elevado el porcentaje de personas en la categoría de "mayor exposición".

\section{Importancia del tema del VIH en el proyecto SDSI}

Durante la encuesta, antes de preguntar sobre Sexto Sentido, los cuestionarios sondeaban si conocían a alguien que fuera portador del VIH o que hubiese muerto por VIH. También se preguntó si habían 
visto a alguien en TV que fuera portador del VIH. Como muestra el diagrama 8, un porcentaje mucho mayor de la población encuestada había visto en TV a alguien con VIH o Sida, más que haber conocido personalmente a alguien con VIH o Sida. Entre 2004 y 2005 aumentó el porcentaje de personas que había visto en televisión a una persona con VIH o Sida, con un incremento significativamente mayor entre los hombres (de 62 por ciento a 74 por ciento). Del número total de personas que habían visto a alguien en televisión que tuviera VIH, el 61 por ciento mencionó Sexto Sentido de forma espontánea como el programa donde habían visto a esa persona.

\section{Diagrama 8 Conoce a alguien o ha visto a un personaje de televisión con VIH o Sida}

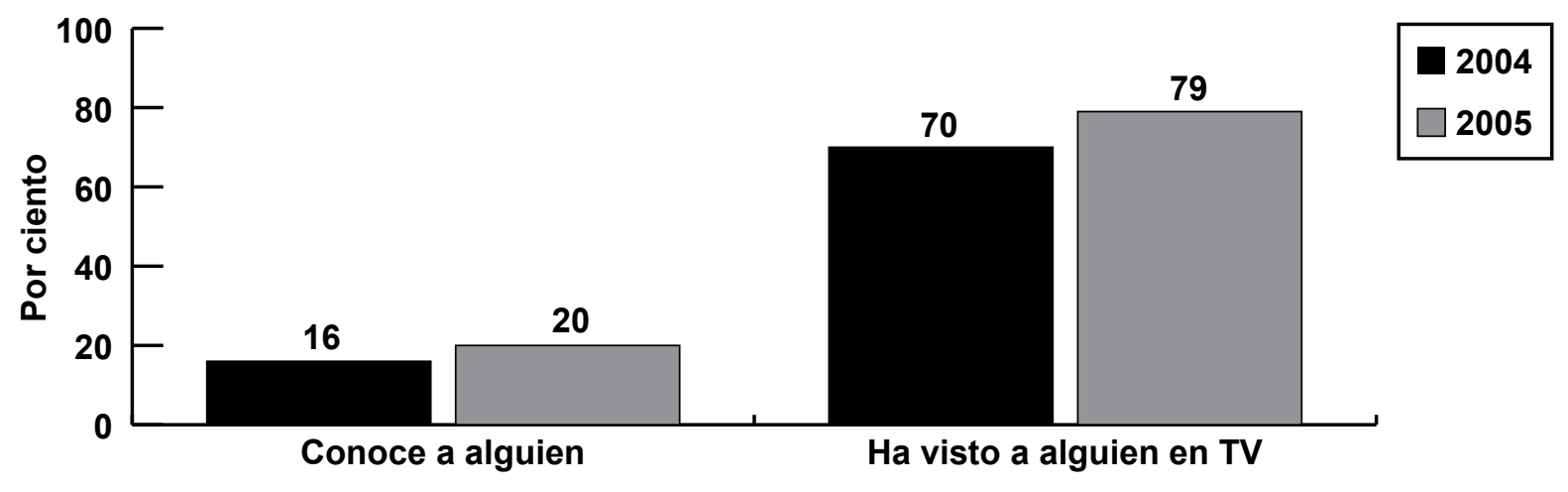

El VIH fue también el tema más mencionado por las audiencias de Sexto Sentido TV y de Sexto Sentido Radio, cuando se les preguntó qué tema les había hecho pensar más. La mitad de los televidentes y de los radioescuchas mencionaron el VIH (más mujeres que hombres), seguido de un tercio que mencionó la violencia doméstica/el abuso sexual (de nuevo, más mujeres que hombres). Las drogas fueron el tercer tema más mencionado (en este caso, más por los hombres que por las mujeres).

\section{Impacto de SDSI}

Se generaron dos tipos de resultados: los que identifican o describen el efecto acumulado de la exposición a SDSI a lo largo del tiempo mediante variables continuas (p. ej., índices); y aquéllos que identifican la probabilidad de que un efecto se deba a la exposición a SDSI mediante el uso de variables categóricas dicotómicas (p. ej., haber usado o no haber usado un condón la última vez que tuvieron relaciones sexuales). En ambos casos se utilizó el análisis con múltiples variables a fin de ajustar el efecto de la variable independiente de interés (exposición a SDSI) en una gama de variables dependientes. El análisis con múltiples variables aisló el efecto de la exposición a SDSI al hacer controles para una gama de otros factores que potencialmente podrían afectar las variables dependientes, como son, municipio, sexo, educación y edad.

\section{Resumen de resultados}

En la tabla 6 se resumen los principales efectos que se pueden atribuir a una mayor exposición a SDSI. Los resultados se describen y se analizan con más detalle en la tabla siguiente: 
Tabla 6 Resumen de resultados

\begin{tabular}{|c|c|c|}
\hline Impacto & Resultados $^{10}$ & $\begin{array}{l}\text { Riesgos atribuibles a la población } \\
\text { (RAP) }\end{array}$ \\
\hline $\begin{array}{l}\text { Mayor equidad de } \\
\text { género }\end{array}$ & $\begin{array}{l}\text { Participantes con mayor exposición a SDSI } \\
\text { presentaron mayores puntajes en el índice } \\
\text { de actitudes hacia el género (hacia una } \\
\text { mayor equidad de género) a lo largo de } \\
\text { la vida del proyecto que participantes con } \\
\text { menor exposición. }\end{array}$ & $\begin{array}{l}\text { Lo siguiente se atribuye a una mayor } \\
\text { exposición a SDSI: } \\
\text { - La actitud del } 22 \text { por ciento de quienes } \\
\text { no están de acuerdo con la afirmación } \\
\text { de que "las mujeres que llevan condones } \\
\text { en sus bolsos son mujeres fáciles" } \\
\text { ( } 15,377 \text { jóvenes en tres ciudades). } \\
\text { - La actitud del } 17 \text { por ciento de quienes } \\
\text { no creen que las mujeres tienen la } \\
\text { responsabilidad de evitar el embarazo } \\
\text { ( } 12,128 \text { jóvenes en tres ciudades). } \\
\text { - La actitud del } 11 \text { por ciento de quienes } \\
\text { no creen que las mujeres deban ser las } \\
\text { únicas responsables del cuidado del } \\
\text { hogar y de los hijos ( } 7,326 \text { jóvenes en } \\
\text { tres ciudades). }\end{array}$ \\
\hline Menor estigma & $\begin{array}{l}\text { Participantes con mayor exposición a } \\
\text { SDSI presentaron mayores puntajes en } \\
\text { el índice de actitudes de estigma (hacia } \\
\text { menos estigma) a lo largo de la vida del } \\
\text { proyecto que los participantes con menor } \\
\text { exposición. Además, los/as participantes } \\
\text { con mayor exposición mostraron: } \\
\text { - Mayor incremento en el tiempo en el } \\
\text { porcentaje que mantendría una amistad } \\
\text { con un amigo homosexual. El porcentaje } \\
\text { subió de } 36 \text { por ciento en } 2003 \text { a } 49 \\
\text { por ciento en } 2005 \text { entre aquéllos/as } \\
\text { más expuestos a SDSI; pasó del } 23 \text { por } \\
\text { ciento al } 32 \text { por ciento durante el mismo } \\
\text { periodo de tiempo entre aquéllos/as con } \\
\text { menos exposición (p < 0.05). } \\
\text { Mayor incremento en el tiempo en el } \\
\text { porcentaje de entrevistados/as que } \\
\text { mantendrían una amistad con una amiga } \\
\text { lesbiana. El porcentaje aumentó de } 38 \\
\text { por ciento en } 2003 \text { a } 48 \text { por ciento en } \\
2005 \text { entre aquellos/as más expuestos/ } \\
\text { as a SDSI; aumentó de } 26 \text { por ciento a } \\
31 \text { por ciento entre aquéllos con menos } \\
\text { exposición (p < } 0.05 \text { ). }\end{array}$ & $\begin{array}{l}\text { Lo siguiente se atribuye a una mayor } \\
\text { exposición a SDSI: } \\
\text { - La actitud del } 19 \text { por ciento de quienes } \\
\text { comerían en la misma mesa con una } \\
\text { persona con VIH (15,673 jóvenes en las } \\
\text { tres ciudades). } \\
\text { - La actitud del } 17 \text { por ciento de quienes } \\
\text { creen que las prostitutas no son las } \\
\text { culpables de la presencia del VIH ( } 9,856 \\
\text { jóvenes en las tres ciudades). } \\
\text { - La actitud del } 18 \text { por ciento de aquellos } \\
\text { entrevistados que creen que las } \\
\text { personas con VIH no deben sentirse } \\
\text { avergonzadas ( } 15,597 \text { jóvenes en las } \\
\text { tres ciudades). } \\
\text { - La actitud del } 18 \text { por ciento de quienes } \\
\text { estarían dispuestos a ser amigos con } \\
\text { alguien que tenga VIH (13,901 jóvenes } \\
\text { en las tres ciudades). } \\
\text { - La actitud del } 20 \text { por ciento de quienes } \\
\text { dijeron que seguirían siendo amigos } \\
\text { de alguien que les dijera que es } \\
\text { homosexual ( } 16,249 \text { jóvenes en las tres } \\
\text { ciudades). }\end{array}$ \\
\hline
\end{tabular}

\footnotetext{
${ }^{10}$ A menos que se diga de otra manera, todos los resultados relacionados con aumento o disminución en una probabilidad provienen del análisis de regresión logística multivariada (con variable tiempo), y Odds Ratios, ajustados por edad, sexo, municipalidad, educación y tiempo. A menos que se diga de otra manera, todos los resultados que se presentan son estadísticamente significativos ( $95 \%$ de intervalo de confianza no incluye 1.0).

${ }^{11}$ Las proporciones atribuibles a la población para la influencia preventiva de SDSI se calcularon para un subconjunto de variables de resultado. $\mathrm{RAP}=[(\%$ de personas expuestas a SDSI entre los casos positivos $) \times($ relación de probabilidades -1$)] /$ relación de probabilidades.
} 


\begin{tabular}{|c|c|c|}
\hline $\begin{array}{l}\text { Mayor } \\
\text { conocimiento } \\
\text { y uso de los } \\
\text { proveedores } \\
\text { de de servicios } \\
\text { sociales y de } \\
\text { salud }\end{array}$ & $\begin{array}{l}\text { Participantes con mayor exposición a SDSI } \\
\text { demostraron: }{ }^{12} \\
\text { - } 33 \text { por ciento mayor probabilidad de } \\
\text { conocer un centro que brinde atención } \\
\text { en casos de violencia doméstica. }{ }^{13} \\
\text { - } 31 \text { por ciento mayor probabilidad de } \\
\text { conocer un centro que brinde atención } \\
\text { para ITS/VIH. }{ }^{14} \\
\text { - } 23 \text { por ciento mayor probabilidad } \\
\text { de conocer un centro para abordar } \\
\text { inquietudes sobre la sexualidad. }{ }^{15} \\
\text { - } 17 \text { por ciento mayor probabilidad de } \\
\text { saber dónde hacerse una prueba de } \\
\text { VIH. }{ }^{16} \\
\text { - } 48 \text { por ciento mayor probabilidad de } \\
\text { haber estado en los últimos seis meses } \\
\text { en un centro que atiende casos de } \\
\text { violencia doméstica. }{ }^{17} \\
\text { - } 58 \text { por ciento mayor probabilidad de } \\
\text { haber visitado en los últimos seis meses } \\
\text { una organización con inquietudes sobre } \\
\text { la sexualidad no relacionadas con el } \\
\text { VIH. }{ }^{18}\end{array}$ & $\begin{array}{l}\text { Lo siguiente se atribuye a una mayor } \\
\text { exposición a SDSI: } \\
\text { - El } 23 \text { por ciento de quienes conocen un } \\
\text { centro que brinda atención para casos } \\
\text { de violencia ( } 13,554 \text { jóvenes en las tres } \\
\text { ciudades). } \\
\text { - El } 20 \text { por ciento quienes conocen un } \\
\text { centro que brinda atención para las } \\
\text { ITS/VIH ( } 14,635 \text { jóvenes en las tres } \\
\text { ciudades). } \\
\text { - El } 17 \text { por ciento quienes saben sobre } \\
\text { un centro donde puedan abordar temas } \\
\text { relacionados con la sexualidad ( } 9,215 \\
\text { jóvenes en las tres ciudades). } \\
\text { - El } 29 \text { por ciento de quienes en los } \\
\text { últimos seis meses han visitado un } \\
\text { centro que atiende casos de violencia } \\
\text { doméstica ( } 2,826 \text { jóvenes en las tres } \\
\text { ciudades). } \\
\text { - El } 25 \text { por ciento de quienes en los } \\
\text { últimos seis meses visitaron un centro } \\
\text { para abordar temas relacionados con } \\
\text { la sexualidad ( } 2,536 \text { jóvenes en las tres } \\
\text { ciudades). }\end{array}$ \\
\hline $\begin{array}{l}\text { Mayor } \\
\text { conocimiento } \\
\text { del VIH y su } \\
\text { prevención }\end{array}$ & $\begin{array}{l}\text { Participantes con mayor exposición a SDSI } \\
\text { demostraron: } \\
\text { - } 21 \text { por ciento mayor probabilidad de } \\
\text { saber que es posible vivir durante } \\
\text { muchos años con el VIH. }{ }^{19} \\
\text { - } 30 \text { por ciento mayor probabilidad de } \\
\text { decir que el uso del condón puede } \\
\text { prevenir el VIH. }{ }^{20}\end{array}$ & \\
\hline
\end{tabular}

\footnotetext{
${ }^{12}$ Estos números son los resultados de los Odds Ratios ajustados por edad, sexo, municipalidad y educación con su correspondiente $95 \%$ Intervalo de Confianza.

${ }^{13} \mathrm{OR}=1.33 ; 95 \% \mathrm{CI}=1.2-1.5$

${ }^{14} \mathrm{OR}=1.31 ; 95 \% \mathrm{CI}=1.2-1.5$

${ }^{15} \mathrm{OR}=1.23 ; \mathrm{CI} 1.11-1.4$

${ }^{16} \mathrm{OR}=1.17 ; 95 \% \mathrm{CI}=1.0-1.3$

${ }^{17} \mathrm{OR}=1.48 ; 95 \% \mathrm{CI}=1.2-1.9$

${ }^{18} \mathrm{OR}=1.58 ; \mathrm{CI}=1.2-2.1$

${ }^{19} \mathrm{OR}=1.2 ; 95 \% \mathrm{CI}=1.1-1.3$

${ }^{20} \mathrm{OR}=1.29 ; 95 \% \mathrm{CI}=1.2-1.5$
} 


\begin{tabular}{|c|c|c|}
\hline $\begin{array}{l}\text { Mayor } \\
\text { personalización } \\
\text { de la percepción } \\
\text { del riesgo del VIH }\end{array}$ & $\begin{array}{l}\text { Participantes con mayor exposición a SDSI } \\
\text { demostraron: } \\
\text { - } 29 \text { por ciento mayor probabilidad de } \\
\text { haber pensado en su propia posibilidad } \\
\text { de contraer el VIH. } \\
\text { - Entre las mujeres entrevistadas, un } 35 \\
\text { por ciento mayor probabilidad de pensar } \\
\text { sobre su propia posibilidad de contraer } \\
\text { el VIH. } \\
\text { - Entre jóvenes de } 18 \text { años y menos, un } \\
27 \text { por ciento mayor probabilidad de } \\
\text { pensar en contraer el VIH. }{ }^{22}\end{array}$ & \\
\hline $\begin{array}{l}\text { Mayor } \\
\text { comunicación } \\
\text { interpersonal } \\
\text { sobre temas de } \\
\text { SDSI }\end{array}$ & $\begin{array}{l}\text { Participantes con mayor exposición a SDSI } \\
\text { demostraron: } \\
\text { - } 62 \text { por ciento mayor probabilidad de } \\
\text { haber hablado con alguien en los últimos } \\
\text { seis meses sobre violencia doméstica, } \\
\text { VIH, homosexualidad o los derechos de } \\
\text { los jóvenes. }{ }^{23} \\
\text { (El desglose de temas específicos es así: } \\
\text { violencia doméstica: } 53 \text { por ciento; VIH: } 49 \\
\text { por ciento; homosexualidad/ lesbianismo: } \\
31 \text { por ciento; derechos de los jóvenes: } 48 \\
\text { por ciento). }\end{array}$ & $\begin{array}{l}\text { Lo siguiente se atribuye a una mayor } \\
\text { exposición a SDSI: } \\
\text { - } 21 \text { por ciento de quienes en los últimos } \\
\text { seis meses habian hablado a otra } \\
\text { persona sobre uno de estos temas } \\
\text { (10,650 jóvenes en las tres ciudades). }\end{array}$ \\
\hline $\begin{array}{l}\text { Mayor } \\
\text { comunicación } \\
\text { con la pareja } \\
\text { sobre la } \\
\text { prevención del } \\
\text { VIH }\end{array}$ & $\begin{array}{l}\text { Participantes con mayor exposición a SDSI } \\
\text { demostraron: } \\
\text { - } 32 \text { por ciento mayor probabilidad (en } \\
\text { análisis longitudinal) de haber hablado } \\
\text { con su pareja sobre el uso del condón. }{ }^{24} \\
\text { - } 43 \text { por ciento mayor probabilidad de } \\
\text { haber hablado con su pareja sobre } \\
\text { hacerse la prueba del VIH. }{ }^{25}\end{array}$ & $\begin{array}{l}\text { Lo siguiente se atribuye a una mayor } \\
\text { exposición a SDSI: } \\
\text { - } 23 \text { por ciento de quienes dijeron que en } \\
\text { los últimos seis meses habían hablado } \\
\text { con sus parejas sobre el uso del condón } \\
\text { ( } 7,897 \text { jóvenes en las tres ciudades). } \\
\text { - } 23 \text { por ciento de quienes han hablado } \\
\text { con sus parejas sobre hacerse la prueba } \\
\text { del VIH ( } 3,104 \text { jóvenes en las tres } \\
\text { ciudades). } \\
\text { - } 18 \text { por ciento de quienes han hablado a } \\
\text { sus parejas sobre previas experiencias } \\
\text { sexuales (4,423 jóvenes en tres } \\
\text { ciudades). }\end{array}$ \\
\hline $\begin{array}{l}\text { Mayor percepción } \\
\text { de eficacia } \\
\text { individual para } \\
\text { negociar el uso } \\
\text { del condón }\end{array}$ & $\begin{array}{l}\text { Participantes con mayor exposición a SDSI } \\
\text { demostraron: } \\
\text { - Mayor percepción de eficacia individual } \\
\text { para negociar el uso del condón que } \\
\text { los/as entrevistados/as que no tuvieron } \\
\text { exposición, a pesar de una reducción } \\
\text { general en eficacia individual ( } p= \\
0.033 \text { ). }\end{array}$ & \\
\hline
\end{tabular}

$\overline{{ }^{21} \mathrm{OR}}=1.35$; CI $1.1-1.6$

${ }^{22} \mathrm{OR}=1.26$; CI $1.1-1.5$

${ }^{23} \mathrm{OR}=1.6$; CI $1.5-1.8$

${ }^{24} \mathrm{OR}=1.32$; CI $1.2-1.5$

${ }^{25} \mathrm{OR}=1.43$; CI $1.2-1.7$ 


\begin{tabular}{|c|c|c|}
\hline $\begin{array}{l}\text { Creciente } \\
\text { sentido de } \\
\text { equidad en las } \\
\text { relaciones }\end{array}$ & $\begin{array}{l}\text { Participantes con mayor exposición a SDSI } \\
\text { demostraron: } \\
\text { - Valores superiores en el índice de poder } \\
\text { y control a los/as entrevistados/as con } \\
\text { menos exposición (i.e., la percepción } \\
\text { del sentido de igualdad de poder de la } \\
\text { persona en las relaciones de pareja), a } \\
\text { pesar de una reducción general en la } \\
\text { población ( } p=0.025) \text {. }\end{array}$ & \\
\hline $\begin{array}{l}\text { Mayor } \\
\text { comunicación } \\
\text { interpersonal } \\
\text { y con la pareja } \\
\text { íntima sobre } \\
\text { temas SDSI y } \\
\text { prevención del } \\
\text { VIH }\end{array}$ & $\begin{array}{l}\text { Participantes con mayor exposición a SDSI } \\
\text { demostraron: } \\
\text { - Mayor comunicación interpersonal y } \\
\text { con la pareja íntima que resultó en una } \\
\text { mayor probabilidad de uso constante del } \\
\text { condón tanto con parejas estables como } \\
\text { casuales (Véase más adelante). }\end{array}$ & \\
\hline $\begin{array}{l}\text { Mayor uso } \\
\text { del condón } \\
\text { en relaciones } \\
\text { sexuales } \\
\text { con parejas } \\
\text { casuales }\end{array}$ & $\begin{array}{l}\text { Participantes con mayor exposición a SDSI } \\
\text { demostraron: } \\
\text { - Mayor uso del condón con parejas } \\
\text { casuales (entre quienes dijeron haber } \\
\text { tenido parejas casuales): } \\
\text { - } 44 \text { por ciento mayor probabilidad de } \\
\text { haber usado un condón durante la última } \\
\text { relación sexual con una pareja casual. } .^{26} \\
\text { - } 42 \text { por ciento mayor probabilidad de } \\
\text { haber usado un condón regularmente } \\
\text { con parejas casuales en los últimos seis } \\
\text { meses. } .^{27} \\
\text { - } 56 \text { por ciento mayor probabilidad entre } \\
\text { los hombres de uso del condón con } \\
\text { parejas casuales en los últimos seis } \\
\text { meses. }{ }^{28} \\
\text { - } 41 \text { por ciento mayor probabilidad (en } \\
\text { la última encuesta) de comunicación } \\
\text { interpersonal sobre temas relacionados } \\
\text { con SDSI ( } 57 \text { por ciento en hombres } \\
\text { y } 27 \text { por ciento en mujeres). La } \\
\text { comunicación interpersonal con una } \\
\text { pareja casual resultó en un } 63 \text { por ciento } \\
\text { de mayor probabilidad de uso regular del } \\
\text { condón. (Haber hablado con su pareja } \\
\text { sobre el uso del condón resultó en tres } \\
\text { veces más probabilidades entre las } \\
\text { mujeres de un uso regular del condón en } \\
\text { los últimos seis meses. }{ }^{29} \text { El incremento } \\
\text { no fue significativo en los hombres. }\end{array}$ & $\begin{array}{l}\text { Lo siguiente se atribuye a una mayor } \\
\text { exposición a SDSI: } \\
\text { - } 18 \text { por ciento de quienes reportaron } \\
\text { haber usado un condón durante su } \\
\text { última relación sexual con una pareja } \\
\text { casual (unos } 2,500 \text { jóvenes en tres } \\
\text { ciudades). }\end{array}$ \\
\hline
\end{tabular}

$\overline{{ }^{26} \mathrm{OR}}=1.44$; CI $1.2-1.8$

${ }^{27} \mathrm{OR}=1.42$; CI $1.1-1.9$

${ }^{28} \mathrm{OR}=1.56$; CI $1.2-2.0$

${ }^{29} \mathrm{OR}=3.06$; CI $1.3-6.9$ 


\begin{tabular}{|c|c|}
\hline $\begin{array}{l}\text { Comunicación y } \\
\text { uso del condón } \\
\text { en relaciones } \\
\text { sexuales } \\
\text { con parejas } \\
\text { estables }\end{array}$ & $\begin{array}{l}\text { Participantes con mayor exposición a SDSI } \\
\text { demostraron: } \\
\text { - No diferencia en el uso del condón } \\
\text { con una pareja estable (entre los que } \\
\text { dijeron tener parejas estables), con una } \\
\text { tendencia general a la baja en el uso del } \\
\text { condón. } \\
\text { - } 29 \text { por ciento mayor probabilidad de } \\
\text { comunicación con la pareja sobre } \\
\text { prevención (en la última encuesta). } \\
\text { - } 41 \text { por ciento (en tercera encuesta) de } \\
\text { mayor probabilidad de comunicación } \\
\text { interpersonal sobre temas relacionados } \\
\text { con SDSI (57 por ciento en hombres } \\
\text { y } 27 \text { por ciento en mujeres). Mayor } \\
\text { comunicación interpersonal está } \\
\text { relacionada de forma indirecta pero } \\
\text { significativa con un mayor uso del } \\
\text { condón. }{ }^{31}\end{array}$ \\
\hline $\begin{array}{l}\text { Mayor } \\
\text { percepción } \\
\text { de eficacia } \\
\text { colectiva } \\
\text { relacionada } \\
\text { con situaciones } \\
\text { de violencia } \\
\text { doméstica }\end{array}$ & $\begin{array}{l}\text { Participantes con mayor exposición a SDSI } \\
\text { demostraron: } \\
\text { - } 11 \text { por ciento mayor probabilidad de } \\
\text { percibir capacidades entre su grupo de } \\
\text { amistades para de manera conjunta } \\
\text { hacer algo para resolver los problemas } \\
\text { de la violencia doméstica. }{ }^{32} \text { (Esto a } \\
\text { pesar de un deterioro generalizado en la } \\
\text { percepción de la eficacia colectiva). }\end{array}$ \\
\hline $\begin{array}{l}\text { Cambios en el } \\
\text { contexto social }\end{array}$ & $\begin{array}{l}\text { Las organizaciones que participaron en } \\
\text { SDSI reportaron: } \\
\text { - Cambios graduales y diversos en } \\
\text { relación al trabajo local y al desarrollo } \\
\text { de iniciativas; apertura hacia el diálogo y } \\
\text { el debate de temas tabú; fortalecimiento } \\
\text { del liderazgo; mayor eficacia colectiva } \\
\text { entre jóvenes vinculados a las } \\
\text { organizaciones; y mayores alianzas. }\end{array}$ \\
\hline
\end{tabular}

\footnotetext{
$\overline{{ }^{30} \mathrm{OR}=1.31 ; \mathrm{CI} 1.2}-1.5$

${ }^{31}$ Interpersonal communication is positively associated with greater personalization of risk perception (51 percent overall; 67 percent in men and 39 percent in women), and more than double probability of sense of self-efficacy (OR $=2.15$; CI 1.7 -2.7). Greater personalization of risk perception was associated with a 62 percent greater probability of actually talking with one's partner about prevention (68 percent in men and 57 percent in women); Those with perceived self-efficacy to negotiate condom use with their partner were more than 3.5 times more likely $(\mathrm{OR}=3.57$; CI $2.7-4.8)$ to actually talk to their partner about prevention. Women were 5 times more likely to talk to their partner (OR $=5.05$; CI $2.8-9.1)$, while men were 3 times more likely $(\mathrm{OR}=3.13$; CI $2.2-4.4)$. Talking about condom use with a steady sexual partner resulted in an 82 percent greater probability of consistent condom use. Talking about condom use resulted in men being twice as likely, and women being 59 percent as likely, to consistently use a condom in the last 6 months (OR $=2.07$; CI $1.4-2.9)$.

${ }^{32} \mathrm{OR}=1.11$; CI $1.0-1.2$
} 


\section{Normas de género}

SDSI contribuyó a cambiar las actitudes hacia normas de género equitativas. Los resultados del análisis en este modelo lineal general revelan que, independientemente del efecto de las variables sociodemográficas (p. ej., sexo, edad, municipio, educación), una mayor exposición a SDSI estuvo asociada $(\mathrm{p}<.001)$ con el mantenimiento de valores superiores del índice de género (véase la tabla 7) en los tres años de la encuesta. Asimismo se observó que la población bajo estudio demostró cambios hacia actitudes de mayor equidad de género durante el periodo en cuestión, independientemente de su exposición a SDSI.

\section{Tabla 7 Elementos en el índice de género*}

- Una muchacha que ha tenido varias parejas es una mujer fácil.

- Dónde hay niñas y niños, es a las niñas a las que les debe tocar en primer lugar apoyar las tareas domésticas.

- Es importante que las mujeres lleguen vírgenes al matrimonio.

- En la familia, son las mujeres las que deben encargarse de la casa y del cuidado de los niños y niñas

- Los hombres necesitan del sexo más que las mujeres.

- Las mujeres son las que tienen la responsabilidad de evitar los embarazos.

- Aún estando bien con su pareja, los hombres necesitan tener otra mujer.

- Las mujeres que andan condones en su cartera son fáciles.

\footnotetext{
* Cada respuesta "no" contribuía a una puntuación más alta. Entre más alta la puntuación, mayor la equidad de género.
}

Entre la primera y la tercera encuesta se observó un incremento promedio del 20 por ciento en el índice de género. Asimismo se observó que el municipio, la escolaridad y la edad de los participantes tenían efectos individuales en este cambio $(\mathrm{p}<.001)$ : En primer lugar Estelí y también León, tenían cifras más altas que Juigalpa; las personas con educación universitaria o técnica produjeron cifras totales más altas que aquéllas con educación secundaria, las que a su vez tuvieron una puntuación mayor que aquéllas con educación primaria o sin educación. El grupo de más edad tuvo cifras totales mayores que el grupo más joven.

Con el uso de un análisis de "riesgos atribuibles a la población", se puede estimar lo siguiente como atribuible a la exposición a:

- el 22 por ciento de los/as jóvenes que no consideran que "las mujeres que llevan condones en su bolsas son mujeres fáciles". Esto se traduce en 15,377 jóvenes en las tres ciudades que no hubieran tenido esa opinión de no haber sido por la influencia de SDSI.

- el 7 por ciento de los/as jóvenes que consideran que "es responsabilidad de las mujeres evitar el embarazo": 12,128 jóvenes en las tres ciudades.

- el 11 por ciento de los/as jóvenes que no consideran que "son las mujeres quienes deben encargarse del hogar y del cuido de los niños": 7,326 jóvenes en las tres ciudades. 
En los estudios cualitativos, la violencia contra las mujeres era uno de los problemas graves identificados en las relaciones entre hombres y mujeres. En términos generales, este tipo de violencia se atribuye al machismo:

Son machistas aquí; cachimbean (golpean) a las mujeres. Si andan con mates (reclaman) les pegan su viaje y ya está. Y después que la golpean le dicen: "mirá, andá haceme tal cosa, y si no lo hacés te vuelvo a dar.

Estudio cualitativo 2; hombre de grupo de control ${ }^{33}$ en Estelí

Nosotras la mujeres muchas veces damos paso a ese machismo porque si mi esposo me dice vos no vas a hacer esto porque esto es cosa de hombres, te vas a quedar en la casa, lavando, planchando y yo lo hago.

Estudio cualitativo 1; mujer de Estelí; mujeres no organizadas

Pienso yo que lo idóneo sería que el hombre trabajara y que la mujer trabajase menos. O sea, que [la mujer] se dedicara un tiempo más a la familia, pues, son los valores de la familia.

Estudio cualitativo 2; hombre de grupo de control en León

Los/as entrevistados/as en los estudios cualitativos reconocieron la contribución de SDSI en los temas de machismo y violencia que se abordaron en las series de televisión, en el programa de radio y en otras actividades. Para quienes que están vinculados con organizaciones y para representantes de éstas, el principal aporte de SDSI fue plantear el tema y brindar herramientas y oportunidades para un trabajo a nivel focal en torno a los temas.

[Sexto Sentido aborda] temas que no se hablan en familia, los prejuicios que hay en la familia; que no se habla de sexo, de enfermedades, no se habla de muchas cosas que en el programa sí los abarcamos.

Varón miembro del grupo focal; monitoreo con las audiencias de
Sexto Sentido Radio y Sexto Sentido TV, 2004

\section{Estigma}

SDSI contribuyó a que hubiera cambios en las actitudes hacia el VIH y hacia la orientación sexual, los cuales reducen el estigma. Sin embargo, ciertas actitudes hacia las personas que viven con VIH o hacia grupos estigmatizados son más difíciles de cambiar.

\section{El estigma relacionado con el VIH}

Los resultados del análisis en este modelo lineal general muestran que, independientemente del efecto de las variables sociodemográficas (sexo, edad, municipio, educación), una mayor exposición a SDSI estuvo significativamente asociada $(\mathrm{p}<.001)$ con los valores más altos en el índice del estigma (véase tabla 8) en todos los tres años de encuestas. Al igual que con el índice de género, y sin importar la exposición a SDSI, con el tiempo la cohorte mostró cambios hacia actitudes menos estigmatizadoras.

\footnotetext{
${ }^{33}$ El "grupo de control" estuvo conformado por jóvenes que no tenían asociación alguna con el estudio de panel.
} 
Tabla 8 Elementos en el índice del estigma*

- Comerías en la misma mesa con una persona con VIH-Sida.

- Un hombre por ser homosexual tiene la culpa de contagiarse del VIH-Sida.

- El VIH-Sida es un castigo de Dios.

- Las prostitutas son culpables del VIH-Sida.

- Te sentirías avergonzado/avergonzada si alguien de tu familia estuviera infectado con $\mathrm{VIH} /$ Sida.

- Estarías dispuesta/dispuesto a tener amistad con una persona infectada con VIH/Sida.

"En este índice, las respuestas "sí" a la primera y la última pregunta y "no" a las otras contribuyeron a elevar el puntaje. Entre más alto el puntaje, más bajo el estigma.

El índice del estigma aumentó en un promedio del 20 por ciento entre la primera y la tercera encuesta, lo que indica una reducción en el estigma relacionado con el VIH a lo largo del tiempo.

Al igual que con el índice de género, hubo diferencias según el municipio, nivel de escolaridad y edad $(\mathrm{p}<.001)$. Estelí y León mostraron mayores cambios que Juigalpa hacia puntajes más altos; las personas con educación universitaria mostraron mayores cambios que aquéllas con educación secundaria, las que a su vez mostraron más cambios que aquéllas con educación primaria o sin ninguna educación. El grupo de más edad mostró un mayor cambio que el grupo de menor edad. El índice de estigma también revela diferencias significativas según el sexo $(\mathrm{p}<.001)$, con más cambios hacia puntajes más altos entre las mujeres que entre los hombres.

El análisis basado en los riesgos atribuibles a la población permite que lo siguiente se atribuya a la exposición a SDSI:

- El 19 por ciento de quienes dijeron que comerían en la misma mesa con una persona portadora del VIH. Esto se traduce en 15,673 jóvenes en las tres ciudades, quienes no hubieran respondido de esa manera de no haber sido por la influencia de SDSI.

- El 17 por ciento de quienes dijeron que las prostitutas no tienen la culpa de que exista el VIH: 9,856 jóvenes en tres ciudades.

- El 18 por ciento de quienes dijeron que las personas que viven con el VIH no deben sentirse avergonzadas: 15,597 jóvenes en las tres ciudades.

- El 18 por ciento de quienes dijeron que tendrían amistad con alguien que fuera portador del VIH: 13,901 jóvenes en las tres ciudades.

Los estudios cualitativos también revelaron un cambio hacia actitudes menos estigmatizadoras:

Conozco a una persona que tiene VIH; no tengo mayor contacto, pero ahora tengo mayor respeto y menos miedo.

Estudio cualitativo 3; mujer joven de Bilwi

\section{El estigma hacia el VIH relacionado con la homosexualidad y el trabajo sexual}

El cuestionario incluyó varias preguntas dirigidas a explorar el estigma relacionado con la orientación sexual y el trabajo sexual. El análisis estadístico reveló que si bien el estigma se redujo en general, existía una mayor probabilidad de una actitud menos estigmatizadora hacia la homosexualidad entre 
aquellos más expuestos a SDSI. Además, el cambio neto en actitud fue mayor entre los más expuestos a SDSI. La respuesta positiva a la idea de mantener una amistad con una amiga al descubrir que es lesbiana, aumentó de 38 por ciento a 48 por ciento ( 26 por ciento a 31 por ciento entre los menos expuestos), mientras que en el caso de un amigo del que se descubre es homosexual, la respuesta positiva aumentó de 36 por ciento a 49 por ciento ( 23 por ciento a 32 por ciento entre los menos expuestos, $\mathrm{p}<0.05)$.

El análisis de los riesgos atribuibles a la población estimó que el 20 por ciento de los/as jóvenes que dijeron seguirían siendo amigos/as de alguien que les dijera ser homosexual, se puede atribuir a la exposición a SDSI. En las tres ciudades donde se hizo el estudio, las proyecciones sugieren el equivalente de unos 16,249 jóvenes con esta actitud debido a la influencia de SDSI.

Los datos sugieren que la mayor aceptación de la homosexualidad podría limitarse al ámbito privado y no extenderse al público. Como ya se mencionó, uno de los elementos que cambió sustancialmente con el tiempo fue si "usted tendría amistad con un homosexual". Sin embargo, no se puede decir lo mismo para los elementos "estaría bien que dos homosexuales vivieran en la misma casa" o "la gente lo aceptaría".

En términos generales, si bien los estudios cualitativos revelaron actitudes y evaluaciones más positivas de los derechos generales de todas las personas, independiente de su orientación sexual, prevalece un fuerte estigma hacia los homosexuales y trabajadoras del sexo a quienes todavía se tiende a culpar por el problema del VIH.

[El VIH-Sida] más que todo se da en los homosexuales y en las prostitutas. Han salido bastantes personas afectadas con esta enfermedad. Me imagino que es porque no tenian precaución. Son personas que no miden las consecuencias de andar con una persona y luego con otra, y no toman tanta precaución.

Estudio cualitativo 2; mujer de grupo de control en Juigalpa

Cabe señalar, que la culpa se atribuye a la falta de protección y no a la identidad de la persona o del grupo.

El primer estudio reveló que los temas vinculados a la homosexualidad en la serie Sexto Sentido TV eran percibidos como muy controversiales o polémicos. Al mismo tiempo, hubo una evaluación muy positiva del hecho que SDSI aborda los temas de las personas que viven con VIH y los prejuicios en la sociedad en contra de los homosexuales. El cuestionamiento de esos prejuicios ha generado cambios en las actitudes de ciertas personas hacia los homosexuales y hacia los trabajadores del sexo. Por ejemplo, algunas de las personas entrevistadas consideraron que SDSI les había ayudado a desarrollar una mayor aceptación de los homosexuales:

Antes de la serie no se creía que gays y lesbianas pensaban igual que nosotros; ahora si sé que son humanos. Siento gran admiración por los gays, son valientes. Antes me repugnaban, ya no.

Estudio cualitativo 3; mujer de Estelí

Nos reunimos los del club para reflexionar lo que se ve en la serie: Cuando vimos el capitulo del gay algunos empezaron a vulgarear, pero nos ayudó a relacionarnos con gente así. Impactó 
porque por ejemplo ahora se relacionan con homosexuales

Estudio cualitativo 3; hombre joven de Juigalpa

\section{Conocimiento y uso de los servicios}

El conocimiento sobre la existencia de centros que brindan servicios relacionados con el VIH y la violencia doméstica, y el uso de dichos centros aumentaron durante el periodo en cuestión y los análisis estadísticos indican una asociación entre este cambio de comportamiento y una mayor exposición a SDSI.

\section{Conocimiento de los servicios}

El conocimiento sobre los servicios disponibles por parte de la población del estudio aumentó entre la primera y la tercera encuesta (de 54 por ciento a 64 por ciento para los centros que trabajan con violencia doméstica y de 61 por ciento a 74 por ciento para los servicios relacionados con el VIH).

El análisis de regresión logística para la variable dicotómica sobre el conocimiento de los servicios (sabe o no sabe) ${ }^{34}$ reveló que la exposición a SDSI aumentó la probabilidad de saber dónde ir en casos de violencia contra las mujeres o de VIH. Los siguientes resultados se basan en relaciones de probabilidad con su respectivo 95 por ciento de intervalos de confianza. Comparado con un grupo menos expuesto, el grupo con la mayor exposición fue: 33 por ciento con mayores probabilidades de conocer un centro dedicado al problema de la violencia; ${ }^{35} 17$ por ciento con mayores probabilidades de saber dónde hacerse la prueba del $\mathrm{VIH} ;{ }^{36}$ y tenía una tercera mayor probabilidad de saber dónde ir en respuesta a inquietudes relacionadas con el VIH o las ITS. ${ }^{37}$ Las personas en este grupo también tenían 23 por ciento más probabilidades de conocer un centro que respondería a inquietudes sobre la sexualidad. $^{38}$

El conocimiento sobre los servicios varió según el género. Las mujeres tenían 44 por ciento más probabilidades que los hombres de conocer un centro de servicios relacionados con la violencia, pero 11 por ciento menos probabilidades de conocer un centro para consultar sobre VIH/ITS ( $p=0.03)$. El municipio y el nivel de escolaridad también tuvieron un efecto sobre el conocimiento de centros que brindan servicios relacionados con VIH/ITS. Una mayor probabilidad de ese conocimiento se asoció con Juigalpa y con un mayor nivel de escolaridad.

El segundo estudio cualitativo reveló el conocimiento de los centros que brindan servicios relacionados con el VIH y con la violencia. En las tres ciudades, los centros de salud y los hospitales fueron los lugares mejor conocidos para recibir servicios relacionados con el VIH, y las Comisarías de la Mujer adscritas a las estaciones de policía y el Ministerio de la Familia (MiFamilia) los más conocidos para los servicios relacionados con la violencia basada en el género. Otros proveedores de

\footnotetext{
${ }^{34}$ Para el análisis de regresión logística, la categoría "no sabe" incluyó a personas que dijeron que conocían un centro pero que no podían recordar su nombre.

${ }^{35} \mathrm{OR}=1.33 ; 95 \% \mathrm{CI}=1.19-1.47$

${ }^{36} \mathrm{OR}=1.17 ; 95 \% \mathrm{CI}=1.04-1.31$

${ }^{37} \mathrm{OR}=1.31 ; 95 \% \mathrm{CI}=1.18-1.46$

${ }^{38} \mathrm{OR}=1.23 ; 95 \% \mathrm{CI}=1.12-1.36$
} 
servicios eran conocidos en localidades específicas, particularmente Ixchen (Estelí, León) y Profamilia (Estelí, Juigalpa).

El análisis de los riesgos atribuibles a la población revela que lo siguiente se puede atribuir a la exposición a SDSI:

- E1 23 por ciento de quienes conocen un centro que aborda casos de violencia. Esto se traduce en 13,554 jóvenes en las tres ciudades que no conocerían sobre la existencia de dicho centro de no haber sido por la influencia de SDSI.

- El 20 por ciento de quienes conocen un centro que brinda servicios relacionados con ITS/VIH: 14,635 jóvenes en las tres ciudades.

- El 17 por ciento de quienes conocen un centro que aborda temas relacionados con la sexualidad: 9,215 jóvenes en las tres ciudades.

\section{Uso de los servicios}

Entre la primera y la última medición se observó un incremento general en el uso de los servicios, si bien el uso como tal sigue siendo infrecuente. El grupo más expuesto a SDSI tenía un 48 por ciento de mayores probabilidades de ir a organizaciones o a centros con inquietudes en torno a la violencia ${ }^{39} \mathrm{y}$ un 58 por ciento de mayores probabilidades de ir a una organización con inquietudes sobre temas de sexualidad (diferentes al VIH).

No hubo diferencia entre hombres y mujeres en términos de buscar servicios. Sin embargo, hubo diferencias según la ciudad y el nivel de escolaridad. Las personas de Estelí tenían tres veces más probabilidades de buscar esos servicios y la gente de León tenían cuatro veces más probabilidades que la de Juigalpa, y aquellas personas con educación técnica y universitaria tenían 27 por ciento más probabilidades que aquéllos con menos escolaridad educación.

El análisis sobre los riesgos atribuibles a la población permite que lo siguiente se atribuya a la exposición a SDSI:

- El 29 por ciento de quienes en los últimos seis meses habían acudido a un centro que brinda atención para casos de violencia. Esto se traduce en 2,826 jóvenes en las tres ciudades que no hubieran ido de no haber sido por la influencia de SDSI.

- El 25 por ciento de quienes en los últimos seis meses habían acudido a un centro para abordar temas relacionados con la sexualidad: 2,536 jóvenes en las tres ciudades.

Según los resultados del segundo estudio cualitativo, no buscar los servicios parece estar relacionado a dos factores principales: conocimiento incompleto de los servicios brindados y que generalmente se ven como centros curativos para atender las enfermedades, en lugar de sitios donde se puede obtener información, buscar apoyo y consejería. Si bien las personas saben sobre la existencia de esos centros, no saben sobre el tipo de servicios que ofrecen o su utilidad.

IXCHEN si he escuchado. [...] Aqui en Esteli he escuchado que ahi le dan ayuda a la mujeres, ... no sé como es, yo nunca he ido, no... Casi no tengo información....

Estudio cualitativo 2; mujer de Estelí; grupo de control de mayores de 18

$\overline{{ }^{39} \mathrm{OR}=1.48 ; 95 \% \mathrm{CI}}=1.2-1.9$ 
Yo digo que tal vez en PROFAMILIA, ahi se puede ir a hacer, porque hay muchas... muchas personas, porque ahi llegan personas a hacerse exámenes cuando tienen cáncer, porque yo he visto. Ahi si hay muchas posibilidades que ellos se vayan hacer un examen.

Estudio cualitativo 2; mujer de grupo de control en Estelí

\section{Conocimiento del VIH y percepción del riesgo}

SDSI ha ayudado a mejorar los conocimientos generales sobre el VIH, su prevención e importantes elementos relacionados con la percepción del riesgo. Este conocimiento aumentó más entre los hombres que entre las mujeres. Además, la probabilidad de considerarse a sí mismo en riesgo fue mayor entre las mujeres en general y en el grupo etario de menor (mujeres y hombres) quienes habían tenido mayor exposición a SDSI.

El estudio incluyó un conjunto extenso de preguntas sobre conocimiento y comportamiento relacionadas con la vida sexual y la prevención del VIH. Las entrevistas cara a cara también incluían preguntas generales relacionadas con la percepción de riesgo por parte de las y los jóvenes.

\section{Conocimientos básicos sobre el VIH}

El conocimiento sobre el VIH era bastante alto. Para fines de este estudio, el conocimiento sobre el VIH se evaluó mediante la afirmación, "es posible vivir con el virus durante muchos años". Entre la primera y la tercera encuesta, la proporción de respuestas afirmativas aumentó de 48 por ciento a 55 por ciento entre la población del estudio. El nivel de exposición a SDSI estuvo positivamente asociado con este conocimiento, en donde el grupo más expuesto tenía 22 por ciento mayores probabilidades que el grupo menos expuesto de responder afirmativamente.

Independiente de la exposición a SDSI, los hombres tenían 35 por ciento mayores probabilidades que las mujeres de responder afirmativamente esta pregunta.

\section{Conocimiento de la prevención del VIH}

El conocimiento sobre la prevención del VIH se evaluó mediante respuestas abiertas a la pregunta, “Cómo puede una persona prevenir el VIH?” La proporción que mencionó el uso del condón durante la primera encuesta fue alta ( 80 por ciento), y aumentó a 83 por ciento en la última encuesta. La exposición a SDSI también estuvo asociada con este incremento, ya que el grupo más expuesto tenía un 30 por ciento de mayores probabilidades de responder "usando condones" que el grupo menos expuesto $(\mathrm{p}<.001){ }^{40}$

\footnotetext{
${ }^{40}$ La última vez que se hizo esta pregunta en una encuesta nacional de jóvenes de ambos sexos fue en la encuesta de ENDESA (Encuesta en Demografía y Salud) de 1998, cuando el 52 por ciento de las mujeres y el 68 por ciento de los hombres espontáneamente mencionaron el uso del condón como una medida preventiva. En la misma encuesta, alrededor del ocho por ciento tanto de hombres como de mujeres mencionaron "abstinencia", mientras que el 20 por ciento de las mujeres y el 17 por ciento de los hombres mencionaron "limitar el número de parejas."
} 
Independiente de la exposición a SDSI, las mujeres tenían 27 por ciento menos probabilidades que los hombres de responder bien a la pregunta. Las personas de Juigalpa y León, los grupos con los niveles más bajos escolaridad y el grupo etario más joven, también tenían menos probabilidades de responder correctamente la pregunta.

\section{Percepción del riesgo individual}

Evaluar la percepción de riesgo es intrínsecamente difícil debido a la probable influencia de varios factores, tales como el conocimiento de la prevalencia del VIH, conocer su situación personal y la de su pareja con respecto al VIH, el uso del condón y creer en la fidelidad individual y mutua. La percepción del riesgo se exploró de varias formas distintas y si bien algunos de los resultados fueron alentadores, otros plantearon contradicciones y preguntas adicionales.

La percepción personal del riesgo o la personalización del riesgo se evaluó utilizando la pregunta “AAlguna vez has pensado que vos podrías contraer el VIH?” Si la respuesta era negativa, la pregunta abierta de seguimiento que se hizo fue "¿Por qué no?” Una de las posibles respuestas fue "porque siempre uso un condón". Se analizaron las respuestas "sí, he pensado que podría contraer el VIH", y "no, no he pensado que podría contraer el VIH porque siempre uso un condón".

La mitad de la muestra (51 por ciento) respondió que en algún momento pensó que podrían infectarse, los hombres tenían un 55 por ciento más probabilidades de reconocerse en riesgo que las mujeres. Un tercio de los hombres y 40 por ciento de las mujeres dijeron que pensaban que no tenían riesgo alguno de infectarse con VIH. ${ }^{41} \mathrm{Si}$ bien con el tiempo no se observaron cambios en la percepción del riesgo entre toda la muestra, los datos indican un incremento entre quienes piensan sobre su propio riesgo personal de contraer el VIH, lo cual se debe a la influencia de SDSI. Una mayor exposición a SDSI condujo a un incremento del 29 por ciento en la probabilidad de que la respuesta fuera "sí, he pensado que podría contraer el VIH." Este efecto fue notorio entre mujeres con mayor exposición, quienes tenían un 35 por ciento más probabilidades de reconocer el riesgo que las mujeres menos expuestas.

El análisis según los grupos etarios reveló que la probabilidad de percepción del riesgo era 72 por ciento más alta entre el grupo más expuesto, comparado con el grupo menos expuesto.

En el análisis step-wise, la personalización de la percepción del riesgo también estuvo vinculada a la comunicación interpersonal sobre el VIH y los temas relacionados. Aquellas personas que habían hablado con alguien sobre VIH y temas relacionados tenían 51 por ciento más probabilidades de tener un sentido del riesgo personal (67 por ciento más probabilidades en hombres y 39 por ciento más probabilidades en mujeres). Al mismo tiempo, no se observó asociación alguna entre la exposición a SDSI y otras variables de percepción del riesgo, incluido el nivel percibido de riesgo. El nivel percibido de riesgo se estableció con la pregunta, “Pensás vos que tu riesgo de adquirir el SIDA es alto, moderado, mínimo o no tenés ningún riesgo?"

\footnotetext{
${ }^{41}$ Los únicos datos comparables son los de la encuesta de mujeres de ENDESA realizada en 2001, donde un 22 por ciento de las jóvenes dijo creer que estaba en riesgo de infectarse y la encuesta de 1998 en la que el 56 por ciento de los hombres dijo creer que estaba en riesgo.
} 
El análisis del segundo estudio cualitativo reveló que muchos de los/as entrevistados/as asocian el riesgo personal de contraer VIH con eventos muy remotos (por ejemplo por resultar heridos con objetos contaminados) y no con el contacto sexual, que es la forma más común de transmisión en Nicaragua. El estudio cualitativo también reveló la tendencia de que los hombres se consideren libres de riesgo, o no utiliza condón porque confían en la fidelidad de su pareja. Esto podría indicar la existencia del conocimiento del riesgo que resulta de tener múltiples parejas, pero una personalización del riesgo muy limitada.

Yo me siento tranquilo de no tener eso, porque uno también tiene que saber con qué tipo de personas se va a relacionar, ¿ya me entendés? Y yo relaciones sólo con mi pareja y no salgo mucho a la calle.

Estudio cualitativo 2; hombre del grupo de control en León

Las mujeres del mismo estudio hablaron mucho más que los hombres sobre la posibilidad de contraer el VIH a través de relaciones sexuales con sus parejas. Sin embargo, esta mayor percepción del riesgo entre las mujeres no necesariamente se traduce en prácticas preventivas. Algunas mujeres dijeron que no utilizan condones a pesar de haber mencionado la posibilidad de contraer el VIH a través de su pareja.

Digo yo que tal vez, puede ser [que me contagie...] porque, tal vez, yo aquí y mi esposo trabajando ¿qué sabemos si tal vez tiene algotra y esa mujer está contagiada? Y tal vez él venga aqui y me contagie a mí.

Estudio cualitativo 2; mujer del grupo de control en Estelí

Yo tengo mi pareja, pero usted sabe que ningún hombre es fiel. Por supuesto que yo no tomo precauciones con mi pareja y no se si el anda con alguien más.

Estudio cualitativo 2; mujer del grupo de control en León

En los estudios cualitativos, las personas entrevistadas hablaron del VIH como un problema y del impacto de usar Sexto Sentido para promover la prevención del VIH. SDSI ha creado conciencia al respecto, y en algunos casos ha promovido procesos relacionados con eficacia individual.

El proceso que vivió el joven con VIH impactó mucho; captó el interés de muchos jóvenes y motivó algunos a buscar más información y llevar condones al colegio para su distribución. Algunos jóvenes de todas las etnias han iniciado a interiorizar la necesidad de protegerse.

Estudio cualitativo 1; hombre joven de Bilwi

En lo personal me ayudó bastante a tomar decisiones y a aclarar dudas. Por ejemplo, con mi pareja puse las cartas sobre la mesa para el uso del condón.

Estudio cualitativo 3; mujer joven de Bilwi

\section{Comunicación}

La exposición a SDSI estuvo asociada con una mayor comunicación interpersonal sobre temas relacionados con el VIH y otros temas, así como con la comunicación con la pareja en torno a la prevención. 


\section{Comunicación con otras personas sobre los temas incluidos en SDSI}

Este aspecto de la comunicación interpersonal se evaluó utilizando la pregunta, “¿Has hablado con alguien sobre estos temas en los últimos seis meses?" Tras recibir las respuestas, los temas se agruparon de la forma siguiente para fines de análisis: 1) violencia en el hogar/abuso sexual/violación, 2) VIH, 3) homosexualidad y lesbianismo, 4) drogas o alcohol, 5) relaciones sexuales/contracepción/ abstinencia/infecciones de transmisión sexual, y 6) los derechos de las y los jóvenes.

Los datos de la encuesta muestran un incremento general en la comunicación con otras personas, mientras que los análisis estadísticos demostraron que una mayor exposición a SDSI aumentó en un 62 por ciento la probabilidad de hablar sobre cualquiera de los temas. ${ }^{42}$ Los hombres, las personas participantes de León y con niveles más altos de escolaridad tenían mayores probabilidades de comunicarse sobre estos temas que las mujeres, las personas participantes de Estelí, y aquéllas con menores niveles de escolaridad.

Los análisis que utilizan los porcentajes de los riesgos atribuibles a la población revelaron que entre quienes que dijeron haber hablado a alguien sobre uno de estos temas en los últimos seis meses, el 21 por ciento se puede atribuir a una mayor exposición a SDSI. Eso equivale a unos 10,650 jóvenes en las tres ciudades que no hubieran tenido ese tipo de comunicación interpersonal, de no haber sido por la influencia de SDSI.

Los estudios cualitativos sugieren que SDSI influye en la decisión de hablar sobre sus problemas personales con una persona en quien confían y a pedir ayuda. Una de las metas sociales de SDSI es aumentar el diálogo formal e informal y la confianza entre las personas, de manera que puedan hablar más entre sí y buscar ayuda dentro de sus redes de amigos/as y miembros de la familia. SDSI utiliza varias herramientas y diferentes actividades metodológicas para este fin. El campamento juvenil anual de SDSI es un buen ejemplo de este proceso.

“[El campamento] ...detona cambios a nivel personal; sensibilización, solidaridad, da herramientas para la vida personal y profesional. Es una experiencia que te cambia, reta tu forma de pensar...

Estudio cualitativo 3; hombre joven de Bilwi

A una escala mayor y más pública, la campaña Necesitamos Poder Hablar fue diseñada con el mismo objetivo. Además, la serie Sexto Sentido TV sirve como un medio para diseminar información sobre diferentes temas, alentando a las personas a hablar de manera más abierta y a generar debate. Algunos/ as jóvenes también reportaron que la serie promovió cambios personales, les alentó a involucrarse en los temas y facilitó el diálogo con sus familias y amistades.

Por lo menos lo que es lo del sida allí se vio [en Sexto Sentido TV]. Por lo menos Gabriel cuando salió infectado a ellos les llamo la atención. Algunos jóvenes nos poníamos a platicar sobre eso.

Estudio cualitativo 2; mujer del estudio de panel en Estelí

$\overline{{ }^{42} \mathrm{OR}=1.62 ; 95 \% \mathrm{CI}}=1.5-1.8 ;$ valor de $\mathrm{p}<.001$ 
Miró esa escena donde tenía el mismo problema con la familia, con los hermanos y todo eso. Lo conmovió y comenzó a llorar y comenzó a recapacitar. Y él le contó a los amigos, a los primeros que les contó fue a los amigos, y los amigos le dijeron que estaba loco, que esto y lo otro, pero él seguía siempre con esa duda, [...] que si lo mismo que le pasaba a él le ocurría a todo mundo. Entonces dice que él nunca jamás en su vida habia hablado con su mamá, y hasta esa vez dice que medio pasó palabra con su mamá. Dice que se sintió aliviado, se sintió otra persona más diferente. Después le fue tomando confianza y la mamá le fue ayudando, y le dijo que esto y lo otro. En conclusión que él ahora logró salir de las drogas, dice que gracias a ese programa.

Estudio cualitativo 1; varón promotor local, Juigalpa

La comunicación interpersonal está vinculada al comportamiento individual y al entorno social más general así como a los temas de diálogo público y privado. Como se plantea más adelante en este informe, la comunicación interpersonal está íntimamente asociada con varios aspectos de la responsabilidad sexual y de la prevención del VIH.

\section{Comunicación con la pareja sobre la prevención del VIH}

Este tema se evaluó basado en las respuestas de las y los jóvenes que dijeron que tenían pareja, en la que "pareja" se define como alguien que se considera un novio/novia, una pareja con quien se hace vida en común o una esposa/esposo, independiente de si tienen o no relaciones sexuales. Se tomaron en cuenta las respuestas a las siguientes preguntas: “¿Has hablado con tu pareja en los últimos seis meses sobre el uso del condón?” y “¿Has hablado con tu pareja en los últimos seis meses sobre hacerse la prueba del VIH?" Para los fines de este análisis se creó una variable para haber hablado con su pareja sobre uno de estos temas.

El análisis longitudinal revela que las y los jóvenes con mayor exposición a SDSI mantuvieron mejores niveles de comunicación que las y los jóvenes menos expuestos. El grupo con mayor exposición tenía 32 por ciento más probabilidades de hablar con su pareja sobre el uso del condón y 43 por ciento más probabilidades de hablar con su pareja sobre la prueba del VIH, comparado con el grupo menos expuesto.

Asimismo, el análisis longitudinal reveló una tendencia general a la baja en cuanto a reportar conversaciones con sus parejas sobre el uso del condón. Este porcentaje bajó de 41 por ciento en 2003 a 30 por ciento en 2005, con importantes diferencias por género. Las conversaciones reportadas por los hombres bajaron del 46 por ciento al 32 por ciento mientras que las reportadas por mujeres bajaron de 37 por ciento a 28 por ciento. Asimismo, el porcentaje de participantes que reportó conversaciones con sus parejas sobre realizarse la prueba del VIH también bajó del 19 por ciento en 2003 al 13 por ciento en 2005.

La tendencia a la baja en la muestra en general, sin tomar en cuenta la exposición a SDSI, fue más marcada en las mujeres, quienes mostraron 39 por ciento menos probabilidades que los hombres de haber hablado sobre prevención. Asimismo, el grupo de hombres y mujeres de mayor edad tenía 13 por ciento más probabilidades que el grupo más joven, de haber hablado sobre prevención. 
Un análisis transversal que compara la medida de línea de base en 2003 con la medida final en 2005 en lo que respecta a la comunicación, específicamente sobre el uso del condón, revela que si bien el nivel de comunicación con las parejas bajó en el grupo menos expuesto, por otro lado aumentó en el grupo más expuesto a SDSI. Para los hombres, el incremento fue de 29 por ciento en la línea de base en 2003 a 38 por ciento en 2005 , mientras que para las mujeres, el incremento fue de 20 por ciento a 26 por ciento. Los hombres que no estuvieron expuestos bajaron en un tres por ciento, mientras que las mujeres que no estuvieron expuestas permanecieron en el mismo nivel.

El análisis utilizando los 'riesgos atribuibles a la población' muestra que los resultados siguientes se pueden atribuir a la exposición a SDSI:

- El 23 por ciento de las y los jóvenes que dijeron que habían hablado con sus parejas sobre el uso del condón. Esto se traduce en 7,897 jóvenes en las tres ciudades que no lo hubieran hecho sin la influencia de SDSI.

- El 23 por ciento de quienes hablaron con sus parejas sobre hacerse la prueba del VIH: 3,104 jóvenes en las tres ciudades.

- El 18 por ciento de quienes han hablado con sus parejas sobre previas experiencias sexuales: 4,423 jóvenes en las tres ciudades.

El segundo estudio cualitativo permitió identificar ciertos factores que motivan a las parejas o que hace que les sea más fácil hablar sobre el VIH. Estos incluyen: 1) confianza entre las parejas; 2) las campañas, reportes o programas transmitidos por los medios de comunicación (incluyendo la serie Sexto Sentido televisión, que fue mencionada de forma espontánea) y los materiales informativos impresos; 3) la participación en actividades relacionadas con el VIH; 4) la percepción de que la pareja sabe sobre el tema; 5) conocer casos de personas que han contraído el VIH o a quienes se les considera en situación de riesgo o se les estigmatiza (p. ej., a los homosexuales); 6) temor a que la pareja resulte infectada por otras parejas (sólo en el caso de las mujeres); y 7) tener conversaciones con las amistades.

Mirábamos cosas así en la televisión, de Sexto Sentido, esas cosas así, entonces ya nos poníamos a hablar de eso. [...] Yo le decía: cuidadito vas hacer esto”, “Por qué me decís eso?", me decía. "Porque yo miro”, le digo yo, "cómo salen esas cosas ahí en televisión, todo eso del sida y eso me da miedo".

Estudio cualitativo 2; mujer del grupo de control en Estelí

El mismo estudio cualitativo también identificó factores que reducen la posibilidad de hablar con la pareja sobre la prevención del VIH, como: 1) no considerarlo necesario porque ya hubo conversaciones previas sobre los temas; 2) porque la comunicación no siempre es verbal ("hablar"), pero también puede contener "entendimiento implícito", leer los mismos materiales informativos sobre VIH, o incluso saber ya suficiente sobre el tema o sobre la posición de su pareja al respecto; 3 ) temor a que "hablar" se puede interpretar como indicación de infidelidad o desconfianza, especialmente si ha habido un episodio previo de infidelidad; o porque podría interpretarse como una invitación a tener relaciones sexuales cuando estas aún no han iniciado; o porque plantearlo se considera vergonzoso o tabú; 4) conflictos generales con su pareja; 5) falta de interés en el tema; 6) falta de tiempo, debido al trabajo; y 7) porque se tienen que ver a escondidas por causa del control de los adultos. 
Él casi no pasa conmigo. Él pasa todo el día trabajando, desde la mañana hasta bien noche y a esa hora yo estoy dormida. Llega la mañana y asi sucesivamente....

Estudio cualitativo 2; mujer del estudio de panel en Juigalpa

No nos queda tiempo [para hablar del tema], porque jalamos escondidos. [...] Nos miramos muy росо, тиу росо tiempo. Pero ahi tengo otro hermano, aqui abajo, que tiene otra casa, cuando está sola ella llega en el día, pero sólo, sólo dos horas, una hora, rápido, lo que vamos hacer y ya...

Estudio cualitativo 2; hombre del estudio de panel en Estelí

\section{Eficacia individual}

Si bien la tendencia en la población general fue hacia una reducción en los valores del índice de eficacia individual y en el índice de poder en la relación, ambos vinculados a la negociación en torno al uso del condón, quienes estuvieron más expuestos a SDSI mantuvieron niveles más altos en ambos índices.

\section{El índice de eficacia individual}

En términos generales, hubo una tendencia hacia la baja en el índice de eficacia individual (véase la tabla 9), tanto en el grupo con mayor exposición a SDSI como en el grupo con menos exposición. El índice de eficacia individual bajó en un 3 por ciento de su valor inicial en la población en general.

Sin embargo, según el modelo lineal general y a pesar de la reducción general, el grupo con mayor exposición a SDSI mantuvo valores más altos que el grupo con menos exposición $(\mathrm{p}=0.033)$.

Una mayor eficacia individual se asoció de forma positiva y dinámica con una mayor comunicación con parejas sexuales en torno al uso del condón, lo que condujo a un uso más regular del mismo. Este análisis se presenta como parte del análisis step-wise.

\section{Tabla 9 Elementos en el índice de eficacia individual* (para negociar el uso del condón)}

- ¿Serías capaz de usar correctamente un condón con tu pareja?

- ¿Serías capaz de negarte a tener relaciones sexuales con tu pareja si no quiere que usen condón y vos querés usarlo?

- ¿Serías capaz de rechazar tener relaciones sexuales con tu pareja si no querés tenerlas?

- ¿Serías capaz de pedirle a tu pareja que usen condón?

- ¿Serías capaz de insistir en el uso del condón con tu pareja, aunque él o ella no quieran usarlo?

*Las respuestas "sí" contribuyeron a puntajes más altos. Entre más alto el puntaje, mayor el sentido de eficacia individual. Las posibles respuestas fueron: no, sí, no sé. 
Los estudios cualitativos revelaron que en general las personas tienen una buena apreciación de su capacidad de tomar diferentes medidas para prevenir el VIH (usar un condón, tener sólo una pareja sexual, mantenerse informado/a y hablar sobre el tema, hacerse la prueba, etc.). Sin embargo, no hubo mucha evidencia de que esto se ponga en práctica, quizás porque no consideran que estén en riesgo o porque no se sienten capaces de negociar el uso del condón. Otros factores fueron las normas sociales que rodean la sexualidad y el estigma vinculado a ciertas medidas preventivas.

Si voy a comprar un condón, ya la gente piensa lo que voy hacer, y por eso da pena ir a comprar un condón. [...] Dicen que sólo las prostitutas usan el condón. Yo puedo ir a comprar un condón a la farmacia y ya van a pensar que soy prostituta, aunque no lo soy....

Estudio cualitativo 2; mujer del estudio de panel en Estelí

\section{El índice de poder y control en la relación}

La segunda y la tercera encuesta miden el índice de poder en la relación (véase la tabla 10), el grado al cual la persona siente que tiene igual poder y control en una relación de pareja íntima. La tendencia de los valores de este índice fue similar a los de la eficacia individual, donde el índice bajó a menos del 3 por ciento en general durante el transcurso de las encuestas. El modelo lineal general reveló que el grupo con la mayor exposición a SDSI mantuvo valores de índice más altos que aquellos con menos exposición. $(\mathrm{p}=0.025)$

\section{Tabla 10 Elementos en el índice de poder en la relación*}

- La mayor parte del tiempo hacen lo que tu pareja quiere hacer.

- Si le pidieras a tu pareja que usara un condón, él o ella pensaría que estás teniendo sexo con otras personas.

- Cuando tu pareja y vos están juntos, vos generalmente estás callada/o.

- Tu pareja hace lo que él o ella quiere, aún si vos no querés que lo haga.

- Te sentís atrapada/o o encerrada/o en la relación que llevás con tu pareja.

- Tu pareja te deja usar cualquier tipo de ropa.

- Tu pareja tiene más peso que vos en las decisiones importantes que les afectan

- Cuando tu pareja y vos están en desacuerdo, ella o él casi siempre se sale con la suya.

- Estás más dedicada/o a la relación que tu pareja.

- Tu pareja puede que esté teniendo sexo con alguien más.

- Tu pareja te dice con quién podés pasar tu tiempo.

- En general, tu pareja se beneficia más o saca más de la relación que vos.

- Tu pareja siempre quiere saber donde estás.

- Si le pidieras a tu pareja que usaran un condón, él o ella se pondría muy enojado/a.

- Si le pidieras a tu pareja que usaran un condón, él o ella se pondría violento/a.

*Las respuestas "no" contribuyen a puntajes más altos. Entre más alto el puntaje mayor sentido de igual poder y control en la relación.

Independientemente de la exposición a SDSI, las mujeres mantuvieron niveles más altos que los hombres para este índice. Las personas de Estelí y aquéllas con mayores niveles de educación también mantuvieron valores superiores. 


\section{Uso del condón y otros comportamientos de prevención}

La encuesta exploró las prácticas directamente vinculadas al coito. Debido a la posible delicadeza de algunos de los temas, estos se abordaron sobre todo en el cuestionario llenado, en donde se les preguntaba a los participantes sobre el uso del condón durante sus más recientes relaciones sexuales y la frecuencia del uso del mismo en los seis meses anteriores. A las y los adolescentes y jóvenes que dijeron que aún no habían tenido relaciones sexuales se les excluyó de este análisis.

\section{Tendencia general a la baja en el uso del condón con las parejas estables (no relacionado con SDSI)}

Hubo una reducción general en el uso regular del condón con una pareja estable (de 38 por ciento a 28 por ciento entre la primera y la tercera encuesta), y una mayor exposición a SDSI no tuvo una asociación directa de importancia estadística con un mayor uso del condón.

Sin embargo, como se describe en el análisis step-wise que se presenta más adelante en este informe, SDSI tuvo un papel indirecto en la promoción del uso más regular del condón, dado su impacto positivo en la comunicación interpersonal, en la eficacia individual y en la comunicación íntima entre pareja sobre el uso del condón.

La principal razón citada para el uso del condón con una pareja estable era la prevención del embarazo. Entre aquéllos que dijeron que usaban condones, el porcentaje que reportó el uso del condón para evitar un embarazo aumentó de 73 por ciento a 83 por ciento entre la primera y la tercera medición.

La información cualitativa permitió la identificación de algunas razones por las cuales las parejas estables no usan condones, como son la confianza en la fidelidad como medida de prevención y el estigma relacionado con el VIH.

Cuando uno tiene su pareja y es casado, pues no es necesario, creo que no es muy necesario usar cualquier otro método. Pero cuando, pongámosle, en el caso de las prostitutas, me imagino que siempre que van a tener relaciones con un hombre [van a] pedirle que usen el condón, porque es la mejor manera, el mejor método de evitarlo, usando el condón. Y cuando los hombres le son infieles a sus mujeres también....

Encuesta cualitativa 2; mujer del grupo de control en Juigalpa

Cuando alguien es vago, camina en las calles y camina más riesgo, porque salen mujeres vagas, mujeres de la vida alegre a las cuentas. Mientras que uno que no sale, está sólo en su casa, y si tiene a su señora, vive con su señora en la casa, ahí, tiene menos peligro.

Estudio cualitativo 2; hombre del panel de estudio en Juigalpa

Los estudios cuantitativos midieron los siguientes comportamientos sexuales no relacionados con SDSI:

- El 30 por ciento de los hombres y el 15 por ciento de las mujeres dijeron que habían usado un condón durante su primer coito. 
- La edad a la cual las y los jóvenes habían iniciado su vida sexual aumentó entre la primera y la última medición, con un incremento promedio de 14 a 15 años entre los hombres y de 16 a 17 años entre las mujeres.

- Hubo una ligera reducción en el número de parejas en los doce meses anteriores a la primera y a la última entrevista, de 2.86 a 2.51 entre los hombres y de 1.30 a 1.17 entre las mujeres.

- Basado en el cuestionario de autollenado, entre la segunda y la tercera encuesta se observó un incremento en la primera experiencia sexual con el uso de coerción, de 14 por ciento a 16 por ciento. Las preguntas exploraron cómo habían tenido lugar las primeras relaciones sexuales, dando las opciones de "quería tener relaciones", "me obligaron a tener relaciones" y "no quería tener relaciones."

\section{Aquellas personas más expuestas a SDSI mantuvieron su nivel de uso del condón con las parejas ocasionales, mientras que la población en su conjunto mostró una reducción general en el uso del condón}

En términos generales, la población bajo estudio mostró una tendencia hacia la reducción en el uso del condón con parejas casuales. La prevalencia en el uso del condón con parejas casuales en la muestra total bajó del 55 por ciento al 50 por ciento entre la primera y la tercera encuesta. ${ }^{43} \mathrm{Sin}$ embargo, el grupo con mayor exposición a SDSI tenía 44 por ciento más probabilidades que sus el menos expuesto de reportar el uso del condón durante su más reciente relación sexual con una pareja casual, y 42 por ciento más probabilidades de "siempre" haber usado un condón durante los seis meses anteriores.

Las mujeres tenían un 79 por ciento menos probabilidades que los hombres de reportar el uso del condón durante su último encuentro sexual con una pareja casual. También hubo diferencias según el nivel de escolaridad, donde las personas con educación técnica y universitaria tenían 2.25 veces más probabilidades de haber usado un condón, comparado con aquéllas con nivel de escolaridad primario o ninguno.

El análisis por género mostró que los hombres con mayor exposición a SDSI tenían 56 por ciento más probabilidades de haber usado un condón en los últimos seis meses con una pareja casual, que aquéllos con menos exposición. No se observó esa diferencia entre mujeres.

Según el análisis basado en los riesgos atribuibles a la población, el uso del condón en el 18 por ciento de quienes reportaron el uso del condón en su última relación sexual con una pareja casual se atribuyó a la exposición a SDSI. Esto es el equivalente a unos 2,500 jóvenes adicionales en las tres ciudades, atribuible a la de SDSI.

El enfoque cualitativo reveló que algunos de los obstáculos para el uso del condón tienen sus raíces en una percepción limitada del riesgo, en la falta de información y en el rechazo de los condones.

\footnotetext{
${ }^{43}$ La encuesta de ENDESA no preguntó sobre parejas estables comparadas con parejas casuales, sino que más bien distinguió a jóvenes sexualmente activos en categorías de quienes están en relaciones estables de pareja en unión y quienes no lo están. Los datos de 2001 para las mujeres revelan que el 6 por ciento de las mujeres jóvenes sexualmente activas usaron un condón en su encuentro sexual más reciente (5 por ciento de aquéllas en unión y 11 por ciento de aquéllas que no están en unión), mientras que los datos de 1998 para los hombres revelan que el 30 por ciento de todos los hombres jóvenes sexualmente activos usaron un condón durante su último encuentro sexual (el 7 por ciento de aquéllos en unión y el 45 por ciento de aquéllos que no están en unión).
} 
Yo sólo tengo relaciones con mi pareja. No sabría como cuidarme con él, porque yo con él no uso nada de preservativos. Pero para las otras personas, quizás se pueden cuidar con el condón....

Estudio cualitativo 2; mujer del grupo de control en León

Con el uso del condón, te decía que suele ser muy molesto al momento de tener la relación. Entonces yo digo que ese puede ser uno de los problemas para seguir las orientaciones a la hora de protegerte, porque solés poner ante todo tu placer personal, antes que la protección de tu pareja y la protección de tu vida.

Estudio cualitativo 2; hombre del estudio de panel en León

\section{Capital social y eficacia colectiva}

La evaluación de los procesos colectivos y de los procesos de cambio social implica múltiples retos metodológicos. Como ya se explicó, el componente cuantitativo examinó la percepción que tienen las personas de su contexto social (capital social) así como su sentido de eficacia colectiva, lo que se entiende como su percepción de que sus círculos inmediatos (amistades, miembros de la familia, barrio) podrían organizar e implementar acciones colectivas relacionadas con el VIH y la violencia doméstica.

Se analizó el impacto de SDSI en el entorno social local usando procesos cualitativos dirigidos a examinar la relación entre los procesos de cambio personal y los cambios en el entorno local. Además, se pretendió examinar los posibles vínculos entre la implementación de SDSI y los efectos provocados a nivel del entorno local y de los procesos colectivos.

Por ejemplo, el segundo estudio cualitativo reveló que si bien las y los jóvenes tenían un mayor conocimiento sobre los derechos de niños/as y los adolescentes, y sobre el derecho de las mujeres a vivir una vida sin violencia, también percibían que estos derechos con frecuencia se transgreden con impunidad. Se citaron casos de violencia doméstica, de abuso sexual y embarazo en adolescentes. Quienes participaron en el estudio criticaron a los medios de comunicación en general por no cubrir adecuadamente los problemas en su entorno social local, a excepción de ciertos programas, incluido Sexto Sentido TV, Sexto Sentido Radio, y los programas de radio que tienen las ONG locales (todo lo cual se mencionó de forma espontánea). Asimismo reconocieron que la participación en las organizaciones facilitaba el ejercicio de los derechos mencionados.

...cuando yo estuve por primera vez en un programa de jóvenes me sentí libre de expresión, bastante; que podía hablar lo que yo quería y lo que yo sentía.

Estudio cualitativo 2; mujer del estudio de panel en Juigalpa

Los resultados del componente cuantitativo revelaron que el grupo más expuesto a SDSI tenía 11 por ciento mayores probabilidades de considerar que su grupo de amistades sería capaz de "hacer algo juntos" para intervenir en una situación de violencia contra las mujeres. 


\section{SDSI promueve un entorno favorable para la prevención del VIH}

El análisis se basó en las percepciones de los siguientes actores clave: jóvenes y adultos de organizaciones, proveedores locales de servicios sociales y de salud, y personas involucradas en los medios de comunicación locales. El análisis consideró las percepciones de estos actores clave sobre los aportes del proyecto hacia un entorno favorable para la prevención del VIH.

Especialmente para fines del tercer estudio cualitativo, el entorno o contexto social se definió como los ámbitos organizacionales de la sociedad civil para forjar alianzas y para promover acciones individuales y colectivas. En particular, el análisis tomó en cuenta las redes informales de personas y organizaciones, incluidas las instituciones estatales y los medios de comunicación.

El estudio y las actividades de monitoreo revelan el impacto de SDSI en los procesos. En particular, se midió cómo SDSI ha contribuido a cambios graduales y diversos en la dinámica local relacionada con:

- El trabajo local y el desarrollo de iniciativas locales.

- La promoción del diálogo y del debate en torno a temas tabú en diferentes ámbitos sociales y culturales.

- El fortalecimiento de los liderazgos.

- La eficacia colectiva.

- Construcción de vínculos y alianzas.

Al mismo tiempo, las conclusiones del estudio identificaron ciertas áreas que requieren una estrategia más coordinada con los temas, objetivos y planes priorizados y con el seguimiento. Esto podría permitir que SDSI aprovechara mejor la creciente sensibilización promovida por el componente de comunicación masiva a fin de contribuir a cambios en el contexto social de manera deliberada y estructurada.

\section{Aportes al trabajo local y al desarrollo de iniciativas}

Los aportes del proyecto a los cambios en el contexto social forman parte de un conjunto de iniciativas desarrollado a nivel local para facilitar los enfoques, las herramientas, la socialización de la información y el debate sobre temas de interés.

Debido a la modalidad del proyecto y al alcance masivo de los medios de comunicación, los diferentes componentes han tenido un efecto "detonador" para facilitar el trabajo de las organizaciones locales. También, las acciones de capacitación han permitido una mayor apropiación de los enfoques, metodologías y herramientas necesarias para trabajar en estos temas con diferentes grupos de población locales.

Con Puntos hemos coordinado talleres sobre salud sexual y salud reproductiva, nos han apoyado en la capacitación del personal técnico del programa, ha habido intercambio de experiencias. Estos talleres nos han permitido profundizar reflexiones y nos han dado metodologías.

Mujer, promotora comunitaria de Juigalpa 
Hemos ido a Managua, nos han ayudado para reproducir estos temas y el material que han distribuido nos ha ayudado en la capacitación de jóvenes y adolescentes. También nos dieron un DVD que nos ha ayudado en la profundización de las temáticas y los enfoques.

Mujer, promotora comunitaria de Juigalpa

La campaña Necesitamos Poder Hablar y el paquete metodológico en DVD tuvieron una amplia aceptación y las organizaciones afirmaron que habían contribuido a promover el desarrollo de actividades locales.

En la última actividad en el campo esperábamos 45 personas, llegaron 150! El video, le gustó a la gente, porque era como ver una película y les permitió interiorizar el mensaje.

Mujer policía de Bilwi

Otra actividad apreciada fue la colocación de vallas con publicidad para Sexto Sentido TV y Radio, donde también se destacaron los nombres de los proveedores locales de servicios sociales y de salud.

Según las entrevistas, los programas de radio y televisión han dado pautas y han estimulado el interés en que se siga prestando atención a estos temas. En Estelí, por ejemplo, un proyecto de comunicación coordinado por la red juvenil y Radio Cumiche reportó que habían adaptado los materiales de Sexto Sentido Radio al contexto local.

Algunas iniciativas locales también incorporaron los enfoques metodológicos del proyecto. Por ejemplo, la red juvenil en Estelí y una diversidad de organizaciones en Bilwi (Tesis, Acción Médica Cristiana, la Comisión contra las drogas, y la clínica de Bilwi) organizaron sus propios campamentos juveniles. Algunos de estos campamentos utilizaron el manual de SDSI y el paquete de Necesitamos Poder Hablar como herramientas metodológicas y los participantes de SDSI en los campamentos participaron en los equipos facilitadores.

\section{Apertura al diálogo y al debate en torno a temas tabú en diferentes áreas}

Como ya se vio, SDSI - y Sexto Sentido TV en particular - pueden haber sido un elemento clave para trascender los ámbitos público y privado, y estimular la comunicación tanto a nivel privado (familia, amistades) como a nivel público (escuelas, organizaciones).

En general, las actividades en los medios de comunicación masiva parecen haber aportado significativamente al desarrollo de un pensamiento crítico en torno a los temas abordados, a generar opiniones, a romper tabúes y a estimular el diálogo y el debate.

Sexto Sentido TV aportó porque se metió en la familia, en el colegio, en los centros de trabajo. Tuvo impacto directo en estos espacios.

Mujer joven de Estelí

Fue bomba cuando salió el programa; ver jóvenes hablar abiertamente sobre temas tabúes (menstruación, relaciones sexuales), existía mucho miedo de tocar temas como la 
homosexualidad; hasta en las mismas organizaciones la serie dio mucha más apertura para hablar.

Mujer joven de Estelí

\section{Mayor diálogo en las familias}

La mitad de las y los participantes en el estudio cuantitativo reportó que miraron la serie con otras personas, y más de un tercio ( 38 por ciento) dijeron que la habían mirado "con toda la familia". Al combinar estos televidentes con quienes dijeron que habían mirado la serie con su madre o con otros miembros de la familia, se concluye que más de ocho de cada diez espectadores ( 84 por ciento) que miraron la serie con otras personas lo hicieron en un entorno familiar.

Los estudios cualitativos revelaron que además de tener una notable influencia en las y los jóvenes, la serie Sexto Sentido TV a menudo logró involucrar a toda la familia, facilitando el diálogo entre padres e hijos/as en torno a los temas abordados.

Si la familia se sienta a verlo se genera debate y discusión, ayuda a las madres y padres a abordar temas. A nosotros nos encanta. No nos lo perdemos.

Mujer adulta de Estelí

Mayor diálogo con las amistades

Más de la mitad de la audiencia (61 por ciento) dijo que había hablado sobre la serie con otras personas. Mientras que la familia fue la compañía más usual para mirar la serie, la comunicación sobre Sexto Sentido se hizo fundamentalmente con amistades (80 por ciento).

Me impactaron varios temas como la violencia y el Sida; me habian hablado de estos temas pero nunca los habia visto tan reales como en Sexto Sentido. He conversado de estos temas con mis amigas.

Joven mujer de Juigalpa

Mayor diálogo en el colegio

Las giras y sesiones de debate con el elenco en varios colegios de Secundaria en cada ciudad promovieron debates espontáneos sobre los temas cubiertos en la serie. Los y las estudiantes hablaron sobre los temas en el contexto de sus propias experiencias. En algunos casos los temas también se debatieron con el personal docente en las aulas.

No se toca el tema de sexualidad en el colegio; con SSTV se empieza a hablar más abiertamente.

Estudiante de Estelí 
Mayor diálogo en las organizaciones locales

El diálogo se desarrolló como parte de las actividades internas de las diversas organizaciones y en su trabajo con grupos y comunidades.

Después de haber visto estos temas lo hemos discutido en la comisión (de jóvenes), inclusive nos dejaron una videocinta para hacer debate sobre el tema. Hubo bastante participación. Muchos se impresionaron, les ayudó a reflexionar sobre su propia vida, a lo mejor algunas cosas las estaban viviendo, pero no sabian qué era.

Mujer de Juigalpa miembro de la comisión de jóvenes

Yo uso los materiales de la serie en la universidad para reflexionar con los muchachos, armar debate y en el campo en las capacitaciones con padres y madres.

Mujer de Juigalpa, promotora comunitaria

\section{Mayor diálogo en los medios}

Las personas entrevistadas en los estudios cualitativos reconocieron que los temas abordados en la serie de televisión son tabú y por consiguiente de difícil manejo en los medios de comunicación masiva. Asimismo, periodistas y otras personas que trabajan en los medios locales reconocieron que el programa radial cubre temas difíciles y de controversia que generalmente no se abordan en otros medios radiales.

\section{Fortalecimiento de las habilidades mediante actividades de capacitación e intercambio}

Las actividades de capacitación e intercambio estuvieron dirigidas a fortalecer las capacidades de las organizaciones y los medios locales ayudándoles a desarrollar habilidades entre líderes y comunicadores/as jóvenes organizados/as. Se analizaron los efectos de SDSI con el insumo de los/ as líderes locales, para medir su habilidad colectiva de incorporar temas y enfoques de interés en los diferentes ámbitos en el entorno local (sociedad civil y gobierno).

En las entrevistas, los/las jóvenes líderes participantes reportaron procesos de transformación personal que incluyeron cambios en sus valores y actitudes personales, el desarrollo de habilidades técnicas útiles y de enfoques metodológicos y un incremento en sus propias capacidades para trabajar en el entorno local.

El tercer estudio cualitativo tras la conclusión del proyecto en 2005, identificó los efectos siguientes de SDSI en los/as líderes locales:

- Contribuyó a un mayor conocimiento y a un examen más detallado de los temas meta (género, sexualidad, VIH, abuso sexual, etc.).

- Facilitó la asimilación personal de los diferentes enfoques (género, generacional, aceptación de la diversidad).

- Introdujo metodologías para abordar los diferentes temas.

- Fortaleció las capacidades técnica y analítica para la comunicación social en torno a estos temas. 
En mi caso especifico cuando estuve en el campamento, sali diferente. Yo creía que sólo las mujeres debian ocuparse de las tareas de la casa y era muy machista. En el campamento conocí más personas, se generaron más amistades de todo el país, comprendí que las tareas de la casa no son sólo de las mujeres, que a los niños no hay que decirles que jueguen sólo con carritos y pistolas, que somos iguales hombres y mujeres.

Hombre, promotor comunitario de Juigalpa

El VIH es un tema dificil, el hecho de haber experimentado el ejercicio de imaginarme si yo tuviera VIH fue tan fuerte que me impactó...Ahora quiero hacerme la prueba y decirle a todo el mundo que es importante... Yo nunca lo había pensado, pero tengo relaciones sexuales... no sé si puedo estar conviviendo con el virus y me gustaría saberlo... aunque me da miedo.

Mujer, campamento de mujeres 2004

Puntos ha dado herramientas para despertar creatividad y tener capacidades nuevas.

Mujer, miembro de la red de jóvenes de Estelí

Los/as comunicadores/as jóvenes se refirieron en particular a los procesos de capacitación técnica y temática que les han brindado importantes elementos para mejorar su desarrollo en el medio de comunicación donde laboran.

Han sido más que útiles, indispensables. He aprendido a hacer guiones, qué lenguaje utilizar. Hombre joven comunicador de Estelí

\section{Identificación de las limitaciones}

Las evaluaciones de las actividades de capacitación, en particular del campamento juvenil, también revelaron las limitaciones en las posibilidades prácticas de traducir las experiencias de los participantes en cambios tangibles dentro de sus organizaciones o comunidades.

Todas las entrevistas destacaron el impacto de la experiencia de campo en las vidas de los participantes y en su realidad personal: abrió mentes, promovió debates e intercambios y creó las condiciones conducentes a los cambios personales. Pero, al mismo tiempo, la mayoría mencionó haber experimentado un momento de desorientación real cuando regresaron a su realidad. En sus propias comunidades locales carecían del tipo de apoyo social que les ayudaría a consolidar sus propios cambios personales. Muchos/as reportaron que les hubiera gustado recibir más orientación sobre cómo aplicar su nuevo conocimiento para influir en la realidad local y organizacional de sus entornos.

Es un sueño estar en el campamento; luego se aterriza en la realidad; no es fácil mantener el entusiasmo.

Mujer de Estelí participante en el campamento

Después del campamento una experimenta un choque: mucha confusión, frustración, peor aún para los varones; no hay redes de apoyo.

Mujer de Bilwi participante en el campamento 
Otra situación que limitó para poner en práctica el aprendizaje adquirido en el campamento fue que al regresar de este no siempre tenían el apoyo de los/as líderes adultos/as en sus organizaciones (ONG y proveedores de servicios sociales y salud) en lo concerniente a los temas y enfoques abordados. Los comunicadores jóvenes también reportaron resistencia en los medios donde trabajan. Asimismo, reportaron limitaciones debido a la falta de recursos.

A pesar de estas limitaciones, la evaluación cualitativa sugiere que SDSI brindó aportes importantes y variados, que en conjunto fortalecen el trabajo de los diferentes actores locales e inspiran a los/las jóvenes. En general, las diferentes modalidades de fortalecimiento de la capacidad han contribuido a consolidar un incremento positivo y significativo en el número de jóvenes con nuevas ideas, capacidades y habilidades para influir en el entorno local. ${ }^{44}$

\section{La construcción de vínculos y alianzas}

SDSI está diseñado para apoyar el trabajo de organizaciones, medios y otras instancias para alcanzar objetivos comunes. Por consiguiente, ha dirigido esfuerzos hacia forjar y mantener vínculos y coordinación con una amplia gama de grupos comunitarios, de organizaciones gubernamentales y no gubernamentales, de proveedores de servicios sociales y de salud, y de medios de comunicación en los diferentes departamentos del país.

Las entrevistas con líderes y representantes de organizaciones destacaron la idoneidad de las metodologías y materiales de Puntos de Encuentro para el trabajo a nivel local. Estas metodologías y materiales crean espacios comunes para el intercambio y la capacitación. Las entrevistas sugieren que esto ha llevado a un reconocimiento mutuo y ha alentado la comunicación y la coordinación.

A nivel del entorno local, esto ha permitido una constante divulgación de los temas y enfoques principales, así como la distribución de los paquetes metodológicos y de otros materiales utilizados para el trabajo de sensibilización en las localidades.

El establecimiento de la red radial y de convenios con empresas de TV por cable también ha sido muy importante, ya que ha facilitado la divulgación de Sexto Sentido radio y televisión a diferentes departamentos en Nicaragua. También ha permitido la participación de profesionales de la radio, tanto jóvenes como adultos/as, en los talleres de comunicación.

El convenio firmado con proveedores locales de servicios sociales y de salud resultó en una evaluación particularmente positiva. Los siguientes factores se mencionaron durante un taller de monitoreo con sus representantes:

Hemos adquirido un nuevo enfoque en el trabajo de salud sexual y salud reproductiva. La firma del convenio ha propiciado un reconocimiento local del trabajo que hemos realizado. Los materiales audiovisuales nos han servido en los talleres. Se compartió la metodología en los talleres. Se formaron nuevos líderes. A través de las publicaciones realizadas por Puntos de Encuentro nos hemos proyectado fuera de nuestros departamentos. El establecimiento

\footnotetext{
${ }^{44}$ Puntos de Encuentro reporta que está tomando en cuenta estos resultados a fin de encontrar formas de resolver algunos de los problemas planteados.
} 
de nuevos vínculos nos ha permitido firmar convenios con otras organizaciones y gobiernos municipales. El convenio nos dio mayor representatividad en las estructuras del gobierno municipal.

Participantes en un taller con representantes locales

\section{Limitaciones identificadas}

El tercer estudio cualitativo reveló ciertas limitaciones en la forma como se establecieron las alianzas con las organizaciones locales durante el periodo del proyecto 2002-2005.

Las percepciones y las evaluaciones en entrevistas con líderes locales sugieren que visitas y una comunicación más sistemáticas entre Puntos de Encuentro y las organizaciones locales hubieran sido beneficiosas para promover más diálogo y la construcción colectiva de iniciativas y de agendas.

Puntos da la iniciativa; un tema o campaña. Se hacen coordinaciones y luego desaparece. No es que esperamos que esté alguien de Puntos todos los dias, sino que sepan comunicarse con los aliados; trabajar como aliados. No tenemos ni voz ni voto en la agenda de Puntos; asi nos sentimos utilizados.

Mujer, líder local de Estelí

El estudio encontró que el énfasis en la coordinación y en los vínculos con los proveedores de servicios sociales y de salud, durante el periodo de proyecto 2002-2005, le restó tiempo y recursos a los grupos y redes juveniles con los cuales Puntos había forjado fuertes relaciones a través de los años. Esto puede haber afectado la participación y la fortaleza del liderazgo local en torno a temas relacionados con el proyecto SDSI. Los y las líderes juveniles señalaron el desplazamiento de los grupos y redes juveniles como promotores del cambio en el entorno local. Asimismo, se mostraron críticos ante la falta de continuidad de la presencia local de Puntos.

Asimismo, el tercer estudio cualitativo reveló que para muchos/as participantes la definición de "alianza" para los fines del proyecto no era clara. Pensaron que la alianza comunitaria con la que se pretendía construir una estrategia de implementación y guiar la ejecución del proyecto no era lo suficientemente inclusiva y no estaba caracterizada por una suficiente toma colectiva de decisiones. También sugirieron que la naturaleza inclusiva y colaboradora de la alianza se diluía por la coordinación bilateral y los convenios específicos, tales como la distribución de materiales producidos por Puntos de Encuentro. ${ }^{45}$

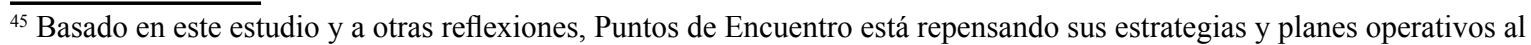
respecto.
} 


\section{Más sobre impacto: dos métodos de análisis revelan el impacto de SDSI}

\section{La relación indirecta de SDSI con el uso del condón: una validación del marco conceptual de SDSI}

La metodología del análisis step-wise se utilizó para aumentar la comprensión del papel de SDSI como detonante de cambios de comportamiento relacionados con la prevención (p. ej., para medir la relación indirecta entre SDSI y el cambio de comportamiento), y para poner a prueba el modelo conceptual en que se basan la estrategia y el proyecto.

Como se planteó antes, los resultados a lo largo del tiempo revelan una reducción general en el uso regular del condón en el transcurso de las tres encuestas, y la exposición a SDSI estuvo directamente asociada sólo con el uso del condón en la relación sexual más reciente con una pareja casual.

Mientras que el marco conceptual de SDSI se utilizó para analizar aún más los diversos elementos que afectan el uso del condón, el análisis step-wise se empleó para explorar las relaciones con otras variables que, controlando o separando el género, la edad y el nivel educativo, podrían haber actuado como detonantes inmediatos que resultarían en un uso más regular del condón.

Una serie de regresiones logísticas basadas en la última encuesta (2005) exploró las posibles asociaciones entre la variable de la exposición, las variables interventoras (comunicación interpersonal y con la pareja íntima, la percepción del riesgo y la eficacia individual), y las variables de resultados (uso del condón con parejas estables y casuales, respectivamente) (Véase el cuadro 3).

\section{Cuadro 3 Resumen del análisis}

Independiente del género, la edad y el nivel educativo, la exposición a SDSI está asociada con una creciente comunicación interpersonal y de pareja en torno a temas relacionados con la prevención del VIH. La comunicación interpersonal eleva la percepción individual del riesgo de contraer el VIH e incrementa la percepción de eficacia individual, o la habilidad de hacer cambios en el comportamiento personal o en el de su pareja. La comunicación interpersonal tiene efectos particulares en las mujeres, quienes tienen tres veces más probabilidades de percibir la eficacia individual cuando practican la comunicación. (Los hombres que sostienen una comunicación tienen dos veces más probabilidades de percibir la eficacia individual que los hombres que no lo hacen). El sentido de eficacia individual es un detonante muy fuerte para realmente hablar con su pareja, en especial para las mujeres, quienes tienen cinco veces más probabilidades de hablar con su pareja sobre prevención cuando perciben su eficacia individual. A su vez, hablar con su pareja está asociado con reportar el uso constante ("siempre") del condón en el tiempo.

Hay dos resultados que cabe destacar: existe, entre los hombres, un vínculo más fuerte entre comunicación y uso del condón con las parejas estables, pero uno aún más fuerte entre comunicación y uso del condón con parejas casuales en el caso de las mujeres. Asimismo, la eficacia individual en sí —el sentido de que uno es capaz de hablar sobre el uso del condón con su pareja- no estuvo directamente asociada con reportes sobre el uso regular del condón. Esa relación está mediada por haber hablado con la pareja. 
Las relaciones se analizaron con cuatro variables dicotómicas relacionadas con este comportamiento, las cuales se incluyeron en el cuestionario autollenado. El análisis de las variables se hizo, tanto en el uso del condón durante la relación sexual más reciente, como en la regularidad de su uso en los últimos seis meses. El uso del condón se midió con la pregunta, “¿Con qué frecuencia ha usado un condón cuando ha tenido relaciones sexuales con tu pareja estable en los últimos seis meses?" Esta variable se dividió en dos, con la respuesta "siempre" que representa el comportamiento preventivo, en comparación con las otras opciones (la mayor parte de tiempo, a veces, rara vez y nunca). Las variables de frecuencia de uso se tomaron del cuestionario que respondieron los participantes a fin de asegurar un mayor nivel de confiabilidad y rigor.

Si bien las asociaciones fueron más fuertes en los modelos construidos basados en el uso del condón durante la relación sexual más reciente, dado que la prevención del VIH requiere el uso regular del condón a los largo del tiempo, esta sección presenta los modelos construidos con las variables de resultados "el uso regular del condón en los últimos seis meses" con una pareja estable y con una pareja casual.

El análisis step-wise reveló un circuito de retroalimentación fortalecedor con respecto a la comunicación y al uso del condón. El grupo con mayor exposición a SDSI tuvo el 41 por ciento ${ }^{46}$ más probabilidades de reportar comunicación interpersonal sobre los temas de interés, medido por "haber hablado con alguien en los últimos seis meses" sobre los temas que aborda SDSI, tales como el VIH, la sexualidad, la violencia, los derechos y otros. ${ }^{47} \mathrm{La}$ comunicación interpersonal corresponde a un incremento del 51 por ciento en la percepción personal del riesgo, medido por la pregunta, "¿Alguna vez has pensado que vos podrías contraer el VIH?", ${ }^{48}$ y un incremento del 100 por ciento en la probabilidad de percibir la eficacia individual, medido por la pregunta, “¿Serías capaz de pedirle a tu pareja que use un condón?".

La percepción, tanto del riesgo personal, como de la eficacia individual, fue a su vez asociada positivamente con la comunicación de la pareja íntima relacionada con la prevención, según midió la pregunta, “¿En los últimos seis meses has hablado con tu pareja sobre el uso del condón?”. La percepción del riesgo personal aumentó la probabilidad de comunicación con la pareja íntima en un 62 por ciento ${ }^{49}$ mientras que la percepción de eficacia individual para solicitar el uso del condón triplicó -y un poco más-la probabilidad de comunicación con la pareja íntima. ${ }^{50}$ (Una mayor exposición a SDSI también aumentó directamente la probabilidad de comunicación con la pareja íntima sobre el uso del condón en un 39 por ciento). ${ }^{51}$

Por último, la comunicación con la pareja íntima está directamente asociada con una mayor probabilidad de uso del condón con parejas estables y casuales. La probabilidad de reportar un comportamiento preventivo - uso regular del condón - con una pareja estable fue 82 por ciento mayor

\footnotetext{
${ }^{46}$ Este análisis se basó en la última encuesta. El análisis longitudinal reveló un 62 por ciento de mayor probabilidad de comunicación interpersonal. Si bien estos resultados no son comparables, se destaca que diferentes formas de análisistodas controlando o separando los factores demográficos tales como edad, sexo y nivel educativo-revelan de manera independiente importantes asociaciones entre la exposición a SDSI y una mayor comunicación interpersonal.

${ }^{47}$ Variable $815 ; \mathrm{OR}=1.41 ; 95 \% \mathrm{CI}=1.2-1.6$

${ }^{48}$ Variable N23; OR $=1.51 ; 95 \% \mathrm{CI}=1.3-1.7$

${ }^{49} \mathrm{OR}=1.62 ; \mathrm{CI}=1.4-1.9$

${ }^{50} \mathrm{OR}=3.57 ; \mathrm{CI}=2.7-4.8$

${ }^{51} \mathrm{OR}=1.39 ; 95 \% \mathrm{CI}=16-1.67$. Una vez más, al igual que con la comunicación interpersonal, el análisis longitudinal reveló una asociación más fuerte.
} 
entre aquellas personas que dijeron haber hablado con sus parejas sobre este tema en particular, ${ }^{52}$ con importantes diferencias entre hombres y mujeres.

La relación entre la comunicación con la pareja y el uso del condón también se demostró con respecto a las parejas casuales, por medio de la pregunta, "En los últimos seis meses, cuando has tenido relaciones sexuales con una pareja ocasional, qué tan a menudo han usado condones?". Quienes habían hablado con sus parejas sobre el tema durante el mismo periodo tenían 63 por ciento más probabilidades de reportar que siempre habían usado un condón con una pareja casual, durante los últimos seis meses. ${ }^{53}$

Como se muestra en la figura 9, la estratificación según el sexo (y controlando o separando para la edad y la educación) reveló importantes diferencias entre hombres y mujeres. Por ejemplo, la probabilidad de que la exposición a SDSI condujera a la comunicación interpersonal fue mayor entre los hombres ( 57 por ciento, comparado con 29 por ciento para las mujeres). Los hombres también tenían mayores probabilidades de percibir el riesgo personal como resultado de la exposición a SDSI, con un incremento en la probabilidad de percepción personal del riesgo del 67 por ciento para los hombres y 39 por ciento para las mujeres. Asimismo, los hombres tenían mayores probabilidades que las mujeres de traducir su percepción de riesgo personal en hablar con sus parejas sobre el uso del condón, y los hombres tenían 68 por ciento más probabilidades y las mujeres el 57 por ciento de usar condones con regularidad con sus parejas estables, como resultado de la comunicación con la pareja íntima.

Otros efectos detonantes fueron más evidentes en las mujeres que en los hombres. Por ejemplo, las mujeres que habían hablado con alguien sobre los temas incluidos en SDSI tenían tres veces más probabilidades de decir que se sentían capaces de proponer que sus parejas usaran un condón, comparado con una probabilidad mayor del 85 por ciento entre los hombres. Y las mujeres que se consideraban capaces de proponer el uso del condón a sus parejas, tenían cinco veces más probabilidades de hablar con su pareja sobre el uso de un condón, mientras que los hombres tenían tres veces más probabilidades de hacerlo.

Tanto hombres como mujeres que en los últimos seis meses habían hablado con sus parejas sobre el uso del condón, tenían mayores probabilidades de haber usado un condón con regularidad con su pareja estable durante el mismo periodo, donde los hombres tenían dos veces más probabilidades (RP 2.07) y las mujeres 59 por ciento más probabilidades. Sin embargo, con las parejas casuales, las diferencias según el sexo eran muy notables: las mujeres que habían hablado con su pareja sobre el uso del condón tenían tres veces más probabilidades de haber reportado un uso regular del condón con las parejas casuales en los últimos seis meses, mientras que en el caso de los hombres, la diferencia no fue estadísticamente significativa.

Este análisis demuestra que Somos Diferentes, Somos Iguales en efecto promueve procesos de comunicación interpersonal, los que a su vez favorecen la comunicación entre parejas y la asimilación de los comportamientos preventivos. Al mostrar la relación dinámica entre actitudes, percepciones, comunicación y comportamientos, el modelo ofrece importantes perspectivas para trabajar en los temas relacionados con aspectos íntimos de las vidas de las personas, tales como la sexualidad, y

\footnotetext{
${ }^{52} \mathrm{OR}=1.82 ; 95 \% \mathrm{CI}=1.4-2.4$

${ }^{53} \mathrm{OR}=1.63 ; 95 \% \mathrm{CI}=1.2-2.3$
} 


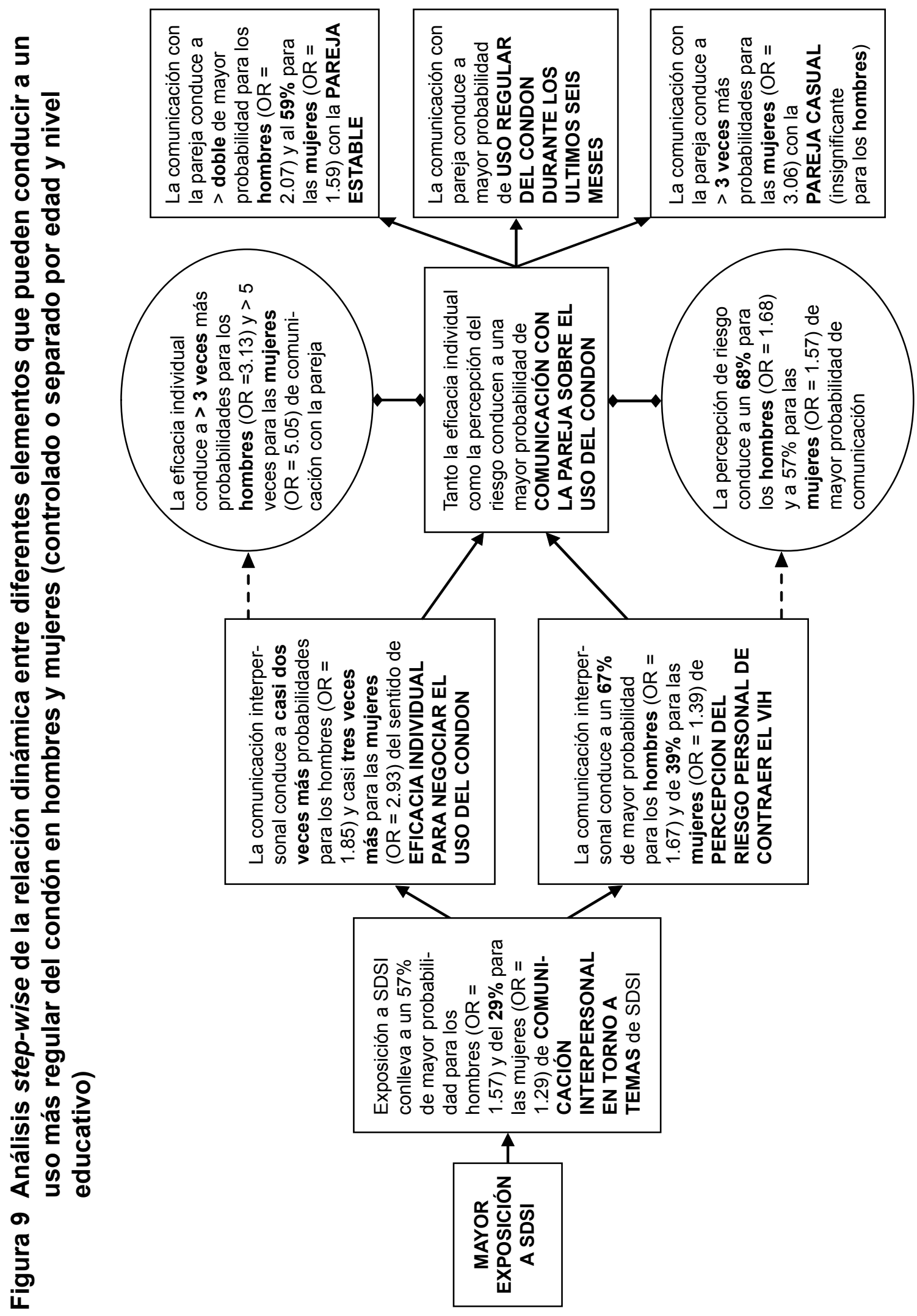


valida la conceptualización de SDSI como una estrategia que promueve un entorno más favorable para la prevención del VIH al detonar procesos sociales y de comunicación íntima.

\section{Entre Amigas: un ejemplo de análisis del impacto sinérgico y neto de Sexto Sentido en niñas de 10 a 14 años}

Entre Amigas fue un proyecto interinstitucional ${ }^{54}$ que se centró en el empoderamiento de niñas entre los 10 y los 14 años en el municipio de clase trabajadora de Ciudad Sandino, cerca de la capital del país, Managua. La intervención combinó la educación entre pares, el fortalecimiento de las redes de apoyo y la serie Sexto Sentido TV. El equipo de investigación cuantitativa para la evaluación del proyecto fue el mismo que para SDSI.

La evaluación de Entre Amigas utilizó una línea de base y encuestas post intervención para medir los cambios. Los tipos de cambios buscados por Entre Amigas y por SDSI eran similares, y la evaluación reveló cambios significativos en varios de los objetivos de SDSI: la visión de género de las niñas, su sentido de eficacia individual y su percepción del riesgo de ITS, VIH y Sida.

Parte del análisis del impacto implicó un ejercicio para determinar el "impacto neto" de los diferentes componentes en el proyecto Entre Amigas, así como su efecto sinérgico. Su objetivo era identificar, distinguir y comparar el impacto neto del trabajo interpersonal intensivo del componente de educación entre pares del proyecto (formar parte de un grupo de "amigas") y la exposición a la intervención de comunicación masiva de la serie de televisión Sexto Sentido. También medir el impacto combinado de varios componentes.

El ejercicio analítico se realizó utilizando la variable de "eficacia individual". En el caso de Entre Amigas, esta variable se definió con respecto a la autoasertividad de las niñas: ellas afirman no creer que es su culpa si las tratan mal y tienen el derecho a hablar si algo les molesta.

Independiente de cualquier otro factor o influencia, las niñas que participaron en un grupo de "amigas" tenían un 73 por ciento más probabilidades de ser autoasertivas. Si tanto ellas como sus madres habían participado, la probabilidad era 91 por ciento mayor. Y si ellas y sus madres habían participado y también mirado Sexto Sentido, tenían 122 por ciento más probabilidades de ser autoasertivas.

De cada 100 niñas que respondieron de manera autoasertiva, 15 se pueden atribuir directamente a la combinación de las tres actividades. Al tomarlas por separado, siete se pueden atribuir en exclusiva a la exposición a Sexto Sentido, y nueve a haber formado parte de un grupo de amigas. Estos resultados muestran que Sexto Sentido aportó de forma considerable al impacto global del proyecto, casi igualando el nivel de impacto neto alcanzado por el trabajo comunitario mucho más intensivo, pero con un mayor alcance y una relación costo-impacto mucho menor.

\footnotetext{
${ }_{54}$ PATH coordinó el proyecto, el cual se implementó en 2002-2004. El Centro de Estudios y Promoción Social (CEPS) aplicó el componente de educación comunitaria y entre pares en Ciudad Sandino y Puntos, el componente con medios de comunicación masiva (Sexto Sentido), cuyo alcance fue más allá de Ciudad Sandino y se amplió al resto del país. CIDS/ UNAN-León y otros consultores aplicaron la evaluación del impacto del proyecto mediante estudios cuantitativos y cualitativos, tanto antes, como después de la intervención.
} 


\section{Debate y reflexiones en torno a los resultados y sus implicaciones}

El desafío de contener la epidemia del VIH requiere la acción conjunta y comprometida de múltiples actores sociales. Los resultados de este estudio de impacto demuestran que la ejecución de una estrategia multimedia y de múltiples niveles promovió procesos de cambio, tanto a nivel individual como colectivo y que el proyecto cumplió su principal objetivo de contribuir a los esfuerzos nacionales en pro de la prevención.

\section{Impacto a gran escala}

Dado el enorme alcance de la intervención, los resultados demuestran que SDSI ha hecho un aporte de una grandísima escala en aspectos clave de la prevención del VIH. Tanto en el análisis longitudinal como transversal, una "mayor exposición" a SDSI estuvo significativamente asociada con cambios en una serie de indicadores que se midieron durante un periodo de tres años entre la misma población de adolescentes y jóvenes, en tres municipios con diferentes características.

Los análisis y resultados relacionados con los cambios asociados a una "mayor exposición" a SDSI aplican al 59 por ciento de la población entrevistada. Basados en proyecciones para la población adolescente y juvenil urbana de Nicaragua, los cambios podrían haber afectado a más de 700,000 adolescentes y jóvenes, un tercio de toda la población adolescente y juvenil del país. ${ }^{55}$ Esto significa que aun cuando los porcentajes o proporciones relacionados con ciertos cambios son relativamente pequeños, esos cambios afectan a un gran número de personas. El análisis de RAP permitió estimar el número de adolescentes y jóvenes cuyos cambios en el tiempo podrían atribuirse a una mayor exposición a SDSI.

También el alcance, la amplitud y la popularidad de Sexto Sentido — así como el hecho de que la gente expuesta a éste mencionó haberlo mirado con otras personas y reportó una mayor comunicación con otros sobre los temas de interés - hacen que sea muy probable que el programa haya tenido una influencia mucho más amplia que la indicada por la simple variable "mayor exposición a Sexto Sentido." Al promover una comunicación más abierta sobre estos temas, es posible que SDSI haya contribuido a cambios entre los jóvenes que no miraron el programa, pero que participaron en debates con otros jóvenes que tenían una mayor exposición al programa.

\footnotetext{
${ }^{55}$ Dado que las muestras de las encuestas eran representativas de la población adolescente y juvenil urbana en cada uno de las tres municipios, es posible proyectar que esos cambios afectaron a unos 55,000 jóvenes entre las edades de 15 y 24 años en los tres municipios, y 105,000 entre las edades de 10 y 29 años. La población urbana en estos tres municipios representa el 15 por ciento de la población juvenil urbana nacional, y si bien la muestra del estudio no tenía representatividad nacional, basado en un 59 por ciento que estuvo "más expuesto" es posible hacer una proyección conservadora de 380,000 jóvenes urbanos entre 15 y 24 años y 730,000 entre 10 y 29 años a nivel nacional. Éste es el equivalente a 33 por ciento de la población juvenil total (urbana y rural) del país en estos grupos etarios, o 14 por ciento de toda la población de Nicaragua.
} 


\section{Impacto sobre procesos complejos}

Los comportamientos individuales (p. ej., el uso regular del condón en las relaciones sexuales) no están aislados del entorno donde viven las personas, sino que están bastante vinculados con los aspectos y los procesos sociales. Los resultados de la evaluación y el análisis de los mismos, revelan la complejidad y la dinámica de los vínculos entre los procesos subjetivos, personales, interpersonales y del entorno. Los hallazgos del estudio destacan como elementos clave los procesos de comunicación interpersonal sobre temas generales o específicos relacionados con las prácticas de la intervención. Asimismo validan la conceptualización de SDSI como una estrategia que promueve un entorno más conducente a la prevención del VIH al influir en esos procesos subjetivos y de comunicación.

Un resultado en particular valida el marco conceptual tanto de la intervención como de la evaluación. Una mayor exposición a SDSI estuvo asociada con una mayor comunicación interpersonal que alienta las percepciones del riesgo personal y de la eficacia individual, lo que a su vez conduce a una mayor probabilidad de acciones concretas, como hablar con su pareja sobre prevención (también asociadas con SDSI). Y en última instancia resulta en una mayor probabilidad de un uso regular del condón.

\section{Género, edad y el paso del tiempo}

Además del nivel de exposición a SDSI, las variables más significativas que afectaron los resultados del programa fueron el género, la edad, el nivel educativo y el paso del tiempo. El segundo estudio cualitativo explora cómo el proceso "natural" de maduración conduce a cambios en las percepciones y en las prioridades de las y los jóvenes a medida que van adquiriendo más experiencia y más responsabilidades.

Las importantes diferencias en los resultados para los hombres y las mujeres, señalan la necesidad de entender mejor lo que está sucediendo detrás del discurso de una mayor equidad de género. Si bien la muestra en general se movió en la dirección de una mayor equidad en las normas de género, esto no parece haber resultado en cambios significativos en las normas sexuales que también se ven enormemente afectadas por las relaciones de género. El cambio en el discurso es en sí positivo puesto que señala un cambio en lo que se considera socialmente aceptable. Sin embargo, las manifestaciones más íntimas de las inequidades de género, como en las relaciones sexuales, probablemente tarden mucho más tiempo en cambiar.

En general, las importantes diferencias en hombres y mujeres en algunos de los principales resultados, señalan la necesidad de que continúe habiendo un enfoque de género muy claro para el trabajo con las y los jóvenes en torno a temas vinculados a las relaciones y a la sexualidad. Dadas las tendencias generales a lo largo del tiempo, sería útil continuar explorando los vínculos entre temas de poder y control de género en las relaciones con comunicación y prácticas entre la pareja íntima.

También es interesante señalar que un estudio separado de Sexto Sentido, en el que se utilizó un enfoque antropológico para comprender cómo las audiencias entendían los temas de género en la serie televisiva (Rock 2005), descubrió que la audiencia se involucra de manera activa con las historias e interpreta los significados de las mismas a través del filtro de su propia experiencia de vida, que rara vez coincide con el tipo de discurso e indicadores sobre "género" o "derechos" que utilizan 
investigadores/as y las ONG. Tanto ese descubrimiento como los hallazgos presentados en el informe descriptivo Expectativas y realidades: Las y los jóvenes nicaragüenses navegan por el género, la sexualidad, el VIH y más, destacan la necesidad de seguir explorando cómo los jóvenes entienden la naturaleza de género de su propia experiencia, para así poder abordar mejor los temas en cuestión.

\section{La relativa falta de uso de los servicios sociales y de salud}

Generalmente se ha considerado que los servicios sociales y de salud pueden ser una fuente importante de apoyo para las y los jóvenes, y tener un efecto positivo en la promoción de comportamientos saludables. Sin embargo, tanto los datos cuantitativos como cualitativos revelan que a pesar de estar al tanto de los servicios sociales y de salud disponibles, hay un bajo nivel de uso de estos servicios. Por una parte, hay una aparente falta de claridad en cuanto a la gama de servicios de apoyo disponibles, y por la otra, hay una cierta estigmatización vinculada al reconocimiento de la necesidad de estos servicios.

Asimismo, existe la percepción de que los servicios son únicamente para personas que están enfermas o que tienen problemas. Se requiere más investigación y análisis para entender mejor la aparente desconexión entre conocer sobre la existencia de los servicios y usarlos, y para comprender mejor las inquietudes de los/as jóvenes a fin de volver a pensar en el papel de los servicios sociales y de salud como parte de la infraestructura social de apoyo. Por último, se necesita más investigación y más análisis para volver a pensar en el significado de "accesible" y examinar con más cuidado el modo cómo estos servicios se promueven en la comunidad. La importancia demostrada de la comunicación interpersonal sugiere que tal vez un enfoque menos formal y más interpersonal podría ser apropiado.

\section{Preservando niveles de prevención a lo largo del tiempo}

Los datos revelaron tendencias generales que apuntan en diferentes direcciones. Es evidente que ciertos aspectos del entorno se han vuelto más favorables para la prevención del VIH y que SDSI ha tenido un impacto positivo: las y los jóvenes reportaron normas de género más equitativas y menos estigma relacionado con el VIH en 2005 que en 2003. Si bien no está asociado con SDSI, en los doce meses anteriores hubo un ligero incremento en la edad de las primeras relaciones sexuales y una leve reducción en el número de parejas sexuales.

Sin embargo, otros indicadores importantes mostraron una tendencia hacia un entorno menos favorable. Por ejemplo, hubo un "empoderamiento" general en la percepción que tienen las y los jóvenes de su contexto social local y a la vez un descenso en el sentido de la eficacia colectiva para resolver problemas. Los estudios cualitativos revelaron que si bien las y los jóvenes perciben un mejor conocimiento de los derechos de la niñez y la adolescencia y del derecho de las mujeres a vivir sin violencia, también perciben que esos derechos frecuentemente se trasgreden con impunidad. Hubo un descenso general en el sentido que tienen los y las jóvenes de su eficacia individual para negociar sus relaciones sexuales, una baja en la comunicación con la pareja íntima y también una disminución en el uso regular del condón, tanto con parejas estables, como casuales. 
En un contexto donde hay un incremento en la prevalencia del VIH y una situación más adversa para la prevención, el impacto positivo de SDSI de mantener los niveles o de restringir el descenso en varias variables importantes puede verse como un aporte para los esfuerzos de prevención.

\section{La importancia de la comunicación interpersonal}

El tema de la comunicación interpersonal como elemento clave para otros procesos, es una consideración importante para el diseño de intervenciones que esperan impactar temas complejos e íntimos como es la sexualidad. El análisis step-wise demuestra una asociación positiva entre la comunicación interpersonal y la percepción del riesgo, la eficacia individual y el uso regular del condón. Esto sugiere que el proceso de comunicación con su pareja es clave entre aquellos que reportaron el uso regular del condón con las parejas estables y con las parejas casuales. En un contexto adverso, promover una mayor apertura en la comunicación parece tener un efecto positivo.

Esto es aún más relevante en el caso de las mujeres que se sienten capaces de hablar con sus parejas sobre el uso del condón, lo que a su vez está asociado con una comunicación eficaz sobre el tema y por último con la práctica del uso del condón. Asimismo, SDSI parece tener un impacto específico mayor en los hombres que practican la comunicación interpersonal, quizás porque en general las mujeres son más comunicativas que los hombres.

Dado que con el tiempo hubo un descenso en la comunicación con la pareja íntima (mitigado por el impacto positivo de SDSI), sería útil explorar más los posibles vínculos entre la percepción del contexto social y su potencial influencia en la apertura en la comunicación con la pareja íntima en torno a temas de prevención.

\section{El asunto de la "predisposición" o la "autoselección"}

Varios de los resultados revelan una tendencia en donde aquellas personas que se identificaron como parte del grupo "más expuesto", demostraron valores más altos en varios de los índices, como equidad de género y estigma, no sólo al final del estudio, sino también en la línea de base. Al final del estudio se clasificó a las y los participantes basado en sus respuestas a lo largo del tiempo. Podría decirse que las personas que miraron Sexto Sentido TV con mayor regularidad (el grupo más expuesto) estaban predispuestas a los tipos de cambios que se detectaron como atribuibles a una mayor exposición a SDSI.

Un análisis independiente del tema de la predisposición ${ }^{56}$ detectó que aquellas personas que estaban en el grupo "más expuesto" y las que mencionaron Sexto Sentido como uno de sus programas locales favoritos demostraron, de hecho, valores superiores en la línea de base de algunas de las variables relacionadas con los temas del estigma, la discriminación y la equidad, y no necesariamente demostraron valores más altos en la línea de base en todas las áreas. Los resultados también muestran cambios significativos entre esta audiencia más regular.

\footnotetext{
${ }^{56}$ Realizado por Brian Linneker y la Dra. Sarah Bradshaw, catedrática superior en Estudios de Desarrollo, Universidad de Middlesex, Inglaterra. La Dra. Bradshaw evaluó la fase 2001 del proyecto SDSI.
} 
Otro resultado interesante es que la muestra en su conjunto generalmente reportó que consideraba que sus propias opiniones en torno a temas como el estigma y la discriminación eran más "progresistas" que las de sus familiares. En este sentido, es posible que para aquellos televidentes que pudieron haber estado "predispuestos" a estar de acuerdo con algunas de las opiniones planteadas en Sexto Sentido, la serie haya venido a reforzar en ellos lo que podría considerarse opiniones de minoría, respaldando así un tipo de pensamiento que va en contra de la norma social percibida.

La religiosidad - que podría considerarse relevante para las actitudes hacia muchos de los temas abordados por SDSI - no fue un factor relevante en términos de la audiencia de Sexto Sentido, es decir que el grupo "más expuesto" era igualmente religioso que el grupo "menos expuesto".

\section{Acercarse e impactar a diferentes grupos dentro de la población juvenil y adolescente}

Si bien se necesitaría un tipo de análisis distinto al que se realizó para esta evaluación, existe evidencia que sugiere que Sexto Sentido posiblemente tuvo más impacto en los sectores de la población joven que empezó con los valores más bajos en muchos de los indicadores: los hombres en general (comparado con las mujeres), la población más joven de 13 a 18 años (comparado con el grupo de 19 a 24 años), y en Juigalpa (considerado el más conservador de los tres municipios y que tiene menor número de organizaciones, servicios sociales y de salud). Asimismo se observó que Juigalpa, el municipio con menos opciones de entretenimiento/recreación que León y Estelí, tuvo una audiencia regular superior a la de éstos.

Si bien los valores finales para estos grupos no eran tan altos como para otros grupos, existe evidencia que sugiere un cambio neto mayor en estos grupos en algunas variables importantes. Puede haber habido un cambio neto mayor en el subgrupo más grande de la población más expuesta que miró la serie "de vez en cuando", comparado con el subgrupo más pequeño que reportó que miraba el programa "casi siempre".

Si esto fuese cierto, señalaría la importancia de las intervenciones mediáticas de educaciónentretenimiento, tales como Sexto Sentido, para impactar en los diferentes subsectores de la población y especialmente en lugares donde tienen lugar menos actividades de otros tipos.

\section{Eficacia con relación al costo de SDSI}

Un estudio de costos realizado por PATH como parte de la evaluación del proyecto Entre Amigas reveló que el costo por adolescente/joven espectador de Sexto Sentido en Nicaragua era de unos USD 0.04 por episodio ó USD 0.60 por temporada (15 episodios). El costo por espectador para las tres temporadas entre 2003 y 2005 es de aproximadamente USD 1.80. Comparado con otros tipos de intervenciones, Sexto Sentido es una manera muy eficaz con relación al costo de acercarse a un gran número de personas y lograr cambios en ellas.

Dado que más de la mitad de los que miraron la serie lo hicieron en compañía de otras personas, muchos de ellos con "toda la familia", la eficacia con relación al costo podría ser mucho mayor, si se 
presupone que se impactó a otros grupos de población. Por ejemplo, la evaluación del proyecto Entre Amigas $^{57}$ reveló que Sexto Sentido tuvo un importante impacto por su propio mérito en niñas de 10 a 14 años y un impacto todavía mayor al interactuar con acciones relacionadas con la educación entre pares y con el fortalecimiento de la redes de apoyo.

El valor de la inversión en la serie televisiva se ha visto fortalecido más por la transmisión de la serie, tanto en la televisión abierta, como en los canales de cable en otros países de la región, lo que incrementa sustancialmente el alcance y el impacto del proyecto. Asimismo, ediciones temáticas especiales de la serie se convierten en paquetes metodológicos (DVD con guías para el debate) para su uso local con jóvenes, y la demanda en toda la región ha sido fuerte; los paquetes han sido usados por grupos locales en América Central y América Latina. ${ }^{58}$

\footnotetext{
${ }^{57}$ El proyecto se elaboró en colaboración con PATH y el Centro de Estudios De Promoción Social (CEPS). El componente de comunicación masiva de SDSI formó parte del proyecto en una relación de colaboración.

${ }^{58}$ Los paquetes metodológicos incluyen videos y guías para el debate en torno al VIH, el abuso sexual en la familia, el machismo en la vida cotidiana, la contracepción de emergencia, el machismo, los dolores de la pubertad, y como romper los círculos de violencia en el hogar y en las relaciones entre jóvenes.
} 


\section{Reflexiones sobre la metodología del estudio}

\section{Rigor y confiabilidad}

El estudio se destacó por su rigor científico y por la complejidad de su enfoque y análisis. El modelo de evaluación multi-estudio cuantitativo y cualitativo de SDSI, permitió la determinación de asociaciones de causa y efecto, y la propuesta de modelos explicativos, dentro de un enfoque de múltiples niveles. Muy pocos estudios en el campo de la comunicación social han sido ejecutados con tanta rigurosidad. En este sentido, los resultados representan una importante contribución para la literatura internacional sobre la eficacia de este tipo de programa.

Una de las principales fortalezas del estudio de panel es que se entrevistó a las y los mismos jóvenes a lo largo de un periodo de tres años, midiendo sus procesos de cambio con respecto a los temas de interés. Este diseño permite que se identifiquen los cambios atribuibles a la intervención con mucha más precisión que en el caso de los estudios transversales "pre y post" intervención, ya que permite el análisis de cambios a nivel individual y no sólo se limita a comparar a grupos de personas.

Otras fortalezas de este estudio en particular, incluyen la alta tasa de respuesta, la tasa aceptable de participantes "perdidos para el seguimiento" a lo largo de los tres años, la confiabilidad de las respuestas como quedó demostrado por las pruebas estadísticas y los modelos estadísticos multivariados que permitieron aislar el efecto de las variables sociodemográficas.

\section{El efecto Hawthorne}

Los análisis en el campo de la investigación cuantitativa han demostrado que los estudios de panel (con repetidas mediciones) pueden generar sus propios efectos en los participantes, algo que se conoce como el efecto Hawthorne. Estos efectos incluyen la posibilidad de que la participación en el estudio aliente a los participantes a brindar respuestas "socialmente más deseables" sugiriendo "cambios" que en realidad no existen. Otra posible consecuencia es que si bien los cambios pueden ser reales, éstos no son tanto el resultado de la exposición a la intervención, sino producto de la reflexión provocada por la participación en el estudio como tal.

$\mathrm{Al}$ analizar esto con relación al estudio actual, los/as investigadores señalan que dado que toda la muestra empezó bajo las mismas condiciones (es decir no tenían exposición a ninguna de las tres temporadas de Sexto Sentido contempladas en el proyecto), el efecto de participar en el estudio en sí podría explicar por qué, tanto las personas que estaban menos expuestas a SDSI, como las que estaban más expuestas, mostraron cambios positivos de actitud a lo largo del tiempo.

En ese sentido, cualquier efecto producido por la participación en el estudio resultaría en la reducción de las diferencias entre los grupos con menor y mayor exposición. Si ése fuera el caso, es posible que el impacto asociado con SDSI de hecho haya podido ser mayor de no haber sido por el efecto Hawthorne. 


\section{Desafíos metodológicos y la necesidad de varios enfoques distintos}

Los resultados que aquí se presentan son sólo los principales hallazgos que permiten identificar los efectos atribuibles a la estrategia de comunicación SDSI. En términos del potencial para entender los cambios sociales y la prevención del VIH, existen muchas posibilidades para futuros análisis que utilicen la base de datos que resultó de este estudio

Varias décadas de investigación han producido una gran cantidad de evidencia sobre el impacto que tiene el uso de los medios de comunicación en los comportamientos sexuales para regular la fertilidad y en la diseminación de la información como factor que influye en el uso de anticonceptivos (Westoff y Rodríguez, 1995; Jato et al., 1999). Existe menos evidencia sobre el impacto y la eficacia de las intervenciones multimedia en relación con la prevención del VIH. SDSI tuvo un impacto en importantes procesos de cambio relacionados con la prevención del VIH entre esta población. Los resultados complementan el creciente número de estudios y análisis que han demostrado el posible impacto de utilizar los medios de comunicación en el campo de la salud sexual y reproductiva, incluida la prevención del VIH (Bertrand y Anhang, 2006; Bertrand et al., 2006; Cochrane Collaborative Review Group on HIV Infection and AIDS, 2004).

Queda mucho por explorar en lo que respecta a la evaluación de los programas de comunicación. Como ya se dijo, la eficacia de las acciones de comunicación se enriquecería mediante el análisis de cómo ese impacto se ha gestado y desarrollado, en lugar de limitar la evaluación a "medir" el impacto (entre la audiencia, por ejemplo). Esto requiere diferentes enfoques. Por ejemplo, se necesita un análisis más profundo de las intervenciones basado en la concepción de audiencias activas, para entender cómo éstas responden a la divulgación de mensajes, cómo las ideas se posicionan, y cómo las audiencias "negocian" el significado según sus propias creencias, actitudes y normas sociales, que o son similares o bien contradicen las perspectivas introducidas por la intervención. Más estudios con enfoques antropológicos (tales como el enfoque de Rock ya mencionado) permitirían una comprensión más matizada de la influencia real de un programa determinado, que de otra manera podría parecer contradictorio o incluso un "fracaso" ${ }^{59}$ Asimismo, la teoría de la complejidad tiene el potencial para entender la dinámica del cambio y el impacto multidimensional de las intervenciones. ${ }^{60}$

Por último, la información contenida en la base de datos del estudio es útil para múltiples fines y en sí es una valiosa fuente de información y análisis para investigadores/as y diseñadores/as de programa. El informe descriptivo de Puntos, titulado Expectativas y Realidades: Jóvenes nicaragüenses navegando entre las olas del genero, sexualidad, VIH y más [Expectations and Realities: Nicaraguan youth navegate gender, sexuality, HIV and more], resume algunos de los patrones más contundentes que emergen de los datos recopilados entre 2003 y 2005. Los datos, desagregados por género, edad y localidad, brindan un complejo retrato de las realidades sexuales y reproductivas entre la juventud nicaragüense. ${ }^{61}$ Los datos también complementan otras fuentes tales como la monografía del Instituto

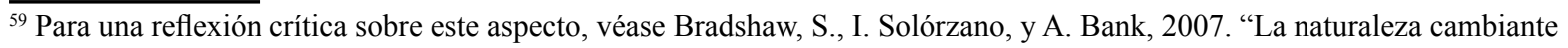
del cambio: una experiencia feminista en la comunicación para el cambio social en Nicaragua”, publicado en World Congress on Communication for Development: Lessons, Challenges, and the Way Forward. Banco Mundial, FAO, Communications Initiative.

${ }^{60}$ Véase "What Complexity Science Teaches Us about Social Change" [Lo que la ciencia de la complejidad nos enseña sobre cambio social] por Virginia Lacayo, publicado en Mazi, la revista del Consorcio de comunicación para el cambio social. http://www.communicationforsocialchange.org/mazi-articles.php?id=.

${ }^{61}$ Disponible en www.puntos.org.ni.
} 
Guttmacher titulada To Assure a Healthier Tomorrow in Central America: Protect the Sexual and Reproductive Health of Today's Youth [Asegurar un mañana más saludable en Centroamérica: Proteger la salud sexual y reproductiva de la juventud de hoy], donde se resumen y comparan los datos nacionales de las encuestas en demografía y salud de cuatro países centroamericanos. ${ }^{62}$

\footnotetext{
${ }^{62}$ Remez, L., E. Prada, S. Singh, L. Rosero Bixby, y A. Bankole. Asegurar un mañana más saludable en Centroamérica: Proteger la salud sexual y reproductiva de la juventud de hoy. New York: Guttmacher Institute, 2008.
} 


\section{Bibliografía}

Bandura, A. 1977. Social Learning Theory. Englewood Cliffs, New Jersey: Prentice-Hall, Inc.

. 1986. Social Foundations of Thought and Action: A Social Cognitive Theory. Englewood Cliffs, New Jersey: Prentice-Hall, Inc.

Bertrand, J. T. and R. Anhang. 2006. "The effectiveness of mass media in changing HIV-related behaviour among young people in developing countries," World Health Organization Technical Report Series 938: 205-41.

Bertrand, J. T. et al. 2006. "Systematic review of the effectiveness of mass communication programs to change HIV-related behaviors in developing countries," Health Education Research 21(4): 567-97.

Brown, L. et al. 2001. "Interventions to reduce HIV stigma: What have we learned?," Horizons Report. Washington, DC: Population Council.

Cochrane Collaborative Review Group on HIV Infection and AIDS. 2004. "Evidence assessment: strategies for HIV prevention, treatment and care."

Cohen, Jon. 2006. “Overview: The overlooked epidemic,” Science 313(5786): 468-469.

Declaration of Commitment on HIV/AIDS. 2001. "Resolution S-26/2," adopted by the General Assembly. http://www.un.org/ga/aids/coverage/FinalDeclarationHIVAIDS.html, consultada en enero 2007.

Figueroa, M.E. et al. 2002. "An integrated model for measuring the process and its outcomes," the Communication for Social Change Working Paper Series, No. 1. New York: Rockefeller Foundation.

Gray-Felder, D. and J. Dean. 1999. "Communication for social change: A position paper and conference report." New York: Rockefeller Foundation.

Greenberg, J. 1996. in AIDS Education: Interventions in Multicultural Settings. Edited by Schenker, I. et al. New York: Plenum Press.

Green, E. C. et al. 2006. "Uganda's HIV prevention success: the role of sexual behavior change and the national response," AIDS Behavior 10(4): 335-46; 347-50.

INIDE. 2005. "8vo Censo de Población y 4to Censo de Vivienda, Vol. V, Municipios.” Managua: Nicaragua.

Jato, M. et al. 1999. "The impact of multimedia family planning promotion on the contraceptive behavior of women in Tanzania," International Family Planning Perspectives 25(2): 60-67. 
Malcolm, A. et al. 1998. "HIV and AIDS-related stigmatization and discrimination: Its form and contexts," Critical Public Health 8(4): 347-370.

Programa Nacional ITS/VIH, 2003. Ministerio de Salud, Nicaragua.

Instituto Nicaragüense de Estadísticas y Censos (INEC). 2002. Encuesta Nicaragüense de Demografía y Salud 2001”. Managua: INEC/MINSA.

—. 2006. “Censo Nacional 2005”. Managua: INEC.

—. Sin fecha. Proyecciones de Población Para El Periodo 2000-2005, consultado el 26 de agosto, 2006, http://www.inec.gob.ni/estadisticas/proyecciones/pob00_05.htm.

Nyblade, Laura and Kerry MacQuarrie. 2006. "Can we measure HIV related stigma and discrimination? Current knowledge about quantifying stigma in developing countries." Washington, DC: ICRW and Policy Project.

Papa, M.J. et al. 2000. "Entertainment-education and social change: An analysis of parasocial interaction, social learning, collective efficacy, and paradoxical communication," Journal of Communication 50(4): 31-55.

Pulerwitz, Julie and Gary Barker. 2007. "Measuring attitudes toward gender norms among young men in Brazil: development and psychometric evaluation of the GEM Scale," Men and Masculinities published online ahead of print, 18 May.

Pulerwitz, J., S. L. Gortmaker, and W. DeJong. 2000. "Measuring relationship power in HIV/STD research," Sex Roles 42(7/8).

Rock, Yerina. 2005. "Television, gender and change: the case of 'Sexto Sentido' television, an education-entertainment initiative in Nicaragua," Master's Thesis. Great Britain: Cambridge University.

Singhal, A. and E. M. Rogers. 1999. Entertainment-education: A communication strategy for social change. Mahwah, New Jersey: Lawrence Earlbaum Associates.

Vigilancia de ITS, VIH y Sida. 2006. Tendencias de la Situación Epidemiológica del VIH y del SIDA en Nicaragua 1987-2006. Managua, Nicaragua: Ministerio de Salud.

Stoneburner, R. et al. 2000. "Knowledge diffusion and the personalisation of risk as key indicators of behaviour change in Uganda compared to Southern Africa," presentation at the XIII International Conference on AIDS, Durban, South Africa, July 9-14.

Westoff, CF and G. Rodríguez. 1995. "The mass media and family planning in Kenya," International Family Planning Perspectives 21(1): 26-31 and 36. 


\title{
Apéndice 1 Agradecimientos adicionales
}

\author{
Estudio de panel \\ Base de datos: Francisco Centeno, Bismark Rodríguez (UNAN-León) \\ Cartografia: Santos Betancourt, Maylen Balladares Cardoza, Arlen Córdobas (UNAN-León)
}

Trabajo de campo: Mariano Salazar Torres, Alfredo Robleto Ruiz, Maylen Balladares Cardoza, Carolina Salinas, Roilen Aguilar, Blanca Rocha, Yaoska Madrigal, Lenin Martínez, Idelva Madrigal, Adela Carolina Rivas, Marcio Jonathan Díaz, Bayardo José Lazo, Deyanira Raquel Dávila, Nacira Hernández Rivas, Karla Paredes, Mélida Hernández, José Adán Hernández, Marbely López Gutiérrez, Marlon Javier Gutiérrez, Shayra García, Francisco Martínez Hurtado, Thelma Rosa García, Yelba Robleto, Hazle Guillermo López, Lucrecia Aragón Álvarez, Marbely López Robleto, Martha Obregón, Royler Aguilar, Esneider Dávila Dávila, Luís González Velásquez, Gloria Rocha Marín, Maritza Hernández Miranda, Martha Maria Díaz, Jacqueline Leiva Huete, Amilcar Armando Aguilar, Harrington Jareth Guerrero, Ademilton Ramírez Miranda, Rommel Antonio Duarte, Arlen Córdobas, Maria Lourdes Lazo, Iris María Caruz, Karen Lissette Alaniz, Nelson Gonzáles, Ligia Ruiz Rodríguez, Fátima López Moreno, Marlon Ernesto Pérez, Egda Narua Vanegas, Dania Bellisa Pineda, Anabel Ruiz Rugada, Lesli Guido Lazo, Sandra Guido Lazo, Osman Téllez Gonzáles, Aurelia Maura Obando, Rommel Espinoza, Arlen Tórrez Fernández, Arles Rene Rodríguez, Zaida Rocha, Lenin Pérez, Durkis Oseguera, Norman Córdobas, Yara Díaz, Mauricio Castillo, Julio Rivera, Yomaris Flores, Griselda Olivas Herdocia, Elsa Avilés, Nora Huete, Lourdes Castillo, Gill Zelaya Pérez, Ernesto López, Magbis Sánchez Zelaya, Carlos Calderón Valdivia, Marlon Moncada, Dania Pineda Herrera, Yorling Moreno, Ana Karelia Zeledón, Freddy Martín Guido, Carlos Calderón Valdivia, Carlos Sotomayor Lanuza, Erick Rizo Morales, Maria Selva, Jessenia García, Oscar David Blandino, Maria Teresa Orozco, Luz Marina Delgado, Aida Luz Flores, Oscar Isacs Martínez, Belkis Vargas Corrales, Benita Bernandina Flores, Miguel Centeno Cárdenas, Eusébio Adolfo Berrios, Elizabet Vanessa Paguagua, Cindy Esmeralda Orozco, Benito Martínez Sáenz, Maria Rosa Pérez, Waleska Lindo, Eduardo Toval, Martha Barcenas, Armando Camacho, Maria José Gabuardi, Edwin Almanza Herrera, Yaquelin Mayorga, Norman Ferrer Alvarado, Gioconda Alvarado, Benito Moreno, Maria Argeñal, Rene Lucia Delgado, Héctor Sánchez, Juan Manuel Lozano, Luís Benito Quintero, Maria Rojas, Maria Elena Espinoza, Maria Isabel Hernández, Luisa Urcuyo Pérez, Carlos Berrios, Héctor Chamorro, Luís Benito Quintero y Carlos Rubio.

\section{Evaluación cualitativa}

\section{Cualitativo 1}

Oswaldo Montoya (investigador principal)

Camilo Antillón, Rosa Argentina Campos y Karime Ulloa

Equipo de apoyo: Carlos Ávalos, Braulio Delgado y Wendy Gaitán

\section{Cualitativo 2}

Camilo Antillón y Henry Espinoza (Investigadores principales)

Karime Ulloa, Vanesa López y León Berrios

Equipo de apoyo: Claudia Espinoza Sánchez, Arlen Altamirano, Carlos Cruz Espinoza e Ivanova Sosa

\section{Cualitativo 3}

Almachiara D'Angelo y Patrick Welsh (investigadores principales)

\section{Apoyo al equipo de Puntos de Encuentro}

Rubén Reyes, Sheila Vega, Charlie Weinberg, Sarah Bradshaw, Ana Criquillion, Margarita Quintanilla, Yerina Rock, Juritzia Cruz, equipo de administración y servicios generales, y todo el colectivo de Puntos de Encuentro, puesto que todo el mundo aportó de una u otra forma. 


\section{Apéndice 2 \\ Organizaciones y medios de comunicación que participaron en los estudios cualitativos}

\begin{tabular}{|c|c|c|c|}
\hline Estelí & Juigalpa & León & Puerto Cabezas \\
\hline \multicolumn{4}{|l|}{ Estudio cualitativo \#1 } \\
\hline \multicolumn{4}{|l|}{ Sociedad civil } \\
\hline $\begin{array}{l}\text { Desafíos } \\
\text { MILAVF } \\
\text { Red de Jóvenes } \\
\text { Club Juvenil Profamilia } \\
\text { Casa de la Mujer } \\
\text { Casa del Adolescente } \\
\text { Funarte }\end{array}$ & $\begin{array}{l}\text { Casa del Adolescente } \\
\text { Alcaldía } \\
\text { Aldea SOS } \\
\text { Profamilia }\end{array}$ & $\begin{array}{l}\text { CISAS } \\
\text { CARAS } \\
\text { IXCHEN } \\
\text { Movimiento Comunal } \\
\text { Proyecto Las Tías } \\
\text { Los Pipitos } \\
\text { CCAN } \\
\text { Centro Escolar }\end{array}$ & $\begin{array}{l}\text { CEDEHCA } \\
\text { Clínica Bilwi } \\
\text { Movimiento de } \\
\text { Mujeres Nidia White } \\
\text { Comisión Antidrogas } \\
\text { Comisaría de la } \\
\text { Mujer, Niñez y } \\
\text { Adolescencia- } \\
\text { Policía Nacional }\end{array}$ \\
\hline \multicolumn{4}{|l|}{ Medios de comunicación } \\
\hline Radio Estéreo Mundo & $\begin{array}{l}\text { Radio Centro } \\
\text { Corresponsal de La Prensa }\end{array}$ & Radio La Cariñosa & \\
\hline \multicolumn{4}{|l|}{ Estudio cualitativo \#3 } \\
\hline \multicolumn{4}{|l|}{ Sociedad civil } \\
\hline $\begin{array}{l}\text { Proyecto Miriam } \\
\text { Instituto Mujer y } \\
\text { Comunidad } \\
\text { Red de Jóvenes de Estelí } \\
\text { Xilonem } \\
\text { Casa de la Adolescencia } \\
\text { Instituto San Francisco } \\
\text { Hermanos Maristas. } \\
\text { Instituto Herman Gmeiner }\end{array}$ & $\begin{array}{l}\text { AMNLAE } \\
\text { ATC } \\
\text { Secretaría del Concejo } \\
\text { Municipal } \\
\text { Club de Jóvenes Profamilia } \\
\text { Aldea SOS } \\
\text { UNAG } \\
\text { Plan Nicaragua-Unidad } \\
\text { de Proyecto Juigalpa- } \\
\text { Chontales } \\
\text { Casa de la Niñez, } \\
\text { Adolescencia y Juventud }\end{array}$ & & $\begin{array}{l}\text { CEDEHCA } \\
\text { Tesis } \\
\text { Movimiento de Mujer } \\
\text { Nidia White } \\
\text { Comisión antidrogas } \\
\text { Clínica Bilwi } \\
\text { Comisión Regional } \\
\text { de Prevención } \\
\text { del VIH/SIDA } \\
\text { (CORESIDA) } \\
\text { AJECIM-Iglesia } \\
\text { Morava }\end{array}$ \\
\hline \multicolumn{4}{|l|}{ Instituciones de gobierno } \\
\hline $\begin{array}{l}\text { MIFAMILIA } \\
\text { Clínica de Adolescentes } \\
\text {-MINSA }\end{array}$ & & & $\begin{array}{l}\text { Comisaría de la } \\
\text { Mujer, Niñez y } \\
\text { Adolescencia- } \\
\text { Policía Nacional }\end{array}$ \\
\hline
\end{tabular}




\begin{tabular}{|l|l|l|l|}
\hline Entes de coordinación & & $\begin{array}{l}\text { Comisión de } \\
\text { la Niñez y } \\
\text { Adolescencia }\end{array}$ \\
\hline $\begin{array}{l}\text { Comisión de la Niñez y la } \\
\text { Adolescencia }\end{array}$ & Casa de la Niñez & \\
\hline Medios de comunicación & $\begin{array}{l}\text { Radio Centro } \\
\text { Radio Centro } \\
\text { Canal 16 } \\
\text { Canal 17 }\end{array}$ & & $\begin{array}{l}\text { Radio Amor } \\
\text { Radio Juvenil }\end{array}$ \\
\hline $\begin{array}{l}\text { Estéreo Mundo } \\
\text { Canal 4 } \\
\begin{array}{l}\text { Radio Liberación } \\
\text { Radio Cumiche }\end{array}\end{array}$ & & \\
\hline
\end{tabular}




\section{Hgrizons}

Horizons es un programa global de investigación operativa diseñado para:

- Identificar y validar estrategias potenciales para mejorar la prevención, el tratamiento, los programas de apoyo y de provisión de servicios para el VIH y sida.

- Divulgar las mejores prácticas y utilizar los hallazgos con el fin de ampliar la escala de intervenciones exitosas.

\section{(2) Population Council}

Horizons es implementado por el Population Council en colaboración con:

- International Center for Research on Women (ICRW)

- International HIV/AIDS Alliance

- PATH

- Tulane University

- Family Health International (FHI)

- Johns Hopkins University

Para más información, por favor contactar a:

Horizons Program, Communications Unit 4301 Connecticut Avenue, NW Suite 280 Washington, DC 20008 USA

Tel: 202-237-9400

Fax: 202-237-8410

Email: horizons@popcouncil.org

www.popcouncil.org/horizons 